\title{
Inhibition of arterial KDR channels by DPO- 1 and activation of cloned human BK channels by BPA-MS
}

\author{
Ibra S. Fancher IV
}

Follow this and additional works at: https://researchrepository.wvu.edu/etd

\section{Recommended Citation}

Fancher IV, Ibra S., "Inhibition of arterial KDR channels by DPO-1 and activation of cloned human BK channels by BPA-MS" (2014). Graduate Theses, Dissertations, and Problem Reports. 5574.

https://researchrepository.wvu.edu/etd/5574

This Dissertation is protected by copyright and/or related rights. It has been brought to you by the The Research Repository @ WVU with permission from the rights-holder(s). You are free to use this Dissertation in any way that is permitted by the copyright and related rights legislation that applies to your use. For other uses you must obtain permission from the rights-holder(s) directly, unless additional rights are indicated by a Creative Commons license in the record and/ or on the work itself. This Dissertation has been accepted for inclusion in WVU Graduate Theses, Dissertations, and Problem Reports collection by an authorized administrator of The Research Repository @ WVU.

For more information, please contact researchrepository@mail.wvu.edu. 


\title{
Inhibition of arterial $K_{D R}$ channels by DPO-1 and activation of cloned human $B K$ channels by BPA-MS
}

\author{
Ibra S. Fancher IV
}

Dissertation submitted to the School of Medicine at West Virginia University

in partial fulfillment of the requirements for the degree of

Doctor of Philosophy in Exercise Physiology

\author{
Gregory M. Dick, Ph.D., Mentor \\ John M. Hollander, Ph.D. \\ Robert Brock, Ph.D. \\ William Wonderlin, Ph.D. \\ Mark Olfert, Ph.D.
}

Center for Cardiovascular and Respiratory Sciences

Morgantown, West Virginia University

2014

Keywords: DPO-1, Kv1.5, vascular smooth muscle, resistance vessel, delayed rectifying $\mathrm{K}^{+}$channels

Copyright 2014 Ibra S. Fancher IV 


\title{
ABSTRACT
}

\section{Inhibition of arterial $\mathrm{K}_{\mathrm{DR}}$ channels by DPO-1 and activation of cloned human BK channels by BPA-MS}

\author{
Ibra S. Fancher IV
}

The following documents our attempt at answering a fundamental question in vascular smooth muscle: Which $\mathrm{K}^{+}$channels control membrane potential, and thus, vascular tone? A number of groups have approached this question and great strides have been made; however, uncertainty remains as to which specific $\mathrm{K}^{+}$channel(s) underlies this physiologically important current. Previous studies using nonselective pharmacological inhibitors of voltage-dependent $\mathrm{K}^{+}\left(\mathrm{K}_{\mathrm{V}}\right)$ channels, particularly delayed rectifier $\mathrm{K}^{+}\left(\mathrm{K}_{\mathrm{DR}}\right)$ channels, indicate membrane depolarization, $\mathrm{Ca}^{2+}$ influx, and vasoconstriction. Importantly, however, there are more than 40 genes known to encode $\mathrm{K}_{V}$ channel subunits. We hypothesize that $K_{D R}$ channels composed of $K_{V} 1$ subunits are responsible for the polarizing current of arterial smooth muscle. Recently, diphenyl phosphine oxide1 (DPO-1) has been suggested as a specific $K_{V} 1.5$ inhibitor. Therefore, we used DPO-1 as a pharmacological tool to investigate the role of $\mathrm{K}_{\mathrm{V}} 1.5$ subunits in the $\mathrm{K}_{\mathrm{DR}}$ channels of arterial smooth muscle. In Chapter 2, we tested the specificity of DPO-1 for $\mathrm{K}_{\mathrm{v}} 1.5$ using $\mathrm{K}_{\mathrm{v}} 1.5$ knockout $(\mathrm{KO})$ mice. Whole-cell patch clamp recordings revealed reduced current and less percent block by DPO-1 in aortic smooth muscle cells from KO mice. Additionally, in Chapter 2, we determined that resistance vessels from rat brain and skeletal muscle contain a DPO-1-sensitive $\mathrm{K}_{\mathrm{DR}}$ current, constrict in response to DPO-1, and these $K_{D R}$ channels control reactivity. In Chapter 3, we investigated the mechanism of block by DPO-1 of $\mathrm{K}_{\mathrm{DR}}$ channels in porcine coronary smooth muscle cells and found that it was largely similar to that known for cloned $K_{v} 1.5$ channels. Together this work suggests that $\mathrm{K}_{\mathrm{V}} 1.5$ is a major contributor to the $\mathrm{K}_{\mathrm{DR}}$ current observed in arterial smooth muscle across a number of species and in a variety of arterial vessel types. Furthermore, these DPO-1-sensitive $\mathrm{K}_{\mathrm{DR}}$ channels regulate vascular tone, buffer vasoconstriction, and control reactivity. An additional interest of our group, and incorporated into the body of this document as Chapter 4, is the effects of the xenoestrogenic endocrine disruptor bisphenol A (BPA). We have previously shown that BPA activates large conductance voltage- and $\mathrm{Ca}^{2+}$-activated $\mathrm{K}^{+}(\mathrm{BK})$ channels and here we build on this knowledge by examining which side of the cell membrane BPA mediates the activity of BK. This was done by formation of a membrane impermeable BPA-monosulfate (BPA-MS) and subsequent electrophysiological experiments determined that BPA may have both intracellular and extracellular binding sites on the $\beta 1$ auxiliary subunit. Collectively, this dissertation is an investigation of the physiology and pharmacology of $\mathrm{K}^{+}$channels with respect to an underlying interest in vascular smooth muscle physiology. 


\section{Acknowledgements}

I would like to thank my mentor, Dr. Gregory M. Dick, for all of his invaluable teaching and advice. He has been crucial in all aspects of my graduate training and maturity as a young scientist. I would also like to thank my dissertation committee: Drs. Mark Olfert, John Hollander, Rob Brock, and Bill Wonderlin for their efforts in assisting me both in and out of the lab. I would like to thank my lab mates, Shin Asano, Drew Nickerson, and Trey Rottgen, for assisting me on this and many other projects. I would also like to extend special gratitude to Janelle Stricker and the late Dr. Mike Morissette for training early in my graduate career. To my parents Toby and Patti and little brother, Sean, I can

only attempt to thank them for all that they have done for me. To all those mentioned, and to those who have helped me come this far - thank you. 


\section{Table of Contents}

ABTLE PAGE

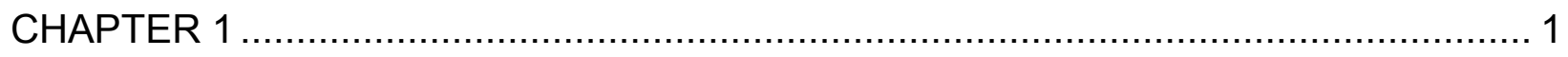

Introduction to $\mathrm{K}_{\mathrm{v}} 1$ channels in the vasculature

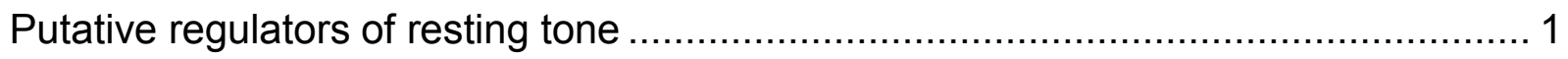

$\mathrm{K}_{\mathrm{V}} 1$ channels, membrane potential, and resting tone ....................................... 8

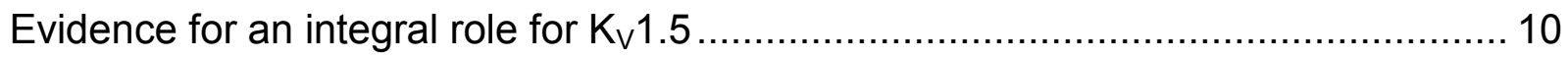

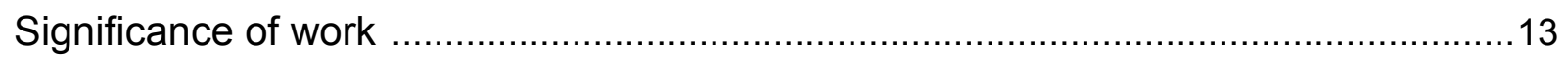

Introduction to BK and BPA

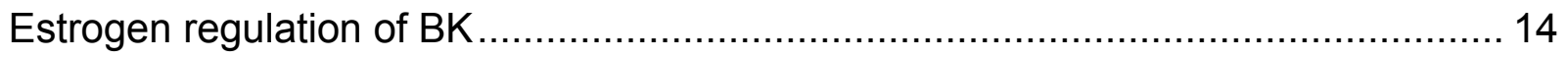

BPA activates BK

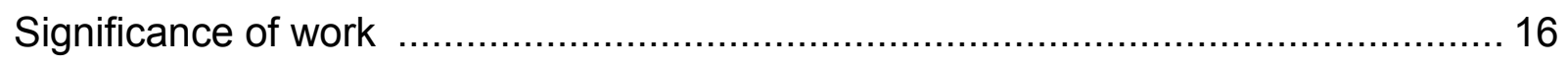

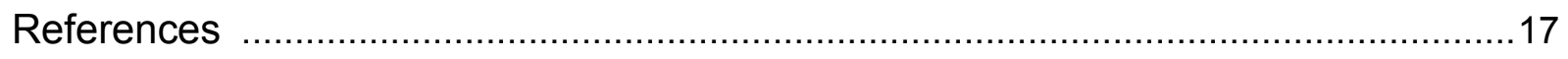

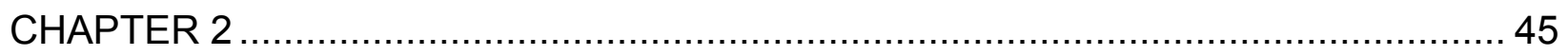

DPO-1-sensitive $\mathrm{K}^{+}$channels contribute to vascular tone in rat cerebral and skeletal microvasculature 
Ibstract

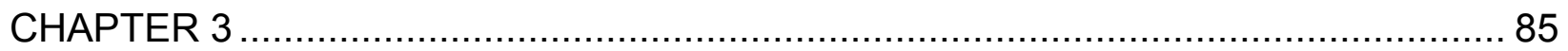

DPO-1 blocks porcine VSM IDR by accelerating inactivation kinetics in porcine right coronary artery

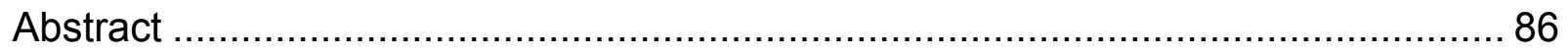

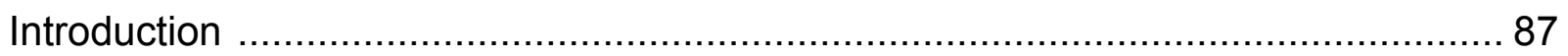

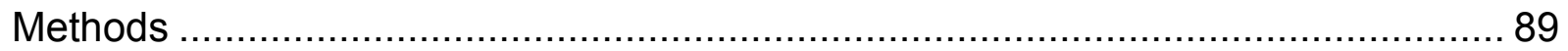

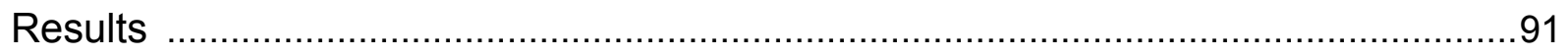

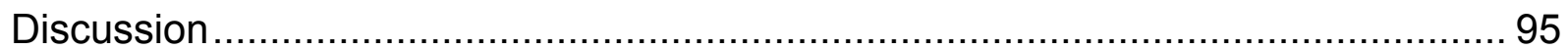

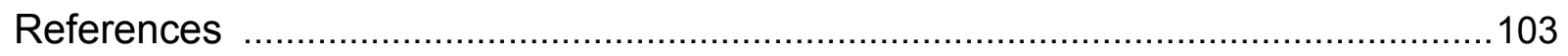

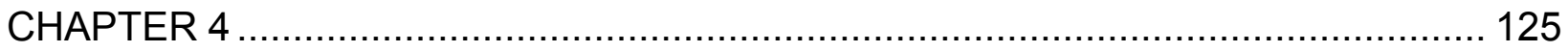

Bisphenol $A$ activates BK channels through effects on $\alpha$ and $\beta 1$ subunits

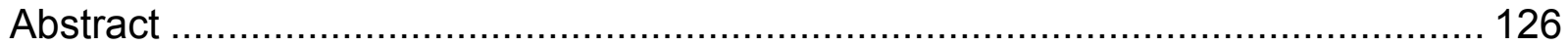

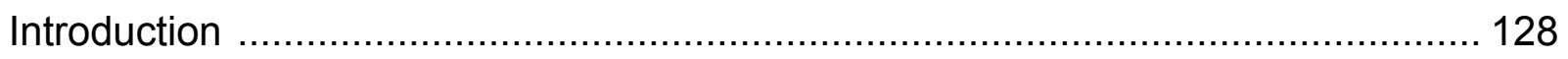

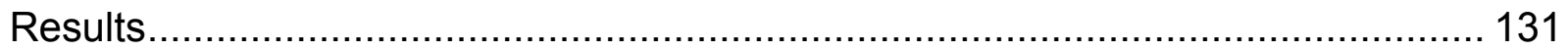


Discussion

Methods

Acknowledgements 144

References 145

CHAPTER 5 167

General discussion, conclusions, and future directions

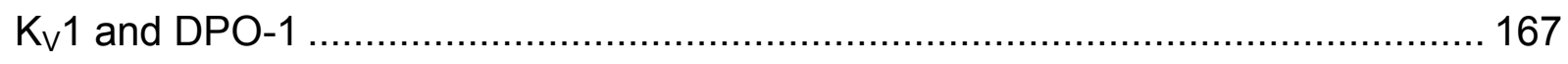

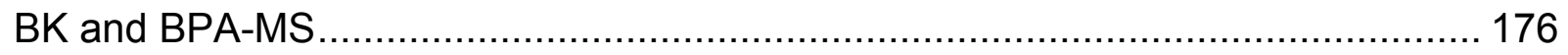

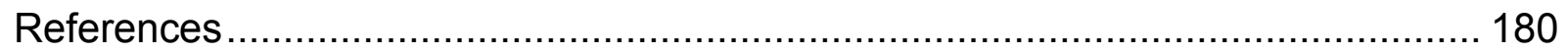

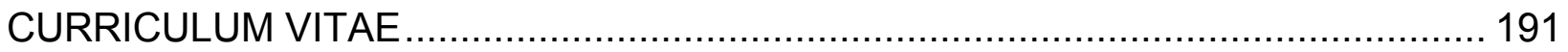




\section{List of Tables}

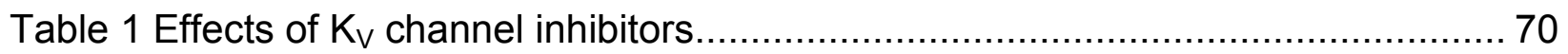




\section{LIST OF FIGURES}

\section{Chapter 1}

1.1 Cartoon depicting arterial smooth muscle cell physiology …........................... 35

$1.2 \mathrm{~K}^{+}$channel expression in an arterial smooth muscle cell ............................... 37

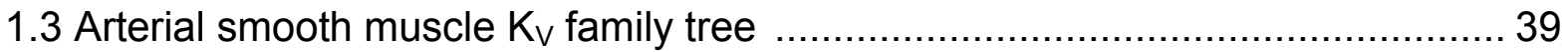

1.4 Example traces of $\mathrm{K}_{\mathrm{DR}}$ from porcine right coronary artery .......................... 41

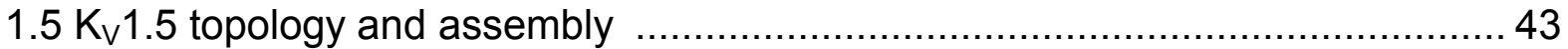

\section{Chapter 2}

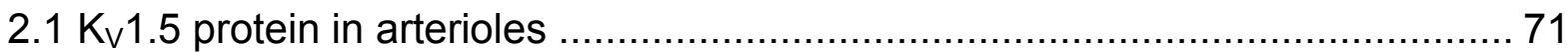

2.2 DPO-1-sensitive currents absent in $\mathrm{K}_{\mathrm{v}} 1.5$ knockout mice.............................. 73

2.3 DPO-1-sensitive $\mathrm{K}_{\mathrm{DR}}$ current in arteriolar smooth muscle ............................. 75

2.4 Concentration-dependent effect of DPO-1 on arteriolar diameter ..................... 77

2.5 DPO-1 augments contractions to serotonin and phenylephrine ...................... 79

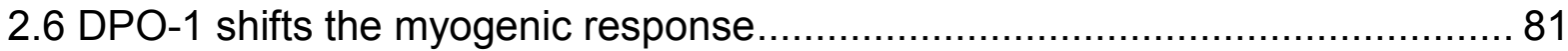

2.7 Relaxations to acetylcholine are impaired by DPO-1 …................................ 83

\section{Chapter 3}

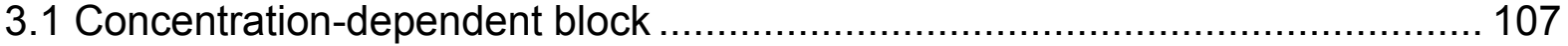

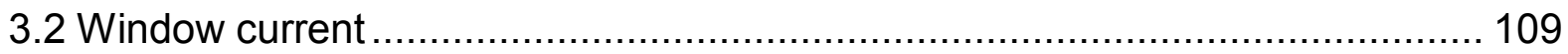

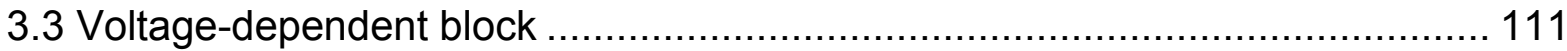

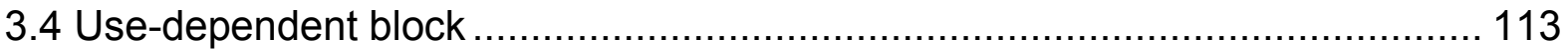

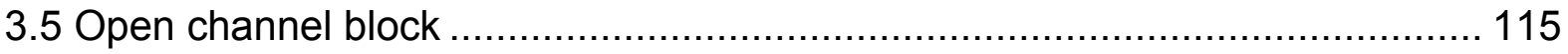




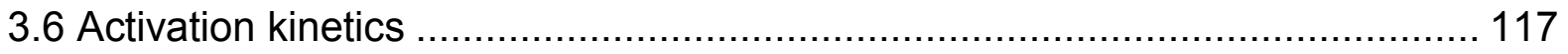

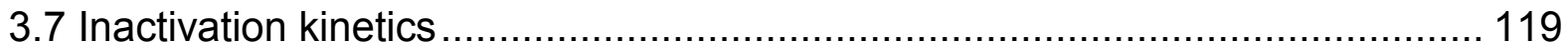

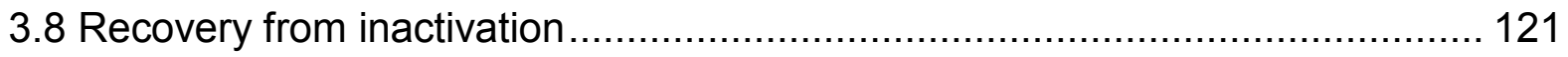

\section{Chapter 4}

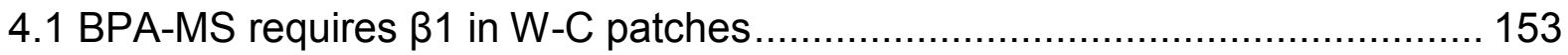

4.2 High concentration of BPA-MS needed to activate BKa .............................. 155

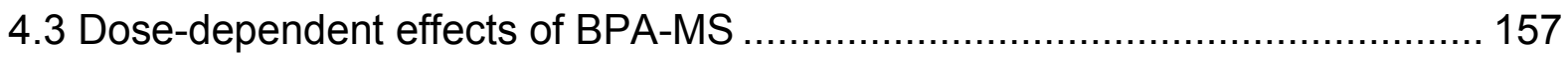

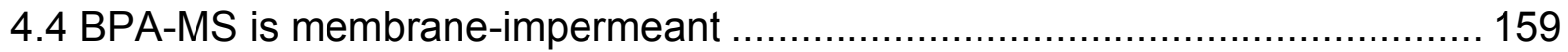

4.5 BPA-MS can activate from the cytoplasmic face of the membrane ................. 161

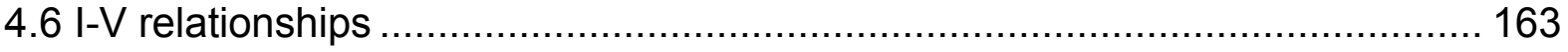

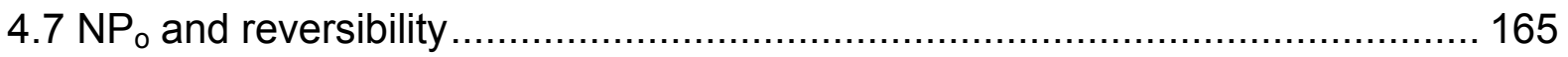




\section{Chapter 1}

\section{Introduction to $\mathrm{K}_{\mathrm{v}} 1$ Channels in the Vasculature}

Voltage-dependent $\mathrm{K}^{+}\left(\mathrm{K}_{\mathrm{V}}\right)$ channels are expressed in excitable tissues including skeletal and cardiac muscle. While $\mathrm{K}_{\mathrm{V}}$ channels are expressed in vascular smooth muscle, their role in regulating membrane potential and tone remains debated. Convincing data suggests $\mathrm{K}_{\mathrm{v}} 1$ channel members, possibly in heterologous conformations (e.g., $\mathrm{K}_{\mathrm{v}} 1.2-1.5$ heteromultimers), are responsible for the physiologically important delayed rectifier $\mathrm{K}^{+}\left(\mathrm{K}_{\mathrm{DR}}\right)$ current. However, evidence also exists for $\mathrm{Ca}^{2+}-$ activated $\mathrm{K}^{+}$channels, ATP-dependent $\mathrm{K}^{+}$channels, and other $\mathrm{K}_{\mathrm{V}}$ channels including the recently popular $\mathrm{K}_{\mathrm{V}} 7$ channels. Which channel(s) is/are responsible for regulating membrane potential and tone? In the following review of the literature, the $\mathrm{K}^{+}$channels that may regulate membrane potential and tone will be discussed and an argument will be made for $K_{v} 1$ channels, specifically $K_{v} 1.5$. Finally, the present knowledge gap with relation to health and disease will be discussed and the significance of the current body of work will be addressed.

Regulators of membrane potential and tone: $A$ variety of $K^{+}$channels in vascular smooth muscle

The electrochemical gradient for $\mathrm{K}^{+}$is arranged such that high concentration of $\mathrm{K}^{+}$ inside the cell exits through $\mathrm{K}^{+}$-permeable ion channels embedded in the otherwise lipophilic cell membrane. The $\mathrm{K}^{+}$current $\left(\mathrm{I}_{\mathrm{K}}\right)$ is essential for setting the polarized membrane potential and $I_{K}$ is therefore responsible for maintaining vascular tone such that vasoconstriction or vasodilation is possible. The membrane potential of arterial 
vascular smooth muscle, at approximately $-50 \mathrm{mV}$, is essential for controlling $\mathrm{Ca}^{2+}$ entry therefore physiological mechanisms of vascular reactivity which ultimately regulate tissue perfusion and pressure within the organism. Figure 1.1 is a cartoon depicting the cellular mechanisms that set resting membrane potential and thereby control arterial tone. While these physiological mechanisms have been intensely investigated and are well documented, the specific $\mathrm{K}^{+}$channels responsible for resting tone in arterial vascular beds remain elusive. This section will discuss the possible candidates, many of which have been reviewed previously (Jackson, 1998, 2000).

Figure 1.2 is a cartoon representing the $\mathrm{K}^{+}$channels expressed in arterial smooth muscle including those hypothesized to control arterial tone at rest. A number of $\mathrm{Ca}^{2+}$ activated $\mathrm{K}^{+}$channels have been implicated as having a role in arterial tone, including small and intermediate $\mathrm{Ca}^{2+}$-activated $\mathrm{K}^{+}$channels (SK and $\mathrm{IK}$, respectively) and the large voltage-dependent $\mathrm{Ca}^{2+}$-activated $\mathrm{K}^{+}$channel (BK). In cerebral arteries, $\mathrm{Ca}^{2+}{ }_{-}$ activated $\mathrm{K}^{+}$channel blockers depolarized and constricted vessels at concentrations that were previously shown to inhibit channel current directly; an effect that was reduced with low intracellular $\mathrm{Ca}^{2+}$ or by blocking $\mathrm{Ca}^{2+}$ channels (Brayden \& Nelson, 1992; Miller, 1988). However, this effect has also been reported as specific to the brain stem basilar artery and absent in middle cerebral artery (Horiuchi, Dietrich, Tsugane, \& Dacey, 2001). BK has been given great attention because of its physiological agonists, voltage and $\mathrm{Ca}^{2+}$, and would thus appear to participate in a negative feedback loop regulating myogenic tone in small arteries (Jackson \& Blair, 1998). However, a paradoxical role for $\mathrm{Ca}^{2+}$ in promoting vasodilation by activating $\mathrm{BK}$ via $\mathrm{Ca}^{2+}$ sparks from ryanodine receptors (RyR) has been shown to regulate membrane potential and arterial tone in 
cerebral arteries as evidenced by iberiotoxin- (BK channel blocker) and ryanodineinduced membrane depolarization and vasoconstriction (Knot, Standen, \& Nelson, 1998). Recently, this mechanism has been shown to be exclusive to cerebral pial arteries vs. parenchymal arteries depending on physiological $\mathrm{pH}$, suggesting that even vessels of the same arcade may have different $\mathrm{K}^{+}$channel regulators of arterial tone (Dabertrand, Nelson, \& Brayden, 2013). To complicate matters further, the auxiliary $\beta 1$ subunit, which increases the sensitivity of $\mathrm{BK}$ channels to $\mathrm{Ca}^{2+}$ and voltage and is physically associated with the BK a pore of vascular smooth muscle, has been the subject of conflicting reports concerning the role of BK channels in arterial tone. One such study using a BK $\beta 1$ deficient mouse reports increased blood pressure due to an uncoupled $\mathrm{BK} / \mathrm{Ca}^{2+}$ spark mechanism, while another study indicates that the elevated blood pressure in BK $\beta 1$ deficient mice is background-dependent and due to changes in aldosterone levels (Pluger et al., 2000; Sachse, Faulhaber, Seniuk, Ehmke, \& Pongs, 2014).

While it remains a possibility that $\mathrm{BK}, \mathrm{SK}$, and IK channels could regulate arterial tone in a few distinct vascular beds or in some species, it appears to be more likely that activation of $\mathrm{BK}$ is indicative of a hyperpolarizing brake upon vasoconstriction. For instance, in the cremaster arterioles of hamster and rat, as well as rat cerebral arterioles, BK has also been found to be silent at rest; arteriolar diameter and whole-cell $\mathrm{I}_{\mathrm{K}}$ from isolated smooth muscle cells was not influenced by iberiotoxin or tetraethylammonium (TEA) (Jackson \& Blair, 1998; Jackson, Huebner, \& Rusch, 1997; Loeb, Godeny, \& Longnecker, 2000; Paterno, Faraci, \& Heistad, 1996). The idea that BK channels regulate arterial tone can also be challenged with the notion that many 
endogenous vasoactive modulators have been shown to tightly regulate $\mathrm{Ca}^{2+}$ spark frequency and amplitude and could then affect BK channel activity in a manner not suitable for maintaining vascular tone, rather a seemingly more suitable mechanism to promote vasoconstriction or -dilation (Jaggar, Stevenson, \& Nelson, 1998; Jaggar, Wellman, et al., 1998; Porter et al., 1998). A possibly more convincing contradiction to the hypothesis that BK governs arterial tone is that the open probability of BK in the potentials of arterial smooth muscle cells at rest should be very low, and intracellular $\mathrm{Ca}^{2+}$ would be in sub-micromolar ranges (Jackson \& Blair, 1998). Furthermore, the elevated expression of BK in models of hypertension, reviewed by Rusch and Liu, is suggestive of a negative feedback to membrane depolarization, elevated intracellular $\mathrm{Ca}^{2+}$, and ultimately increased myogenic tone (M. Asano, Masuzawa-Ito, \& Matsuda, 1993; M. Asano, Matsuda, Hayakawa, Ito, \& Ito, 1993; Rusch \& Liu, 1997). While BK channels, and therefore $\mathrm{Ca}^{2+}$ and membrane potential, may have a role in arterial tone in some vascular beds, metabolic regulation of $\mathrm{K}^{+}$channels has also been investigated.

ATP-dependent $\mathrm{K}^{+}$channels $\left(\mathrm{K}_{\mathrm{ATP}}\right)$ are inhibited by ATP and have also been implicated in regulating arterial tone. $\mathrm{K}_{\mathrm{ATP}}$ channels have been extensively reviewed (Brayden, 2002; Quayle, Nelson, \& Standen, 1997). The proposed molecular makeup of these channels in human vascular smooth muscle has been shown to be the weakly inwardly rectifying pore Kir6.1 and the ATP-binding auxiliary sulfonylurea receptor subunit SUR2B as evidenced by transcript expression in pulmonary artery smooth muscle (Cui, Tran, Tinker, \& Clapp, 2002). Deletion of the Kir6.1 subunit in the smooth muscle of mice rendered the mice hypertensive and $\mathrm{K}_{\mathrm{ATP}}$ agonists such as pinacidil failed to induce vasodilation, perhaps indicating that $\mathrm{K}_{\mathrm{ATP}}$ regulates arterial tone at rest 
(Aziz et al., 2014). In addition, the $\mathrm{K}_{\mathrm{ATP}}$ channel blocker glibenclamide constricted hamster cheek pouch microvessels at rest and abolished vasodilatory actions of pinacidil and cromakalim (Jackson, 1993). Furthermore, the resting membrane potential of single smooth muscle cells isolated from rat and hamster depolarized with application of glibenclamide (Jackson et al., 1997). Glibenclamide also increased basal phrenic resistance in an in vivo anesthetized dog model while it also reduced baseline blood flow in the calf of human subjects, further supporting that $\mathrm{K}_{\mathrm{ATP}}$ regulates arterial tone at rest (Kosmas, Levy, \& Hussain, 1995; Vanelli \& Hussain, 1994).

While a growing body of literature shows that blockade of $\mathrm{K}_{\mathrm{ATP}}$ constricts vessels at rest, including the systemic, coronary, mesenteric, pulmonary, and renal circulations, evidence too exists that it plays no role in some of these same vascular beds (Comtois, Sinderby, Comtois, Grassino, \& Renaud, 1994; Gardiner, Kemp, March, Fallgren, \& Bennett, 1996; Jackson, 1993; Moreau et al., 1994; Parekh \& Zou, 1996). In studies investigating the skeletal muscle and pulmonary vasculature of dogs and cats, neither glibenclamide nor a non-sulphonylurea (U378838) $\mathrm{K}_{\mathrm{ATP}}$ blocker had an effect on baseline arterial flow or resistance (DeWitt et al., 1996; Lippton et al., 1995). In fact, numerous animal models have failed to show any connection to $\mathrm{K}_{\mathrm{ATP}}$ in resting arterial tone in the pulmonary circulation (DeWitt et al., 1996; Duncker, Oei, Hu, Stubenitsky, \& Verdouw, 2001; Hasunuma, Rodman, \& McMurtry, 1991; Lippton et al., 1995). Furthermore, $\mathrm{K}_{\mathrm{ATP}}$ is expressed and functional throughout the cerebral vasculature, yet no role has been suggested for the channel in regulating resting arterial tone (Faraci \& Heistad, 1998). Glibenclamide alone failed to constrict basilar arteries or cerebral arterioles in a variety of in vivo studies and only prevented vasodilation in the presence 
of $K_{\text {ATP }}$ agonists (Bari, Errico, Louis, \& Busija, 1996; Faraci \& Heistad, 1993; Kitazono, Faraci, \& Heistad, 1993; Lang, Paterno, Faraci, \& Heistad, 1997; Wahl, Parsons, \& Schilling, 1994). Similarly to the $\mathrm{Ca}^{2+}$-activated $\mathrm{K}^{+}$channels, $\mathrm{K}_{\mathrm{ATP}}$ may play a role in regulating arterial tone at rest in specific vascular beds of certain species, but probably plays a more important role in coupling metabolic cues to blood flow, thus promoting vasodilation when oxygen tension decreases.

The superfamily of voltage-dependent $\mathrm{K}^{+}$channels $\left(\mathrm{K}_{\mathrm{V}}\right)$, are activated by membrane depolarization at potentials positive to $-50 \mathrm{mV}$ and are therefore popular candidates for regulating resting arterial membrane potential and tone. This is a diverse family of $\mathrm{K}^{+}$ channels almost ubiquitously blocked by 4-aminopyridine (4-AP) and many members are expressed in arterial smooth muscle (Figures 1.2 and 1.3). Application of 4-AP depolarized membrane potential and increased intracellular $\mathrm{Ca}^{2+}$ in isolated arterial smooth muscle cells of dog and hamster (Dick et al., 2008; Jackson et al., 1997). 4-AP also reduced resting coronary flow in an in vivo dog model, suggesting that $\mathrm{K}_{\mathrm{V}}$ channels are responsible for coronary arterial tone (Dick et al., 2008). In rabbit cerebral arteries, 4-AP depolarized isolated smooth muscle cells and reduced vessel diameters; an effect that was not prevented by prior additions of numerous other $\mathrm{K}^{+}$channel blockers, suggesting that $\mathrm{K}_{\mathrm{V}}$ channels alone regulate cerebral arterial resting tone (Knot \& Nelson, 1995). Furthermore, 4-AP blockade of $K_{V}$ channels constricted both the basilar and middle cerebral arteries of rats (Horiuchi et al., 2001). While evidence for $K_{V}$ channels in regulating resting arterial tone exists across numerous vascular beds in a variety of species, the lack of specificity with 4-AP does not allow for the identification of particular $\mathrm{K}_{\mathrm{V}}$ channels that may contribute. 
A few subfamilies have been most investigated and include the $K_{v} 1 s$ and, more recently, the $K_{v} 7 s$. The $K_{V} 7$ channel blockers linopirdine and XE991 have been shown to produce both membrane depolarization and vasoconstriction at rest (Joshi, Balan, \& Gurney, 2006; Yeung \& Greenwood, 2005). Furthermore, the effect on arterial reactivity was abolished by L-type $\mathrm{Ca}^{2+}$ channel block, indicating the necessary mechanisms of membrane depolarization and intracellular $\mathrm{Ca}^{2+}$ in vasoconstriction upon $\mathrm{K}_{\mathrm{v}} 7$ blockade (Joshi et al., 2006). Interestingly, $\mathrm{K}_{\mathrm{V}} 7.1$ blockers alone could not constrict intrapulmonary arteries yet $\mathrm{K}_{\mathrm{V}} 7.1$ activators relaxed arteries and linopirdine induced constrictions, indicating the presence of $\mathrm{K}_{\mathrm{v}} 7.1$ in vascular smooth muscle without a role in arterial tone (Madeley, 1988). A functional heterotetrameric assembly has been proposed and may consist of $\mathrm{K}_{\mathrm{v}} 7.1$ and $\mathrm{K}_{\mathrm{v}} 7.5$ subunits, diversifying vascular smooth muscle channels and complicating physiological and pharmacological approaches (Oliveras et al., 2014). Negative data regarding a role for the $\mathrm{K}_{\mathrm{v}} 7 \mathrm{~s}$ is sparse, however, preliminary data show that neither linopiridine nor flupirtine have an effect on resting or metabolic coronary flow during in vivo, open chest experiments in swine (Goodwill et al., 2013). In addition, neither flupirtine nor retigabine have produced the predicted effects in isolated arterial smooth muscle cells from pig right coronary artery or rat aorta in our own investigations (unpublished observations). However, others and we claim that the $\mathrm{K}_{\mathrm{V}} 1$ subfamily plays a critical role in resting arterial tone and that further investigation of this group, as well as its specific members, should be entertained. An introduction to the $\mathrm{K}_{\mathrm{V}} 1$ subfamily and a putative role in arterial tone and reactivity follows.

$K_{V} 1$ channels, membrane potential, and resting tone 
$\mathrm{K}_{\mathrm{V}} 1$ channels arise from the KCNA Shaker family of genes and are expressed in a variety of excitable and non-excitable cells. In excitable cells, such as neurons and cardiac muscle, these channels have been associated with repolarizing currents following membrane depolarization during the action potential (Murray et al., 1994; Rowan, Tranquil, \& Christie, 2014). The role of $\mathrm{K}_{v} 1$ channels in many non-excitable cells, including vascular smooth muscle, is still under investigation. Recent evidence has suggested roles in inflammation and cell division of cancer cells, thus implicating $\mathrm{K}_{\mathrm{v} 1}$ channels as possible therapeutic targets in some disease states (Comes et al., 2013; Koch Hansen et al., 2014; Koeberle \& Schlichter, 2010).

$\mathrm{K}_{\mathrm{V}} 1$ channels are comprised of four membrane-spanning proteins that together make a functional ion channel selective for $\mathrm{K}^{+}$flux. Each protein of the subfamily has six transmembrane segments: S1-S4 represents the voltage-sensitive domains, with S4 being the voltage sensor containing positively charged arginine and lysine residues. The S5 and S6 segments form the pore domain for the selectivity and conductance of $\mathrm{K}^{+}$ (Aggarwal \& MacKinnon, 1996; Long, Campbell, \& Mackinnon, 2005; Seoh, Sigg, Papazian, \& Bezanilla, 1996). Each of the four voltage-sensing domains must react to membrane depolarization for the channels to activate (open). The $\mathrm{K}_{\mathrm{DR}}$ current from $\mathrm{K}_{\mathrm{V}} 1$ channels displays unique kinetics due to, in most members of the subfamily, an $\mathrm{N}$-type gating mechanism (Prince \& Pfaffinger, 2013). $K_{D R}$ kinetic properties are such that while in the presence of the continued depolarization, the open channels inactivate (one type of closure) in a time-dependent manner. $\mathrm{K}_{\mathrm{V}} 1$ channels deactivate (another type of closure) when the stimulus is removed during repolarization. Figure 1.4 shows example traces of whole-cell patch clamp recordings from porcine coronary smooth muscle cells. 
$\mathrm{K}_{\mathrm{DR}}$ current is shown during depolarization to $+20 \mathrm{mV}$ in $\mathrm{A}$ ) 'short' and $\mathrm{B}$ ) 'long' pulse protocols. Activation and deactivation are readily appreciated from the 'short' pulse, while inactivation is more clearly demonstrated in 'long' pulse. Regulatory subunits, endogenous proteins and physiological molecules, and drugs can affect $\mathrm{K}_{\mathrm{v}} 1$ channel activity and kinetics. Mechanisms of drug block, i.e. during which channel state (open or closed) the drug is binding and therefore inhibiting $K_{D R}$, are useful ways to study $K_{D R}$ currents.

The role of $\mathrm{K}_{\mathrm{v}} 1$ channels in resting arterial tone remains unclear, however, some reports indicate that $\mathrm{K}_{\mathrm{DR}}$ from $\mathrm{K}_{\mathrm{V}} 1$ channels sets resting membrane potential. Previous work conducted by my mentor shows that correolide ( $\mathrm{K}_{\mathrm{v}} 1$ specific antagonist)-sensitive $\mathrm{K}_{V}$ channels make up a significant portion of the total $\mathrm{K}_{\mathrm{DR}}$ population in canine coronary smooth muscle, and that this $\mathrm{K}_{\mathrm{DR}}$ is responsible for resting arterial tone and membrane potential (Dick et al., 2008). Others have reported that the 4-AP-sensitive $K_{D R}$ is attributed to $\mathrm{K}_{\mathrm{v}} 1$ channels by comparison of native cells to that of cloned $\mathrm{K}_{\mathrm{v}} 1$ expression systems (Clement-Chomienne, Ishii, Walsh, \& Cole, 1999; Grissmer et al., 1994; Kerr et al., 2001; Po, Roberds, Snyders, Tamkun, \& Bennett, 1993). In one such report, rabbit vascular smooth muscle cell $\mathrm{K}_{\mathrm{DR}}$ was similar to a cloned complex of $\mathrm{K}_{\mathrm{V}} 1.2$ and $\mathrm{K}_{\mathrm{V}} 1.5$ indicating this $\mathrm{K}_{\mathrm{v}} 1$ channel conformation could be the dominant form of the 4AP-sensitive $K_{V}$ channel population in vascular smooth muscle (Kerr et al., 2001). Molecular analyses from numerous groups have revealed a number of $\mathrm{K}_{\mathrm{v}} 1$ transcripts and proteins in a variety of vascular smooth muscle from different species and a few reports support the formation of heterotetrameric conformations (Albarwani et al., 2003; 
Archer et al., 1998; Cheong, Dedman, \& Beech, 2001; Cheong, Dedman, Xu, \& Beech, 2001; Kerr et al., 2001; Plane et al., 2005; Po et al., 1993; Thorneloe et al., 2001).

The identification of $\mathrm{K}_{\mathrm{v}} 1$ heterotetramers may underlie the differences observed with drug effects in native cells versus cloned $\mathrm{K}_{\mathrm{v}} 1$ homotetramers, yet the lack of $\mathrm{K}_{\mathrm{v}} 1$ member-specific inhibitors has limited the field in delineating the true molecular identity of native $\mathrm{K}_{\mathrm{DR}}$ in arterial smooth muscle. Recently, however, diphenyl phosphine oxide-1 (DPO-1) was synthesized and proposed as a $\mathrm{K}_{\mathrm{V}} 1.5$ specific inhibitor. Fortunately, this specific $\mathrm{K}_{\mathrm{V}} 1$ member has been implicated by a number of previous studies and therefore further examination of DPO-1 is warranted. In the following section, the studies that have investigated a role in arterial tone and reactivity specifically for $\mathrm{K}_{\mathrm{v}} 1.5$ will be addressed as will a rationale to use DPO-1 to further investigate the molecular identity of native $\mathrm{K}_{\mathrm{DR}}$.

\section{Evidence for an integral role for $K_{v} 1.5$}

As discussed in the previous section pertaining $\mathrm{K}_{\mathrm{V}} 1$ subfamily topology and assembly, $\mathrm{K}_{\mathrm{v}} 1.5$ proteins contain six transmembrane segments with $\mathrm{S} 4$ being the prominent voltage sensor (Figure 1.5 A). Assembly is such that four $\mathrm{K}_{\mathrm{v}} 1.5$ proteins make a functional ion channel, with regulatory $\mathrm{N}$-terminal $\mathrm{T} 1$ domains from each protein self-tetramerizing within the cell (Figure 1.5 B) (Pfaffinger \& DeRubeis, 1995). $K_{V} 1.5$ exhibits ultra-rapid fast activation and slow inactivation $\mathrm{K}_{\mathrm{DR}}$ kinetics (Feng, Wible, Li, Wang, \& Nattel, 1997; Feng, Xu, Wang, \& Nattel, 1998). The inactivation kinetics are such that $\mathrm{K}^{+}$binding to intracellular and extracellular sites of $\mathrm{K}_{\mathrm{v}} 1.5$ promote two components (fast and slow) of P-type channel inactivation (Fedida, Maruoka, \& Lin, 1999). Interestingly, mutation of certain intracellular $\mathrm{N}$-terminus residues in the T1 
domain switches the $\mathrm{K}_{\mathrm{v}} 1.5$ inactivation from $\mathrm{P}$ - to U-type, drastically altering inactivation-voltage relationships (Kurata et al., 2002). Therefore, mutations in $\mathrm{K}_{v} 1.5$ likely have clinical relevance as changes in the $\mathrm{K}_{\mathrm{DR}}$ of excitatory tissue could possibly influence action potential duration/frequency. For instance, some forms of atrial fibrillation are proposed to derive from atrial $\mathrm{K}_{\mathrm{V}} 1.5$ loss-of-function mutations (Olson et al., 2006). $K_{V} 1.5$ has also been shown to be expressed in vascular smooth muscle, in some studies at high levels relative to other $\mathrm{K}_{\mathrm{v}} 1$ members, and so too, may present an issue with decreased expression in pathologies such as vasospasm (Albarwani et al., 2003; Cheong, Dedman, \& Beech, 2001; Plane et al., 2005; Platoshyn et al., 2006; Platoshyn et al., 2001; Pozeg et al., 2003).

Cole and colleagues conducted a series of studies that suggest $\mathrm{K}_{\mathrm{V}} 1.5$ and other $\mathrm{K}_{\mathrm{V}}$ channel members form functional heterotetramers and thus provide great diversity to vascular smooth muscle electrophysiology. This finding complicates attempts to delineate the importance of $\mathrm{K}_{\mathrm{v}} 1.5$ in resting arterial tone, however, pharmacological evidence from these experiments suggests $\mathrm{K}_{\mathrm{v}} 1.5$ may be present in all or most complexes (Plane et al., 2005). A comparison of native rabbit portal vein myocyte $K_{D R}$ to cloned $\mathrm{K}_{\mathrm{V}} 1.5$ properties revealed many electrophysiological similarities except for some components of inactivation (Clement-Chomienne et al., 1999). Subsequently, they later identified a complex of $\mathrm{K}_{\mathrm{v}} 1.2$ and $\mathrm{K}_{\mathrm{V}} 1.5$ as a putative heteromultimeric channel in rabbit portal vein that may attest for the differences in inactivation seen in the previous study comparing native cells to a cloned $\mathrm{K}_{\mathrm{V}} 1.5$ homotetramer (Kerr et al., 2001).

In vascular smooth muscle, the normal $\mathrm{P}$-type, slow inactivation phenotype of $\mathrm{K}_{\mathrm{V}} 1.5$ would seemingly act as a brake to myogenic constriction with increased intraluminal 
pressure (myogenic response), counteracting depolarizing fluxes to control arterial tone. This has been demonstrated by transfection of murine cerebral arteries with dominantnegative $\mathrm{K}_{\mathrm{V}} 1.5$, which had suppressed negative feedback to the myogenic response and thusly enhanced arterial constriction with increasing pressure. However, this study did not conduct an experiment with 4-AP on resting arterial tone to identify whether $\mathrm{K}_{\mathrm{DR}}$, and potentially resting membrane potential and tone, were mediated by $\mathrm{K}_{\mathrm{v}} 1.5$ (Chen, Luykenaar, Walsh, Walsh, \& Cole, 2006). $\mathrm{K}_{\mathrm{v}} 1.5$ has been examined in the pulmonary circulation due to its role as an oxygen sensor in acute hypoxia, which inhibits the channel and depolarizes membrane potential (Platoshyn et al., 2006; Yuan, 1995). In resistance pulmonary arteries, $\mathrm{K}_{\mathrm{v}} 1.5$ current inhibition by antibody binding contributed more than $\mathrm{K}_{\mathrm{v}} 2.1$ to membrane depolarization in rats (Archer et al., 2004). However, few investigations have discerned a specific role for $\mathrm{K}_{\mathrm{V}} 1.5$ in resting arterial tone in other vascular beds and at least one account accredits $K_{v} 2.1$, with no role for $K_{v} 1.5$ despite its expression, in rat pulmonary artery (Archer et al., 1998). Furthermore, Chong et al. show a complete absence of $\mathrm{K}_{\mathrm{V}} 1.5$ in murine cerebral smooth muscle cells, which contradicts other reports (Albarwani et al., 2003; Cheong, Dedman, \& Beech, 2001; Cheong, Dedman, Xu, et al., 2001).

While convincing evidence exists that members of the $K_{V}$ channel superfamily control resting membrane potential and therefore regulate arterial tone, a role for $\mathrm{K}_{\mathrm{v}} 1.5$ has not been clear in many vascular beds. With the synthesis of DPO-1, however, a possible direct pharmacological tool to deduce the role of $K_{v} 1.5$ in this setting is now available. DPO-1 comparably varied kinetics of cloned human $\mathrm{K}_{\mathrm{V}} 1.5$ channels and ultrarapidly activating delayed rectifier $\mathrm{K}^{+}$currents $\left(\mathrm{I}_{\mathrm{Kur}}\right)$ of human atrial myocytes expected 
to be conducted by $\mathrm{K}_{\mathrm{V}} 1.5$ (Lagrutta, Wang, Fermini, \& Salata, 2006). DPO-1 also prevented atrial arrhythmias in vivo with no effect in ventricles of dogs, rats, and nonhuman primates further supporting the specificity of DPO-1 for $\mathrm{K}_{V} 1.5$ versus non-IKur channels (Regan, Wallace, Cresswell, Atkins, \& Lynch, 2006; Stump, Wallace, Regan, \& Lynch, 2005). Based on these reports and our own findings, we believe that DPO-1 is a sufficient pharmacological tool to pursue the role of $\mathrm{K}_{\mathrm{V}} 1.5$ in resting arterial tone of a variety of vascular beds. In the final section of this introduction to $\mathrm{K}^{+}$channels and arterial tone, we briefly summarize the significance of the current body of work.

\section{Significance of work}

In the subsequent chapters of this document we 1) describe the specificity for DPO1 for $\mathrm{K}_{\mathrm{V}} 1.5$ in a KCNA5 knockout mouse model (Chapter 2), 2) determine a role for

DPO-1 sensitive $K_{D R}$ channels in tone and reactivity of microvessels (Chapter 2), and 3) investigate the effects of DPO-1 on native porcine coronary smooth muscle cell $K_{D R}$ channel kinetics (Chapter 3). The goal of this portion of the doctoral dissertation was two-fold: First, we examined DPO-1 as a tool for investigating $\mathrm{K}_{\mathrm{DR}}$ channels in vascular smooth muscle, including pressurized vessel and electrophysiological experiments. Second, we support a role for $\mathrm{K}_{\mathrm{V}} 1.5$ in both conduit and resistance type vessels of different vascular beds in resting arterial tone.

This body of work supports a role for $\mathrm{K}_{\mathrm{v}}$ channel dependent control of arterial tone and membrane potential and suggests that $\mathrm{K}_{\mathrm{v}} 1.5$ specifically is an important mediator. Further investigation of $\mathrm{K}_{\mathrm{V}}$ member specific drugs and discovery of $\mathrm{K}_{\mathrm{V}}$ channels that regulate resting arterial tone may provide essential therapeutic targets to combat such pathologies as hypertension and peripheral vascular disease, especially in small 
arteries and arterioles. We believe that $\mathrm{K}_{\mathrm{V}} 1.5$, alone or in complex with other $\mathrm{K}_{\mathrm{V}}$ members, could be one such target.

\section{Introduction to BK and BPA}

\section{Estrogen regulation of $B K$}

Large conductance voltage- and $\mathrm{Ca}^{2+}$-activated $\mathrm{K}^{+}(\mathrm{BK})$ channels are composed of four $\alpha$ pore subunits each containing seven transmembrane segments. Auxiliary $\beta$ subunits can alter BK channel properties and in vascular smooth muscle, $\beta 1$ increases the sensitivity to $\mathrm{Ca}^{2+}$ and voltage (Sweet \& Cox, 2009). $\beta$ subunits can also affect or mediate the actions of pharmacological agents. For instance, iberiotoxin is a potent inhibitor of BK channels but cannot block neuronal BK containing $\beta 4$ subunits (Meera, Wallner, \& Toro, 2000). Furthermore, estrogens and xenostrogens (e.g. tamoxifen) activate BK channels by binding $\beta 1$ subunits (Dick, Hunter, \& Sanders, 2002; Dick, Rossow, Smirnov, Horowitz, \& Sanders, 2001; Dick \& Sanders, 2001; Valverde et al., 1999). These findings suggest important physiological roles for BK channels in endocrine signaling and emphasize the importance of tissue specific $\beta$ subunit expression.

BK channels are dynamically regulated by endogenous endocrine mediators, ultimately influencing the expression, splicing, and function of BK. The effect of sex hormones and the role BK plays in testicular cells and uterine myometrium have been documented. Findings suggest that BK activation reduces androgen production and regulates myometrium excitability during gestation (Benkusky, Korovkina, Brainard, \& England, 2002; Matzkin et al., 2013). In the uterine vasculature estrogen activation of BK channels induces vasodilation (Hu et al., 2011; Rosenfeld, Cornfield, \& Roy, 2001). 
It is conceivable that circulating estrogens could reach BK channels located in other tissue including brain and non-reproductive vascular beds. One such study investigating the estrogenic effects on BK expression revealed tissue specific changes in the expression of $\alpha$ and $\beta$ subunits. Specifically, BK subunit expression was increased in aorta while brain BK subunits were unaffected by estrogen (Jamali, Naylor, Kelly, \& Ronnekleiv, 2003). This is contradicted by data showing that cells transfected with BK $\alpha$ and $\beta 1$ exposed to $17 \beta$-estradiol expressed less BK channels than non-exposed cells (Korovkina, Brainard, Ismail, Schmidt, \& England, 2004). Nonetheless, the putative long-term genomic effect of estrogens increasing vascular smooth muscle BK channel expression coupled to the acute activation of BK channels inducing vasodilation are proposed components of cardioprotective events in women (Jamali et al., 2003). However, exposure to endocrine disruptors that contain similar molecular composition

to estrogens could promote synergistic estrogenic effects or competitive inhibition of intracellular signaling targets, perhaps negatively affecting BK channel expression and function.

\section{$B P A$ activates $B K$}

Bisphenol A (BPA) is a byproduct during formation of polycarbonate plastics and epoxy resins. Therefore, human exposure to BPA is largely through the diet as many plastics and canned goods contain these compounds. The resins that line canned goods, for instance, protect consumer goods from contact with metal yet may leach BPA instead (Howe \& Borodinsky, 1998). This was brought to public attention because investigation of BPA exposure in rats suggests maladaptive effects (Farabollini, Porrini, \& Dessi-Fulgherit, 1999; Khurana, Ranmal, \& Ben-Jonathan, 2000; Steinmetz et al., 
1998). More importantly, the Center for Disease Control estimates over $90 \%$ of the population contains BPA in the urine (Lakind \& Naiman, 2008).

Our group recently showed that BPA activates BK channels with and without the $\beta 1$ subunit present (S. Asano, Tune, \& Dick, 2010). However, the presence of the $\beta 1$ subunit increased the potency of BPA by one order of magnitude. BPA also increased conductance of BK channels in coronary smooth muscle and we suggest that increased BK activity may underlie potential toxicological effects of BPA. However, how the membrane permeant-BPA activates BK channels directly is unknown, and we therefore set to determine from which side of the cell membrane BPA activates BK channels in Chapter 4.

\section{Significance of work}

Xenoestrogens such as BPA are known endocrine disruptors, however, their nongenomic effects are often not given attention. In Chapter 4, we show published data regarding the effect of BPA-monosulfate (BPA-MS) on cloned human BK channels. This documents our attempts at determining from which side of the cell membrane BPA activates BK channels as the monosulfate moiety renders BPA membrane impermeable. The significance of these data resides mostly in pharmacodynamics of BPA on BK channels but might also provide toxicological insight to circulating BPA upon exposure. Furthermore, we add to a growing body of literature that suggests that BPA directly affects a variety of ion channels in a non-genomic manner. 


\section{References}

Aggarwal, S. K., \& MacKinnon, R. (1996). Contribution of the S4 segment to gating charge in the Shaker K+ channel. Neuron, 16(6), 1169-1177.

Albarwani, S., Nemetz, L. T., Madden, J. A., Tobin, A. A., England, S. K., Pratt, P. F., \& Rusch, N. J. (2003). Voltage-gated $\mathrm{K}^{+}$channels in rat small cerebral arteries: molecular identity of the functional channels. J Physiol, 551(Pt 3), 751-763. doi: 10.1113/jphysiol.2003.040014

jphysiol.2003.040014 [pii]

Archer, S. L., Souil, E., Dinh-Xuan, A. T., Schremmer, B., Mercier, J. C., El Yaagoubi, A., ... Hampl, V. (1998). Molecular identification of the role of voltage-gated K+ channels, Kv1.5 and Kv2.1, in hypoxic pulmonary vasoconstriction and control of resting membrane potential in rat pulmonary artery myocytes. J Clin Invest, 101(11), 2319-2330. doi: 10.1172/JCl333

Archer, S. L., Wu, X. C., Thebaud, B., Nsair, A., Bonnet, S., Tyrrell, B., . . Michelakis, E. D. (2004). Preferential expression and function of voltage-gated, O2-sensitive $\mathrm{K}+$ channels in resistance pulmonary arteries explains regional heterogeneity in hypoxic pulmonary vasoconstriction: ionic diversity in smooth muscle cells. Circ Res, 95(3), 308-318. doi: 10.1161/01.RES.0000137173.42723.fb 
Asano, M., Masuzawa-Ito, K., \& Matsuda, T. (1993). Charybdotoxin-sensitive K+ channels regulate the myogenic tone in the resting state of arteries from spontaneously hypertensive rats. Br J Pharmacol, 108(1), 214-222.

Asano, M., Matsuda, T., Hayakawa, M., Ito, K. M., \& Ito, K. (1993). Increased resting $\mathrm{Ca} 2+$ maintains the myogenic tone and activates $\mathrm{K}+$ channels in arteries from young spontaneously hypertensive rats. Eur J Pharmacol, 247(3), 295-304.

Asano, S., Tune, J. D., \& Dick, G. M. (2010). Bisphenol A activates Maxi-K (K(Ca)1.1) channels in coronary smooth muscle. Br J Pharmacol, 160(1), 160-170. doi: 10.1111/j.1476-5381.2010.00687.x

Aziz, Q., Thomas, A. M., Gomes, J., Ang, R., Sones, W. R., Li, Y., . . Tinker, A. (2014). The ATP-Sensitive Potassium Channel Subunit, Kir6.1, in Vascular Smooth Muscle Plays a Major Role in Blood Pressure Control. Hypertension. doi: 10.1161/HYPERTENSIONAHA.114.03116

Bari, F., Errico, R. A., Louis, T. M., \& Busija, D. W. (1996). Interaction between ATPsensitive $\mathrm{K}+$ channels and nitric oxide on pial arterioles in piglets. J Cereb Blood Flow Metab, 16(6), 1158-1164. doi: 10.1097/00004647-199611000-00010

Benkusky, N. A., Korovkina, V. P., Brainard, A. M., \& England, S. K. (2002). Myometrial maxi-K channel beta1 subunit modulation during pregnancy and after 17betaestradiol stimulation. FEBS Lett, 524(1-3), 97-102. 
Brayden, J. E. (2002). Functional roles of KATP channels in vascular smooth muscle. Clin Exp Pharmacol Physiol, 29(4), 312-316.

Brayden, J. E., \& Nelson, M. T. (1992). Regulation of arterial tone by activation of calcium-dependent potassium channels. Science, 256(5056), 532-535.

Chen, T. T., Luykenaar, K. D., Walsh, E. J., Walsh, M. P., \& Cole, W. C. (2006). Key role of Kv1 channels in vasoregulation. Circ Res, 99(1), 53-60. doi: 01.RES.0000229654.45090.57 [pii]

10.1161/01.RES.0000229654.45090.57

Cheong, A., Dedman, A. M., \& Beech, D. J. (2001). Expression and function of native potassium channel $[\mathrm{K}(\mathrm{V})$ alpha1] subunits in terminal arterioles of rabbit. $J$ Physiol, 534(Pt 3), 691-700.

Cheong, A., Dedman, A. M., Xu, S. Z., \& Beech, D. J. (2001). K(V)alpha1 channels in murine arterioles: differential cellular expression and regulation of diameter. Am J Physiol Heart Circ Physiol, 281(3), H1057-1065.

Clement-Chomienne, O., Ishii, K., Walsh, M. P., \& Cole, W. C. (1999). Identification, cloning and expression of rabbit vascular smooth muscle Kv1.5 and comparison with native delayed rectifier K+ current. J Physiol, 515 ( Pt 3), 653-667. 
Comes, N., Bielanska, J., Vallejo-Gracia, A., Serrano-Albarras, A., Marruecos, L., Gomez, D., . . . Felipe, A. (2013). The voltage-dependent K(+) channels Kv1.3 and Kv1.5 in human cancer. Front Physiol, 4, 283. doi: 10.3389/fphys.2013.00283

Comtois, A., Sinderby, C., Comtois, N., Grassino, A., \& Renaud, J. M. (1994). An ATPsensitive potassium channel blocker decreases diaphragmatic circulation in anesthetized dogs. J Appl Physiol (1985), 77(1), 127-134.

Cui, Y., Tran, S., Tinker, A., \& Clapp, L. H. (2002). The molecular composition of K(ATP) channels in human pulmonary artery smooth muscle cells and their modulation by growth. Am J Respir Cell Mol Biol, 26(1), 135-143. doi: 10.1165/ajrcmb.26.1.4622

Dabertrand, F., Nelson, M. T., \& Brayden, J. E. (2013). Ryanodine receptors, calcium signaling, and regulation of vascular tone in the cerebral parenchymal microcirculation. Microcirculation, 20(4), 307-316. doi: 10.1111/micc.12027

DeWitt, B. J., Cheng, D. Y., McMahon, T. J., Marrone, J. R., Champion, H. C., \& Kandowitz, P. J. (1996). Effects of U-37883A, a vascular selective KATP+ channel antagonist, in the pulmonary and hindlimb circulation. Am J Physiol, 271(6 Pt 1), L924-931. 
Dick, G. M., Bratz, I. N., Borbouse, L., Payne, G. A., Dincer, U. D., Knudson, J. D., . . Tune, J. D. (2008). Voltage-dependent $\mathrm{K}+$ channels regulate the duration of reactive hyperemia in the canine coronary circulation. Am J Physiol Heart Circ Physiol, 294(5), H2371-2381. doi: 10.1152/ajpheart.01279.2007

Dick, G. M., Hunter, A. C., \& Sanders, K. M. (2002). Ethylbromide tamoxifen, a membrane-impermeant antiestrogen, activates smooth muscle calcium-activated large-conductance potassium channels from the extracellular side. $\mathrm{Mol}$ Pharmacol, 61(5), 1105-1113.

Dick, G. M., Rossow, C. F., Smirnov, S., Horowitz, B., \& Sanders, K. M. (2001). Tamoxifen activates smooth muscle BK channels through the regulatory beta 1 subunit. J Biol Chem, 276(37), 34594-34599. doi: 10.1074/jbc.M104689200

Dick, G. M., \& Sanders, K. M. (2001). (Xeno)estrogen sensitivity of smooth muscle BK channels conferred by the regulatory beta 1 subunit: a study of beta 1 knockout mice. J Biol Chem, 276(48), 44835-44840. doi: 10.1074/jbc.M106851200

Duncker, D. J., Oei, H. H., Hu, F., Stubenitsky, R., \& Verdouw, P. D. (2001). Role of $\mathrm{K}(\mathrm{ATP})(+)$ channels in regulation of systemic, pulmonary, and coronary vasomotor tone in exercising swine. Am J Physiol Heart Circ Physiol, 280(1), H22-33. 
Farabollini, F., Porrini, S., \& Dessi-Fulgherit, F. (1999). Perinatal exposure to the estrogenic pollutant bisphenol A affects behavior in male and female rats. Pharmacol Biochem Behav, 64(4), 687-694.

Faraci, F. M., \& Heistad, D. D. (1993). Role of ATP-sensitive potassium channels in the basilar artery. Am J Physiol, 264(1 Pt 2), H8-13.

Faraci, F. M., \& Heistad, D. D. (1998). Regulation of the cerebral circulation: role of endothelium and potassium channels. Physiol Rev, 78(1), 53-97.

Fedida, D., Maruoka, N. D., \& Lin, S. (1999). Modulation of slow inactivation in human cardiac Kv1.5 channels by extra- and intracellular permeant cations. J Physiol, 515 ( Pt 2), 315-329.

Feng, J., Wible, B., Li, G. R., Wang, Z., \& Nattel, S. (1997). Antisense oligodeoxynucleotides directed against Kv1.5 mRNA specifically inhibit ultrarapid delayed rectifier $\mathrm{K}+$ current in cultured adult human atrial myocytes. Circ Res, $80(4), 572-579$.

Feng, J., Xu, D., Wang, Z., \& Nattel, S. (1998). Ultrarapid delayed rectifier current inactivation in human atrial myocytes: properties and consequences. $A m \mathrm{~J}$ Physiol, 275(5 Pt 2), H1717-1725. 
Gardiner, S. M., Kemp, P. A., March, J. E., Fallgren, B., \& Bennett, T. (1996). Effects of glibenclamide on the regional haemodynamic actions of alpha-trinositol and its influence on responses to vasodilators in conscious rats. Br J Pharmacol, 117(3), $507-515$.

Goodwill, A. G., Casalini, E. D., Owen, M. K., Conteh, A., Sassoon, D., Shatagopam, K., . . . Tune, J. D. (2013). Role of Voltage-dependent Kv7 Channels in the Regulation of Coronary Blood Flow. The FASEB Journal, 27(1_MeetingAbstracts), 1185.1184 .

Grissmer, S., Nguyen, A. N., Aiyar, J., Hanson, D. C., Mather, R. J., Gutman, G. A., . . Chandy, K. G. (1994). Pharmacological characterization of five cloned voltagegated $\mathrm{K}+$ channels, types $\mathrm{Kv1} 1.1,1.2,1.3,1.5$, and 3.1 , stably expressed in mammalian cell lines. Mol Pharmacol, 45(6), 1227-1234.

Gutman, G. A., Chandy, K. G., Grissmer, S., Lazdunski, M., McKinnon, D., Pardo, L. A., . . Wang, X. (2005). International Union of Pharmacology. LIII. Nomenclature and molecular relationships of voltage-gated potassium channels. Pharmacol Rev, 57(4), 473-508. doi: 10.1124/pr.57.4.10

Hasunuma, K., Rodman, D. M., \& McMurtry, I. F. (1991). Effects of K+ channel blockers on vascular tone in the perfused rat lung. Am Rev Respir Dis, 144(4), 884-887. doi: 10.1164/ajrccm/144.4.884 
Horiuchi, T., Dietrich, H. H., Tsugane, S., \& Dacey, R. G., Jr. (2001). Role of potassium channels in regulation of brain arteriolar tone: comparison of cerebrum versus brain stem. Stroke, 32(1), 218-224.

Howe, S. R., \& Borodinsky, L. (1998). Potential exposure to bisphenol A from foodcontact use of polycarbonate resins. Food Addit Contam, 15(3), 370-375. doi: $10.1080 / 02652039809374653$

Hu, X. Q., Xiao, D., Zhu, R., Huang, X., Yang, S., Wilson, S., \& Zhang, L. (2011). Pregnancy upregulates large-conductance $\mathrm{Ca}(2+)$-activated $\mathrm{K}(+)$ channel activity and attenuates myogenic tone in uterine arteries. Hypertension, 58(6), 11321139. doi: 10.1161/HYPERTENSIONAHA.111.179952

Jackson, W. F. (1993). Arteriolar tone is determined by activity of ATP-sensitive potassium channels. Am J Physiol, 265(5 Pt 2), H1797-1803.

Jackson, W. F. (1998). Potassium channels and regulation of the microcirculation. Microcirculation, 5(2-3), 85-90.

Jackson, W. F. (2000). Ion channels and vascular tone. Hypertension, 35(1 Pt 2), 173178.

Jackson, W. F., \& Blair, K. L. (1998). Characterization and function of $\mathrm{Ca}(2+)$-activated $\mathrm{K}+$ channels in arteriolar muscle cells. Am J Physiol, 274(1 Pt 2), H27-34. 
Jackson, W. F., Huebner, J. M., \& Rusch, N. J. (1997). Enzymatic isolation and characterization of single vascular smooth muscle cells from cremasteric arterioles. Microcirculation, 4(1), 35-50.

Jaggar, J. H., Stevenson, A. S., \& Nelson, M. T. (1998). Voltage dependence of Ca2+ sparks in intact cerebral arteries. Am J Physiol, 274(6 Pt 1), C1755-1761.

Jaggar, J. H., Wellman, G. C., Heppner, T. J., Porter, V. A., Perez, G. J., Gollasch, M., . . . Nelson, M. T. (1998). Ca2+ channels, ryanodine receptors and $\mathrm{Ca}(2+)-$ activated K+ channels: a functional unit for regulating arterial tone. Acta Physiol Scand, 164(4), 577-587. doi: 10.1046/j.1365-201X.1998.00462.x

Jamali, K., Naylor, B. R., Kelly, M. J., \& Ronnekleiv, O. K. (2003). Effect of 17betaestradiol on mRNA expression of large- conductance, voltage-dependent, and calcium-activated potassium channel alpha and beta subunits in guinea pig. Endocrine, 20(3), 227-237. doi: 10.1385/ENDO:20:3:227

Joshi, S., Balan, P., \& Gurney, A. M. (2006). Pulmonary vasoconstrictor action of KCNQ potassium channel blockers. Respir Res, 7, 31. doi: 10.1186/1465-9921-7-31

Kerr, P. M., Clement-Chomienne, O., Thorneloe, K. S., Chen, T. T., Ishii, K., Sontag, D. P., . . . Cole, W. C. (2001). Heteromultimeric Kv1.2-Kv1.5 channels underlie 4aminopyridine-sensitive delayed rectifier $\mathrm{K}(+)$ current of rabbit vascular myocytes. Circ Res, 89(11), 1038-1044. 
Khurana, S., Ranmal, S., \& Ben-Jonathan, N. (2000). Exposure of newborn male and female rats to environmental estrogens: delayed and sustained hyperprolactinemia and alterations in estrogen receptor expression. Endocrinology, 141(12), 4512-4517. doi: 10.1210/endo.141.12.7823

Kitazono, T., Faraci, F. M., \& Heistad, D. D. (1993). Effect of norepinephrine on rat basilar artery in vivo. Am J Physiol, 264(1 Pt 2), H178-182.

Knot, H. J., \& Nelson, M. T. (1995). Regulation of membrane potential and diameter by voltage-dependent $\mathrm{K}+$ channels in rabbit myogenic cerebral arteries. Am $\mathrm{J}$ Physiol, 269(1 Pt 2), H348-355.

Knot, H. J., Standen, N. B., \& Nelson, M. T. (1998). Ryanodine receptors regulate arterial diameter and wall $[\mathrm{Ca} 2+]$ in cerebral arteries of rat via $\mathrm{Ca} 2+-$ dependent K+ channels. J Physiol, 508 ( Pt 1), 211-221.

Koch Hansen, L., Sevelsted-Moller, L., Rabjerg, M., Larsen, D., Hansen, T. P., Klinge, L., . . Kohler, R. (2014). Expression of T-cell K1.3 potassium channel correlates with pro-inflammatory cytokines and disease activity in ulcerative colitis. J Crohns Colitis. doi: 10.1016/j.crohns.2014.04.003

Koeberle, P. D., \& Schlichter, L. C. (2010). Targeting K(V) channels rescues retinal ganglion cells in vivo directly and by reducing inflammation. Channels (Austin), 4(5), 337-346. doi: 10.1038/cdd.2009.113 
Korovkina, V. P., Brainard, A. M., Ismail, P., Schmidt, T. J., \& England, S. K. (2004). Estradiol binding to maxi-K channels induces their down-regulation via proteasomal degradation. J Biol Chem, 279(2), 1217-1223. doi: 10.1074/jbc.M309158200

Kosmas, E. N., Levy, R. D., \& Hussain, S. N. (1995). Acute effects of glyburide on the regulation of peripheral blood flow in normal humans. Eur J Pharmacol, 274(1-3), 193-199.

Kurata, H. T., Soon, G. S., Eldstrom, J. R., Lu, G. W., Steele, D. F., \& Fedida, D. (2002). Amino-terminal determinants of $\mathrm{U}$-type inactivation of voltage-gated $\mathrm{K}+$ channels. J Biol Chem, 277(32), 29045-29053. doi: 10.1074/jbc.M111470200

Lagrutta, A., Wang, J., Fermini, B., \& Salata, J. J. (2006). Novel, potent inhibitors of human $\mathrm{Kv} 1.5 \mathrm{~K}+$ channels and ultrarapidly activating delayed rectifier potassium current. J Pharmacol Exp Ther, 317(3), 1054-1063. doi: 10.1124/jpet.106.101162

Lakind, J. S., \& Naiman, D. Q. (2008). Bisphenol A (BPA) daily intakes in the United States: estimates from the 2003-2004 NHANES urinary BPA data. $J$ Expo Sci Environ Epidemiol, 18(6), 608-615. doi: 10.1038/jes.2008.20

Lang, M. G., Paterno, R., Faraci, F. M., \& Heistad, D. D. (1997). Mechanisms of adrenomedullin-induced dilatation of cerebral arterioles. Stroke, 28(1), 181-185. 
Lippton, H., Choe, E., Franklin, E., Grivas, T., Flint, L., Hyman, A., \& Ferrara, J. (1995). Femoral vasodilation to cromakalim is blocked by U37883A, a non-sulphonylurea that selectively inhibits KATP channels. J Pharm Pharmacol, 47(3), 243-245.

Loeb, A. L., Godeny, I., \& Longnecker, D. E. (2000). Functional evidence for inwardrectifier potassium channels in rat cremaster muscle arterioles. Microvasc Res, 59(1), 1-6. doi: 10.1006/mvre.1999.2187

Long, S. B., Campbell, E. B., \& Mackinnon, R. (2005). Crystal structure of a mammalian voltage-dependent Shaker family K+ channel. Science, 309(5736), 897-903. doi: 10.1126/science. 1116269

Madeley, R. (1988). Preventing sudden infant death syndrome: future strategies. Health Visit, 61(8), 241-243.

Matzkin, M. E., Lauf, S., Spinnler, K., Rossi, S. P., Kohn, F. M., Kunz, L., . . . Mayerhofer, A. (2013). The Ca2+-activated, large conductance K+-channel (BKCa) is a player in the LH/hCG signaling cascade in testicular Leydig cells. Mol Cell Endocrinol, 367(1-2), 41-49. doi: 10.1016/j.mce.2012.12.015

Meera, P., Wallner, M., \& Toro, L. (2000). A neuronal beta subunit (KCNMB4) makes the large conductance, voltage- and $\mathrm{Ca} 2+$-activated $\mathrm{K}+$ channel resistant to charybdotoxin and iberiotoxin. Proc Natl Acad Sci U S A, 97(10), 5562-5567. doi: 10.1073/pnas. 100118597 
Miller, C. (1988). Competition for block of a Ca2(+)-activated $\mathrm{K}+$ channel by charybdotoxin and tetraethylammonium. Neuron, 1(10), 1003-1006.

Moreau, R., Komeichi, H., Kirstetter, P., Yang, S., Aupetit-Faisant, B., Cailmail, S., \& Lebrec, D. (1994). Effects of glibenclamide on systemic and splanchnic haemodynamics in conscious rats. Br J Pharmacol, 112(2), 649-653.

Murray, K. T., Fahrig, S. A., Deal, K. K., Po, S. S., Hu, N. N., Snyders, D. J., . . . Bennett, P. B. (1994). Modulation of an inactivating human cardiac $\mathrm{K}+$ channel by protein kinase C. Circ Res, 75(6), 999-1005.

Oliveras, A., Roura-Ferrer, M., Sole, L., de la Cruz, A., Prieto, A., Etxebarria, A., . . . Felipe, A. (2014). Functional assembly of kv7.1/kv7.5 channels with emerging properties on vascular muscle physiology. Arterioscler Thromb Vasc Biol, 34(7), 1522-1530. doi: 10.1161/ATVBAHA.114.303801

Olson, T. M., Alekseev, A. E., Liu, X. K., Park, S., Zingman, L. V., Bienengraeber, M., . . . Terzic, A. (2006). Kv1.5 channelopathy due to KCNA5 loss-of-function mutation causes human atrial fibrillation. Hum Mol Genet, 15(14), 2185-2191. doi: $10.1093 / \mathrm{hmg} / \mathrm{ddl} 143$

Parekh, N., \& Zou, A. P. (1996). Role of prostaglandins in renal medullary circulation: response to different vasoconstrictors. Am J Physiol, 271(3 Pt 2), F653-658. 
Paterno, R., Faraci, F. M., \& Heistad, D. D. (1996). Role of Ca(2+)-dependent K+ channels in cerebral vasodilatation induced by increases in cyclic GMP and cyclic AMP in the rat. Stroke, 27(9), 1603-1607; discussion 1607-1608.

Pfaffinger, P. J., \& DeRubeis, D. (1995). Shaker K+ channel T1 domain selftetramerizes to a stable structure. J Biol Chem, 270(48), 28595-28600.

Plane, F., Johnson, R., Kerr, P., Wiehler, W., Thorneloe, K., Ishii, K., . . Cole, W. (2005). Heteromultimeric Kv1 channels contribute to myogenic control of arterial diameter. Circ Res, 96(2), 216-224. doi: 01.RES.0000154070.06421.25 [pii]

10.1161/01.RES.0000154070.06421.25

Platoshyn, O., Brevnova, E. E., Burg, E. D., Yu, Y., Remillard, C. V., \& Yuan, J. X. (2006). Acute hypoxia selectively inhibits KCNA5 channels in pulmonary artery smooth muscle cells. Am J Physiol Cell Physiol, 290(3), C907-916. doi: 10.1152/ajpcell.00028.2005

Platoshyn, O., Yu, Y., Golovina, V. A., McDaniel, S. S., Krick, S., Li, L., . . Yuan, J. X. (2001). Chronic hypoxia decreases $K(V)$ channel expression and function in pulmonary artery myocytes. Am J Physiol Lung Cell Mol Physiol, 280(4), L801812.

Pluger, S., Faulhaber, J., Furstenau, M., Lohn, M., Waldschutz, R., Gollasch, M., . . . Pongs, O. (2000). Mice with disrupted BK channel beta1 subunit gene feature 
abnormal $\mathrm{Ca}(2+)$ spark/STOC coupling and elevated blood pressure. Circ Res, 87(11), E53-60.

Po, S., Roberds, S., Snyders, D. J., Tamkun, M. M., \& Bennett, P. B. (1993). Heteromultimeric assembly of human potassium channels. Molecular basis of a transient outward current? Circ Res, 72(6), 1326-1336.

Porter, V. A., Bonev, A. D., Knot, H. J., Heppner, T. J., Stevenson, A. S., Kleppisch, T., . .. Nelson, M. T. (1998). Frequency modulation of Ca2+ sparks is involved in regulation of arterial diameter by cyclic nucleotides. Am J Physiol, 274(5 Pt 1), C1346-1355.

Pozeg, Z. I., Michelakis, E. D., McMurtry, M. S., Thebaud, B., Wu, X. C., Dyck, J. R., . . Archer, S. L. (2003). In vivo gene transfer of the O2-sensitive potassium channel Kv1.5 reduces pulmonary hypertension and restores hypoxic pulmonary vasoconstriction in chronically hypoxic rats. Circulation, 107(15), 2037-2044. doi: 10.1161/01.CIR.0000062688.76508.B3

Prince, A., \& Pfaffinger, P. J. (2013). Conserved N-terminal negative charges support optimally efficient N-type inactivation of Kv1 channels. PLoS One, 8(4), e62695. doi: 10.1371/journal.pone.0062695

Quayle, J. M., Nelson, M. T., \& Standen, N. B. (1997). ATP-sensitive and inwardly rectifying potassium channels in smooth muscle. Physiol Rev, 77(4), 1165-1232. 
Regan, C. P., Wallace, A. A., Cresswell, H. K., Atkins, C. L., \& Lynch, J. J., Jr. (2006). In vivo cardiac electrophysiologic effects of a novel diphenylphosphine oxide IKur blocker, (2-Isopropyl-5-methylcyclohexyl) diphenylphosphine oxide, in rat and nonhuman primate. J Pharmacol Exp Ther, 316(2), 727-732. doi: jpet.105.094839 [pii]

10.1124/jpet.105.094839

Rosenfeld, C. R., Cornfield, D. N., \& Roy, T. (2001). Ca(2+)-activated K(+) channels modulate basal and $E(2)$ beta-induced rises in uterine blood flow in ovine pregnancy. Am J Physiol Heart Circ Physiol, 281(1), H422-431.

Rowan, M. J., Tranquil, E., \& Christie, J. M. (2014). Distinct Kv channel subtypes contribute to differences in spike signaling properties in the axon initial segment and presynaptic boutons of cerebellar interneurons. J Neurosci, 34(19), 66116623. doi: 10.1523/JNEUROSCI.4208-13.2014

Rusch, N. J., \& Liu, Y. (1997). Potassium channels in hypertension: homeostatic pathways to buffer arterial contraction. J Lab Clin Med, 130(3), 245-251.

Sachse, G., Faulhaber, J., Seniuk, A., Ehmke, H., \& Pongs, O. (2014). Smooth muscle BK channel activity influences blood pressure independent of vascular tone in mice. J Physiol, 592(Pt 12), 2563-2574. doi: 10.1113/jphysiol.2014.272880 
Seoh, S. A., Sigg, D., Papazian, D. M., \& Bezanilla, F. (1996). Voltage-sensing residues in the S2 and S4 segments of the Shaker K+ channel. Neuron, 16(6), 1159-1167.

Steinmetz, R., Mitchner, N. A., Grant, A., Allen, D. L., Bigsby, R. M., \& Ben-Jonathan, N. (1998). The xenoestrogen bisphenol A induces growth, differentiation, and c-fos gene expression in the female reproductive tract. Endocrinology, 139(6), 27412747. doi: 10.1210/endo.139.6.6027

Stump, G. L., Wallace, A. A., Regan, C. P., \& Lynch, J. J., Jr. (2005). In vivo antiarrhythmic and cardiac electrophysiologic effects of a novel diphenylphosphine oxide IKur blocker (2-isopropyl-5-methylcyclohexyl) diphenylphosphine oxide. J Pharmacol Exp Ther, 315(3), 1362-1367. doi: 10.1124/jpet.105.092197

Sweet, T. B., \& Cox, D. H. (2009). Measuring the influence of the BKCa $\{$ beta\}1 subunit on Ca2+ binding to the BKCa channel. J Gen Physiol, 133(2), 139-150. doi: 10.1085/jgp.200810129

Thorneloe, K. S., Chen, T. T., Kerr, P. M., Grier, E. F., Horowitz, B., Cole, W. C., \& Walsh, M. P. (2001). Molecular composition of 4-aminopyridine-sensitive voltagegated $\mathrm{K}(+)$ channels of vascular smooth muscle. Circ Res, 89(11), 1030-1037. 
Valverde, M. A., Rojas, P., Amigo, J., Cosmelli, D., Orio, P., Bahamonde, M. I., . . . Latorre, R. (1999). Acute activation of Maxi-K channels (hSlo) by estradiol binding to the beta subunit. Science, 285(5435), 1929-1931.

Vanelli, G., \& Hussain, S. N. (1994). Effects of potassium channel blockers on basal vascular tone and reactive hyperemia of canine diaphragm. Am J Physiol, 266(1 Pt 2), H43-51.

Wahl, M., Parsons, A. A., \& Schilling, L. (1994). Dilating effect of perivascularly applied potassium channel openers cromakalim and pinacidil in rat and cat pial arteries in situ. Cardiovasc Res, 28(12), 1803-1807.

Yeung, S. Y., \& Greenwood, I. A. (2005). Electrophysiological and functional effects of the KCNQ channel blocker XE991 on murine portal vein smooth muscle cells. $\mathrm{Br}$ J Pharmacol, 146(4), 585-595. doi: 10.1038/sj.bjp.0706342

Yuan, X. J. (1995). Voltage-gated K+ currents regulate resting membrane potential and [Ca2+]i in pulmonary arterial myocytes. Circ Res, 77(2), 370-378. 
Figure 1.1

Arterial Smooth Muscle Cell

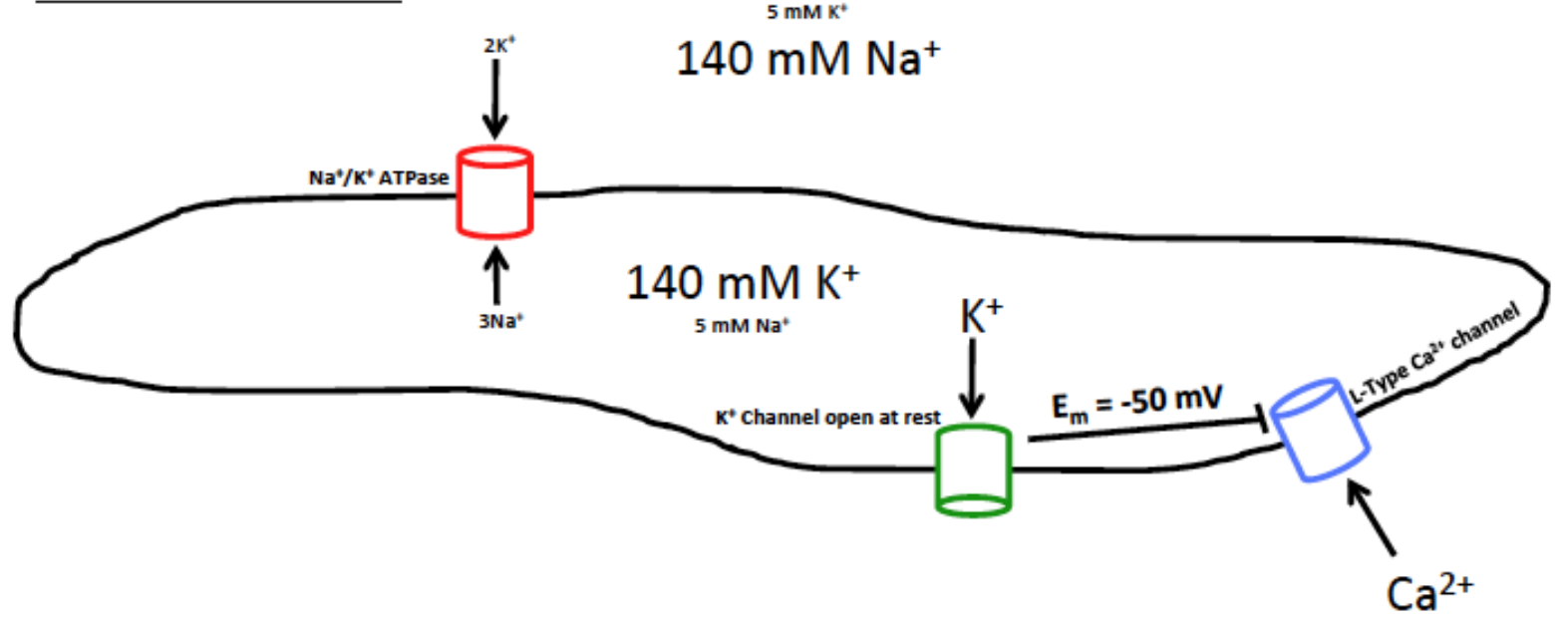


Figure 1.1 Cartoon depicting the ionic basis of the membrane potential in arterial smooth muscle. The $\mathrm{Na}^{+} / \mathrm{K}^{+}$ATPase moves $2 \mathrm{~K}^{+}$into the cell and $3 \mathrm{Na}^{+}$out of the cell against concentration gradients. The result is a separation of ions across the sarcolemma. An unknown population of open channels allows $\mathrm{K}^{+}$efflux and drives membrane potential toward $E_{K}$. However, $E_{K}$ is not reached, as its polarizing influence is tempered by depolarizing conductances $\left(\mathrm{Na}^{+}, \mathrm{Ca}^{2+}\right.$, and $\left.\mathrm{Cl}^{-}\right)$; the resulting $\mathrm{E}_{\mathrm{m}}$ is approximately $-50 \mathrm{mV}$. At this potential, L-type $\mathrm{Ca}^{2+}$ channels are just in their active voltage range, thus providing the rationale that arterial smooth muscle $\mathrm{K}^{+}$channels control arterial tone. Specifically, if more $\mathrm{K}^{+}$channels open, $\mathrm{E}_{\mathrm{m}}$ is hyperpolarized, L-type channels close, and tone is reduced (vasodilation). Conversely, if $\mathrm{K}^{+}$channels are inhibited, more L-type channels open, and tone is increased (vasoconstriction). 
Figure 1.2

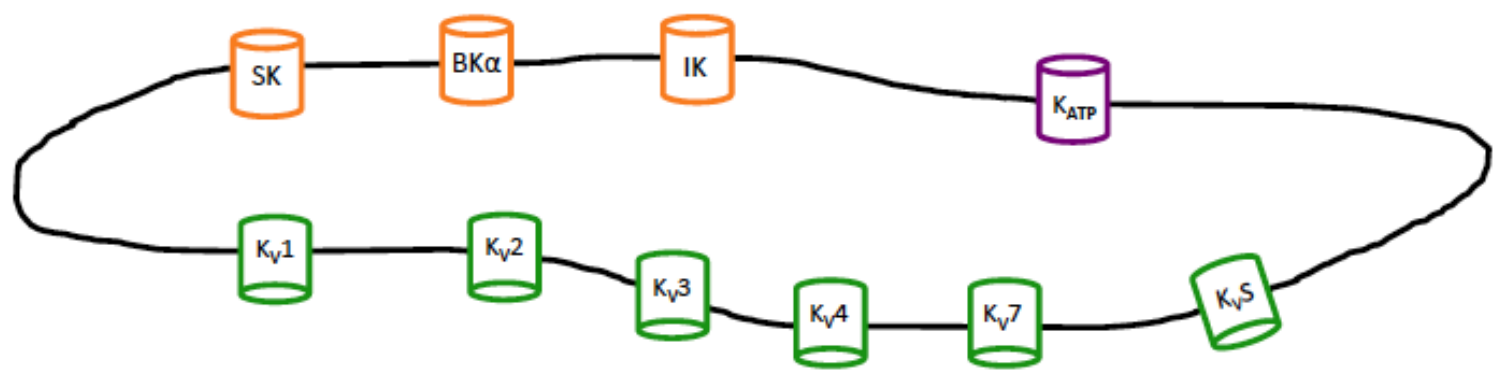


Figure 1.2 Cartoon depicting $\mathrm{K}^{+}$channel expression in arterial smooth muscle. $\mathrm{K}^{+}$ channels expressed in arterial smooth muscle include $\mathrm{Ca}^{2+}$-activated (SK, BK, and IK) channels, $\mathrm{K}_{\mathrm{ATP}}$ channels comprised of the Kir6.1 pore and SUR2B regulatory subunit, and members of the $\mathrm{K}_{\mathrm{v}}$ superfamily $\left(\mathrm{K}_{\mathrm{v}} 1, \mathrm{~K}_{\mathrm{v}} 2, \mathrm{~K}_{\mathrm{v}} 3, \mathrm{~K}_{\mathrm{v}} 4, \mathrm{~K}_{\mathrm{v}} 7\right.$, and the silent $\mathrm{K}_{\mathrm{v}}$ : $\mathrm{K}_{\mathrm{v}} 5$ and 9). It should be noted that only specific members from each subfamily are expressed and some members are exclusive to certain vascular beds. It is our supposition that a member of the $K_{v} 1$ subfamily is important for controlling $E_{m}$ and arterial tone. 
Figure 1.3

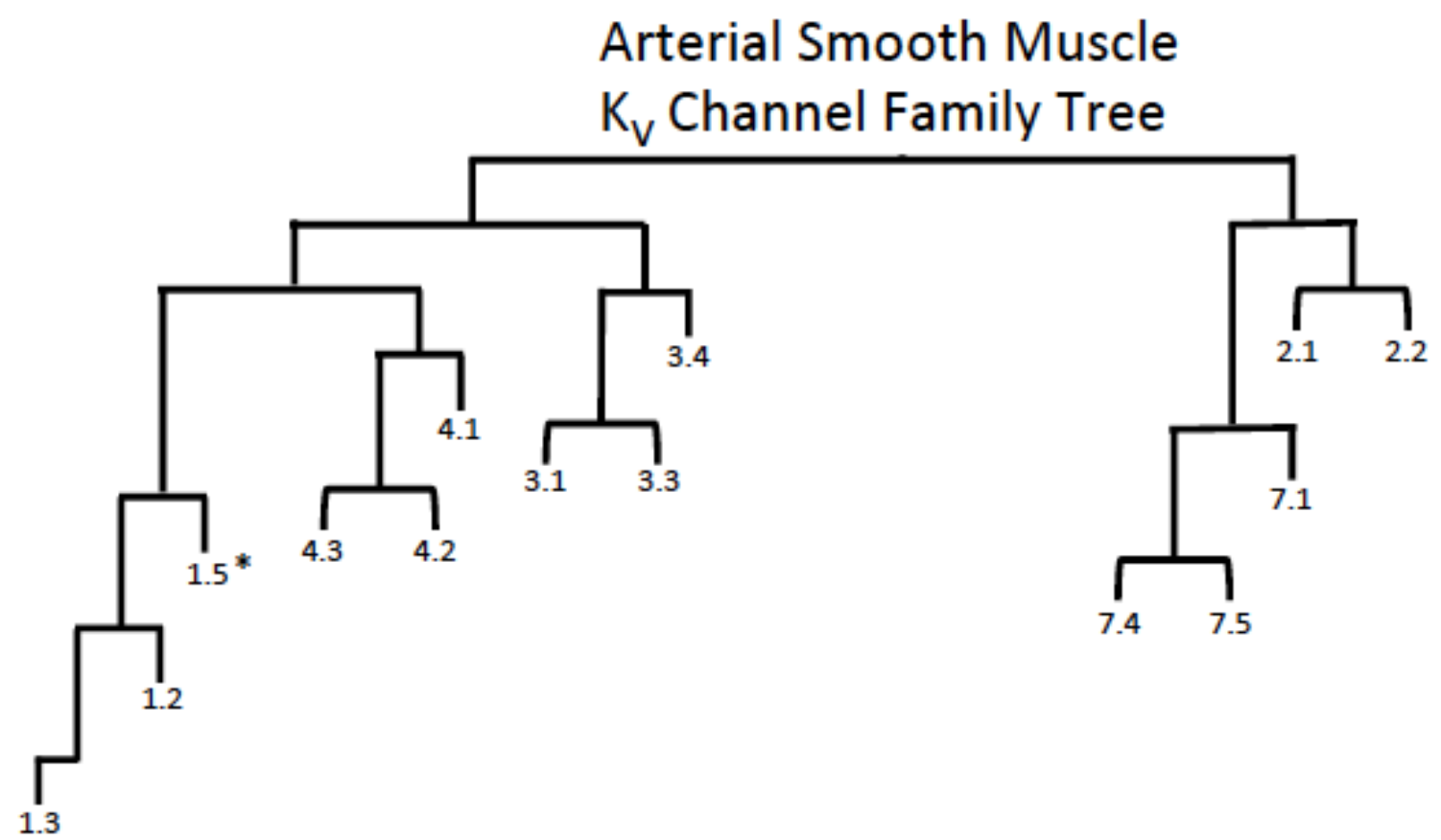


Figure 1.3 Arterial smooth muscle $\mathrm{K}_{\mathrm{V}}$ family tree. The phylogeny of $\mathrm{K}_{\mathrm{V}}$ channels expressed in arterial smooth muscle is shown. The figure is adapted from Guttman et al. where CLUSTALW alignment of sequences was followed by Phylogenetic Analysis Using Parsimony to construct the family tree (Gutman et al., 2005). Members of the silent $K_{V} S$ subfamilies are not depicted. It is our supposition that $K_{v} 1.5$ contributes to $E_{m}$ and arterial tone $\left(^{*}\right)$. 
Figure 1.4
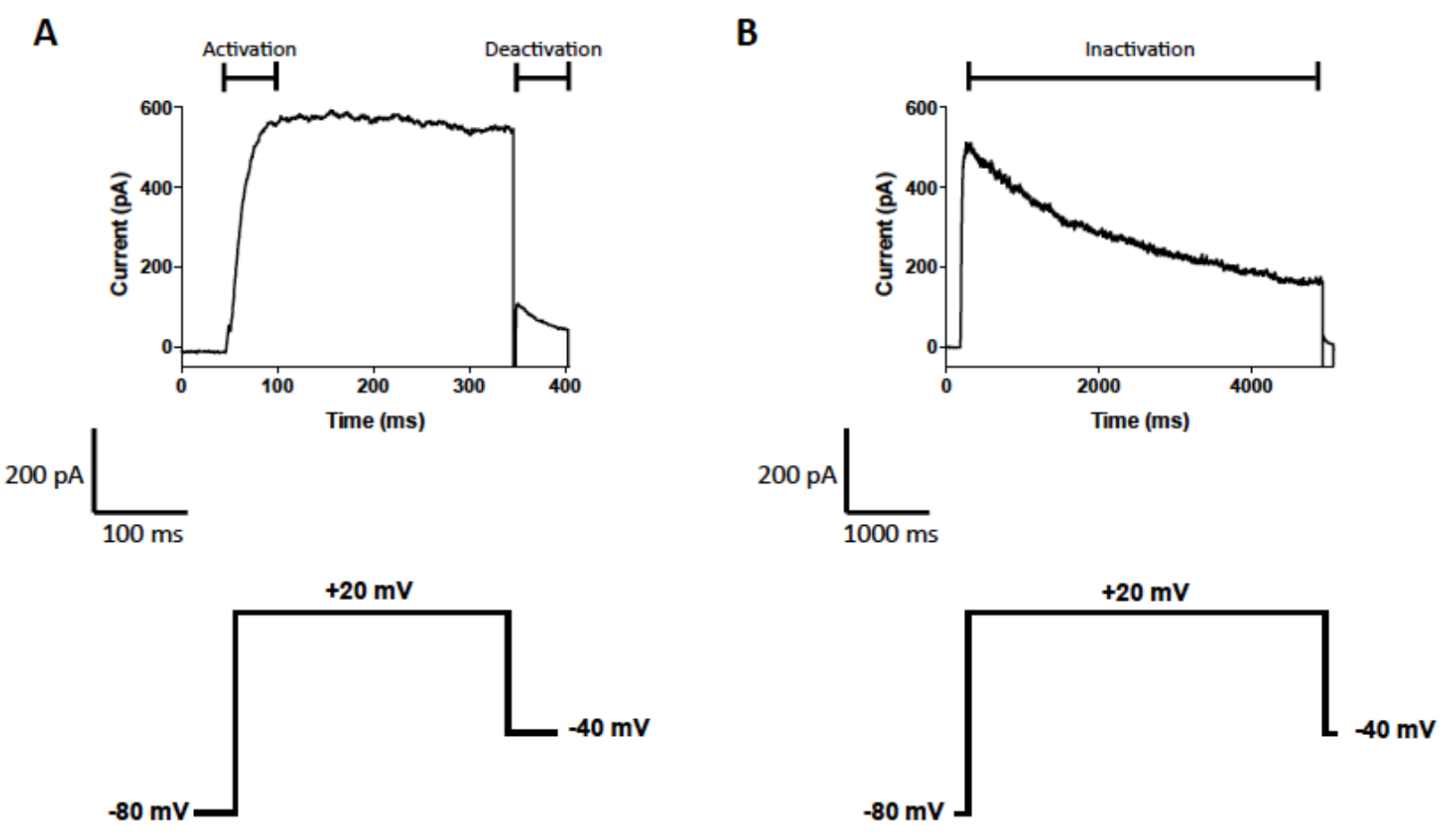
Figure 1.4 Example traces of delayed rectifier $\left(\mathrm{K}_{\mathrm{DR}}\right)$ current in smooth muscle cells isolated from the porcine right coronary artery. A) A 300 ms 'short' pulse shows the fast activation of $K_{D R}$ channels upon a $+20 \mathrm{mV}$ stimulus. Stepping back to $-40 \mathrm{mV}$ deactivates $K_{D R}$ channels and produces tail currents. B) A $5 \mathrm{~s}$ 'long' pulse clearly shows that, in the continued presence of the $+20 \mathrm{mV}$ stimulus, $\mathrm{K}_{\mathrm{DR}}$ channels inactivate over time. In Chapter 3, we use these biophysical properties and pharmacology to investigate a role for $\mathrm{K}_{\mathrm{V}} 1.5$ in native $\mathrm{K}_{\mathrm{DR}}$ channels in coronary smooth muscle. 
Figure 1.5

A

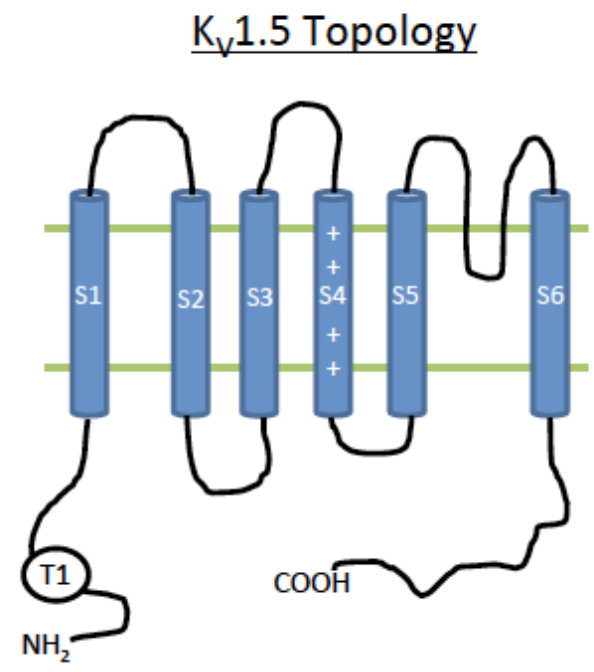

B

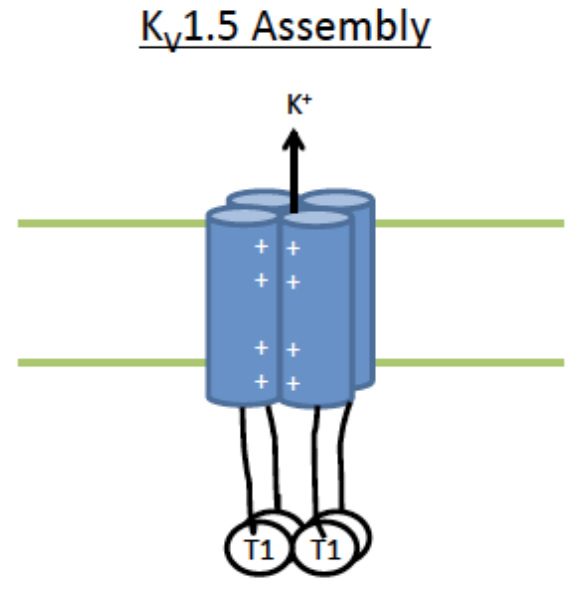


Figure $1.5 \mathrm{~K}_{\mathrm{V}} 1.5$ topology and assembly. A) $\mathrm{K}_{\mathrm{V}} 1.5$ has six transmembrane segments, where S1-S4 comprises the voltage-sensing domain. The S4 segment contains positively charged arginine and lysine residues sensitive to membrane depolarization and responsible for gating charges. The $\mathrm{N}$-terminal $\mathrm{T} 1$ domains are regulatory sites as well as mediators of inactivation. B) Assembly of four separate $K_{v} 1.5$ subunits into a single functional $\mathrm{K}^{+}$-selective ion channel is shown. $\mathrm{T} 1$ domains from each individual $\mathrm{K}_{\mathrm{v}} 1.5$ protein are shown as a self-tetramerizing intracellular unit. 


\section{Chapter 2}

\section{DPO-1-sensitive $\mathrm{K}^{+}$channels contribute to the vascular tone and reactivity of arterioles from brain and skeletal muscle}

As submitted to Microcirculation (in revision, 2014)

Ibra S. Fancher, Joshua T. Butcher, Steven D. Brooks, Trey S. Rottgen, Paulina R. Skaff, Jefferson C. Frisbee, and Gregory M. Dick

Center for Cardiovascular and Respiratory Sciences

West Virginia University School of Medicine

Short title: $\mathrm{K}_{\mathrm{v}} 1.5$ in the microcirculation

Grant numbers and sources of support: NIH T32 HL 090610 supported I.S. Fancher and J.T. Butcher.

Please address correspondence to:

Gregory M. Dick, Ph.D.

1 Medical Center Drive

P.O. Box 9105

Morgantown, WV 26506-9105

Phone (304) 293-2542

Email gmdick@hsc.wvu.edu 


\section{Abstract}

Objective: Many types of vascular smooth muscle cells exhibit prominent delayed rectifier $\mathrm{K}^{+}\left(\mathrm{K}_{\mathrm{DR}}\right)$ currents. These $\mathrm{K}_{\mathrm{DR}}$ currents may be mediated, at least in part, by $\mathrm{K}_{\mathrm{V}} 1.5$ channels, which are sensitive to inhibition by diphenyl phosphine oxide-1 (DPO1). We tested the hypothesis that DPO-1-sensitive $K_{D R}$ channels regulate the tone and reactivity of resistance-sized vessels from rat brain (middle cerebral artery) and skeletal muscle (gracilis artery). Methods: Middle cerebral and gracilis arterioles were isolated and subjected to three kinds of experimental analysis: a) Western blot; b) patch clamp electrophysiology; and c) pressure myography. Results: Western blot experiments demonstrated $\mathrm{K}_{\mathrm{V}} 1.5$ immunoreactivity in arterioles. Whole-cell patch clamp experiments revealed arteriolar smooth muscle cells to possess a $\mathrm{K}_{\mathrm{DR}}$ current that was blocked by DPO-1. Arterioles constricted in response to increasing concentrations of DPO-1. DPO1 enhanced constrictions to phenylephrine and serotonin in gracilis and middle cerebral arterioles, respectively. The relationship between diameter and internal pressure (i.e., myogenic response) was shifted down in parallel fashion by DPO-1. Dilations in response to acetylcholine were reduced by DPO-1. Conclusion: We suggest that $\mathrm{K}_{\mathrm{V}} 1.5$, a DPO-1-sensitive $\mathrm{K}_{\mathrm{DR}}$ channel, plays a major role in determining microvascular tone and the arteriolar response to vasoconstrictors and vasodilators.

Key words: diphenyl phosphine oxide-1; delayed rectifier potassium current; KCNA5; $\mathrm{K}_{\mathrm{v}} 1.5$, smooth muscle 


\section{Introduction}

Resistance vessels regulate tissue perfusion by integrating a variety of stimuli. Microvascular adjustments include: a) myogenic responses; b) metabolic vasodilation; c) vasoconstriction in response to neurohumoral factors; and d) vasodilation due to flow and paracrine agents. While some of the mechanisms involve endothelial cells and sympathetic nerves, it is the contractile state of smooth muscle that is the final element in any of the pathways. When it comes to smooth muscle, however, a knowledge gap exists regarding the end effectors controlling membrane potential and, thus, the intracellular $\mathrm{Ca}^{2+}$ concentration and vascular tone. $\mathrm{K}^{+}$channels are known to regulate this process of electromechanical coupling, but the type of $\mathrm{K}^{+}$channel(s) involved is less clear. It is our supposition that voltage-dependent $\mathrm{K}^{+}\left(\mathrm{K}_{\mathrm{V}}\right)$ channels, especially the delayed rectifier $\left(K_{D R}\right)$ type of $K_{V}$ channels, are critically important for regulating arteriolar vascular reactivity.

Vascular smooth muscle cells express a variety of $\mathrm{K}^{+}$channels, including $\mathrm{K}_{\mathrm{DR}}$ channels (Dick \& Tune, 2010). The $\mathrm{K}^{+}$channels of microvascular smooth muscle have been reviewed previously (Jackson, 1998, 2005). $\mathrm{K}_{\mathrm{DR}}$ channels produce a prominent current in the physiological voltage range (Gollasch, Ried, Bychkov, Luft, \& Haller, 1996; Volk, Matsuda, \& Shibata, 1991). Evidence suggests that these $K_{D R}$ channels are important for the membrane potential and reactivity of smooth muscle (Knot \& Nelson, 1995 ) in regulating tissue blood flow (Dick et al., 2008). There are $100-$ plus $\mathrm{K}^{+}$channel gene loci in the human genome and more than one-third of them encode $K_{V}$ channels (including both pore-forming $\square$ subunits and modulatory subunits). Therefore, based on the sheer number of candidates, it has been difficult to determine the molecular entities 
underlying the $\mathrm{K}_{\mathrm{DR}}$ channels of smooth muscle. Excellent evidence, however, supports a role for the $\mathrm{K}_{\mathrm{V}} 1$ subfamily (Albarwani et al., 2003; Chen, Luykenaar, Walsh, Walsh, \& Cole, 2006; Cheong, Dedman, \& Beech, 2001; Plane et al., 2005), particularly Kv1.5 (Clement-Chomienne, Ishii, Walsh, \& Cole, 1999; Kerr et al., 2001; Thorneloe et al., 2001).

Recently, novel and selective $\mathrm{K}_{\mathrm{v}} 1.5$ channel inhibitors have become available, including diphenyl phosphine oxide-1 (DPO-1) (Lagrutta, Wang, Fermini, \& Salata, 2006; Regan, Wallace, Cresswell, Atkins, \& Lynch, 2006; Stump, Wallace, Regan, \& Lynch, 2005). DPO-1 allows us to test whether $K_{D R}$ channels of arteriolar smooth muscle contain $\mathrm{K}_{\mathrm{v}} 1.5$ as a major component. Further, it lets us test whether DPO-1sensitive $\mathrm{K}_{\mathrm{DR}}$ channels control the tone and reactivity of resistance-sized arterioles from brain (middle cerebral artery; MCA) and skeletal muscle (gracilis artery; GA). In the present study, we describe the presence of $\mathrm{K}_{\mathrm{V}} 1.5$ immunoreactivity in rat MCA and GA as well as DPO-1-sensitive $K_{D R}$ current in smooth muscle cells isolated from MCA and GA. Further, we provide functional data indicating that inhibition of $K_{D R}$ by DPO-1 increases the sensitivity of contraction to phenylephrine (PE) and serotonin (5-HT) and reduces vasodilation to acetylcholine (ACh). These data lead us to suggest that DPO-1sensitive $\mathrm{K}_{\mathrm{v}} 1.5$ channels play a major role in determining microvascular tone and the arteriolar response to vasoconstrictors and vasodilators. 


\section{Methods}

Animal care and use. Animal studies were approved by an institutional Animal Care and Use Committee and conformed to recommendations of the National Research Council (National Research Council, 2011). Male Sprague Dawley rats (200-250 g) were given access to standard chow and water ad libitum. Rats were anesthetized with sodium pentobarbital (150 mg/kg, i.p.). A carotid artery was cannulated to record mean arterial pressure, as this value was required to calculate the appropriate distending pressure for pressure myography experiments. Animals were euthanized and the MCA and GA were removed. Arterioles were stored at $-80{ }^{\circ} \mathrm{C}$ for molecular analysis or used the same day for patch clamp electrophysiology and pressure myography.

In another set of experiments designed to test the specificity of DPO-1, we used smooth muscle cells isolated from the aortae of wild type and $\mathrm{K}_{\mathrm{V}} 1.5$ knockout ( $\mathrm{KO}$; $\mathrm{KCNA}^{-{ }^{-}}$) mice. Tissues taken from these animals were kindly provided by Dr. William Chilian (Northeast Ohio Medical University; Rootstown, $\mathrm{OH}$ ) (Ohanyan, Bratz, Guarini, Yin, \& Chilian, 2010 (Abstract)).

Western blots. MCA and GA lysates (20 $\mu \mathrm{g}$ of protein) were loaded onto $4-12 \%$ polyacrylamide gels, separated by electrophoresis, and transferred to polyvinylidene difluoride membranes. A rabbit primary antibody targeting the intracellular C-terminus of $\mathrm{K}_{\mathrm{v}} 1.5$ (Alomone; 1:200) and an anti-rabbit secondary antibody conjugated to horseradish peroxide were used. Membranes were incubated with SuperSignal West Dura substrate (Thermo Scientific) and bands were imaged using a G-Box detection system (Syngene). 
Patch clamp electrophysiology. Mouse aortae and rat MCA and GA were treated with a low $\mathrm{Ca}^{2+}$ physiological saline solution (PSS) supplemented with $(\mathrm{mg} / \mathrm{ml}) 2$ collagenase, 1 elastase, 1 soybean trypsin inhibitor and 1 bovine serum albumin at $37^{\circ} \mathrm{C}$ for 30 minutes. Low $\mathrm{Ca}^{2+}$ PSS contained (mM) $135 \mathrm{NaCl}, 5 \mathrm{KCl}, 0.36 \mathrm{CaCl}_{2}, 1$ $\mathrm{MgCl}_{2}, 10$ glucose, 10 HEPES, and 5 Tris; $\mathrm{pH}$ 7.4. Arterioles were then gently passed through the tip of a fire-polished Pasteur pipet to isolate single smooth muscle cells. Arteriolar smooth muscle cells were pelleted at $400 \mathrm{~g}$ for 5 minutes and resuspended in PSS. A drop of this cell suspension was placed on a glass chip, cells were allowed to adhere, and then the chip was placed into the recording chamber (volume approximately $300 \mu \mathrm{l}$ ) atop an inverted microscope. PSS flowed through the chamber at approximately $3 \mathrm{ml} / \mathrm{min}$. The bath solution contained (in $\mathrm{mM}$ ) $135 \mathrm{Na}$-isethionate, $5 \mathrm{~K}$ gluconate, $2 \mathrm{MnCl}_{2}, 1 \mathrm{MgCl}_{2}$, 10 glucose, 10 HEPES, 5 Tris; $\mathrm{pH}$ 7.4. Whole-cell patch access was obtained using heat polished borosilicate glass pipets with resistances of 2$5 \mathrm{M} \Omega$. Pipets were filled with a solution containing (in $\mathrm{mM}$ ) $140 \mathrm{~K}$-gluconate, $1 \mathrm{MgCl}_{2}, 3$ Mg-ATP, 1 Na-GTP, 10 BAPTA, 10 HEPES, and 5 Tris, pH 7.1. $\mathrm{Ca}^{2+}$-activated currents were limited by the nominally $\mathrm{Ca}^{2+}$-free PSS and the $10 \mathrm{mM}$ BAPTA pipette. $\mathrm{Cl}^{-}$currents were minimized by the anion replacement. Penitrem $A(1 \mu M)$ and glibenclamide (10 $\mu \mathrm{M})$ further minimized the contribution of $\mathrm{BK}$ and $\mathrm{K}_{\mathrm{ATP}}$ currents, so that $\mathrm{K}_{\mathrm{DR}}$ could be studied in relative isolation. Upon whole-cell access, series resistance and capacitance were compensated as fully as possible and a voltage template of $-60 \mathrm{mV}$ to $+20 \mathrm{mV}$ was applied in $10 \mathrm{mV}$ steps. Currents were filtered at $1 \mathrm{kHz}$ and digitized at $5 \mathrm{kHz}$.

Pressure myography. Resistance arterioles were cannulated and pressurized to $80 \%$ of mean arterial pressure $(83 \pm 3 \mathrm{~mm} \mathrm{Hg})$ and visualized using a video 
microscope, as described previously (Butcher, Goodwill, \& Frisbee, 2012). Measurements of arteriole diameter were made using video calipers before and after DPO-1 (Tocris; stock solutions prepared in ethanol). Experiments included determining the response of arterioles to increasing concentrations of DPO-1 and the effect of DPO1 on: a) myogenic responses $(40-140 \mathrm{mmHg}$ in random order $20 \mathrm{mmHg}$ steps); b) constrictions to 5-HT in MCA and PE in GA); and 3) dilations to ACh.

Statistics. Two-way repeated measures analysis of variance (2RM-ANOVA) was used to analyze data, including: a) current-voltage (I-V) relationships in arteriolar smooth muscle cells before and after addition of DPO-1 and b) arteriolar responses to constrictors, pressure, and ACh before and after DPO-1. A value of $p<0.05$ was considered significantly different and Bonferroni post-hoc analysis followed 2RMANOVA to identify specific differences when appropriate. 


\section{Results}

Expression of $K_{V} 1.5$. Fig. 1 shows $K_{V} 1.5$ protein expression in MCA and GA. Probing for $\mathrm{K}_{\mathrm{V}} 1.5$ protein in MCA and GA lysates detected a single band between 50 and $70 \mathrm{kDa}$ (Fig. 1). The predicted molecular weight of $\mathrm{K}_{\mathrm{v}} 1.5$ is approximately $66 \mathrm{kDa}$.

$K_{D R}$ channels are blocked by DPO-1. To determine the specificity of DPO-1 as a pharmacological tool to inhibit $\mathrm{K}_{\mathrm{V}} 1.5$-containing $\mathrm{K}_{\mathrm{DR}}$ channels, we measured whole-cell currents of smooth muscle cells isolated from the aortae of wild type and $\mathrm{K}_{\mathrm{v}} 1.5 \mathrm{KO}$ mice (Figs. 2A and B). Current was significantly smaller in cells from $\mathrm{K}_{\mathrm{V}} 1.5 \mathrm{KO}$ mice (Fig. $2 C$ ), indicating that $K_{V} 1.5$ subunits are important for forming $K_{D R}$ channels in vascular smooth muscle. DPO-1 (1-10 $\mu \mathrm{M})$ significantly inhibited current in smooth muscle cells from wild type, but not $\mathrm{K}_{\mathrm{V}} 1.5 \mathrm{KO}$ mice (Figs. 2D, 2E, and 2F). These data indicate that DPO-1 is a $\mathrm{K}_{\mathrm{v}} 1.5$-selective inhibitor.

We performed whole-cell patch clamp experiments to investigate the effect of DPO-1 on $\mathrm{K}_{\mathrm{DR}}$ channel currents in vascular smooth muscle cells isolated from rat MCA and GA. Depolarization elicited robust $K_{D R}$ currents in cells from the MCA and GA (Fig. 3A and $B$, control). DPO-1 $(10 \mu \mathrm{M})$ inhibited $\mathrm{K}_{\mathrm{DR}}$ current in smooth muscle cells from both the MCA and GA (Fig. 3A and B, DPO-1). Fig. $3 C$ and D contain the current-voltage relationships for cells isolated from the MCA and GA, respectively. In cells from the MCA, $10 \mu \mathrm{M}$ DPO-1 inhibited current significantly at potentials greater than or equal to $20 \mathrm{mV}$ (e.g., current block at $0 \mathrm{mV}$ was $74 \pm 4 \%, \mathrm{n}=6$ ). Similarly, in cells from the $\mathrm{GA}$, $10 \mu \mathrm{M}$ DPO-1 inhibited current significantly at potentials greater than or equal to $-10 \mathrm{mV}$ (e.g., current block at $0 \mathrm{mV}$ was $61 \pm 7 \%, \mathrm{n}=4$ ). 
Inhibition of $K_{D R}$ channels constricts arterioles. We investigated the effect of $K_{D R}$ channel inhibition on the diameter of arterioles with active tone. MCA and GA were cannulated and pressurized to $80 \%$ of mean arterial pressure. The resting diameters of MCA and GA were $105 \pm 3$ and $105 \pm 1 \mu \mathrm{m}$, respectively ( $\mathrm{n}=4$ each). When increasing concentrations of DPO-1 (10 nM, $100 \mathrm{nM}, 1 \mu \mathrm{M}$, and $10 \mu \mathrm{M})$ were added to MCA, diameter decreased $4 \pm 1,11 \pm 1,21 \pm 2$, and $24 \pm 2 \%$, respectively (Fig. 4A). Similarly, when the same increasing concentrations of DPO-1 were added to GA, diameter decreased $5 \pm 1,12 \pm 1,16 \pm 3$, and $20 \pm 3 \%$ (Fig. 4B). Constrictions in response to DPO-1 were statistically significant with all concentrations of DPO-1 that were tested (10 $\mathrm{nM}$ and higher).

DPO-1 increases the sensitivity to vasoconstrictors. 5-HT and PE were used to constrict MCA and GA, respectively. We performed concentration-response experiments with these constrictors before and after arterioles were treated with $10 \mu \mathrm{M}$ DPO-1. When pressurized to $80 \%$ of mean arterial pressure, MCA diameter was $101 \pm$ $3 \mu \mathrm{m}(\mathrm{n}=8)$. MCA contracted $1 \pm 1,6 \pm 1,13 \pm 1,21 \pm 2,32 \pm 2$, and $36 \pm 3 \%$ in response to $0.001,0.01,0.1,1,10$, and $100 \mu \mathrm{M}$ 5-HT (Fig. 5A). DPO-1 constricted MCA to $76 \pm 3 \mu \mathrm{m}$. In the presence of DPO-1, responses to the same $5-\mathrm{HT}$ concentrations were $2 \pm 1,12 \pm 2,19 \pm 3,24 \pm 4,30 \pm 3$, and $33 \pm 4 \%$ (Fig. 5A). Compared to control, MCA diameter in the presence of DPO-1 was significantly different at baseline and every 5-HT concentration. GA diameter under control conditions was $105 \pm 2 \mu \mathrm{m}(\mathrm{n}=$ 8). GA contracted $2 \pm 1,6 \pm 1,13 \pm 1,21 \pm 1,29 \pm 2$, and $43 \pm 1 \%$ in response to 0.001 , $0.01,0.1,1,10$, and $100 \mu \mathrm{M}$ PE (Fig. 5B). DPO-1 constricted MCA to $79 \pm 2 \mu \mathrm{m}$. In the presence of DPO-1, responses to the same PE concentrations were $1 \pm 1,6 \pm 2,18 \pm 3$, 
$29 \pm 3,34 \pm 3$, and $40 \pm 3 \%$ (Fig. 5B). GA diameter in the presence of DPO-1 was significantly different at baseline and every PE concentration when compared to the control condition. When normalized to the maximum response, the effect of DPO-1 to enhance the sensitivity to vasoconstrictors can be appreciated (Fig. 5C and 5D).

DPO-1 and myogenic tone. We investigated the effect of $\mathrm{K}_{\mathrm{DR}}$ channel inhibition on the myogenic responses of MCA and GA. With $80 \mathrm{mmHg}$ of pressure, the diameters of MCA and GA were $107 \pm 3$ and $106 \pm 1 \mu \mathrm{m}$, respectively ( $\mathrm{n}=4$ each). When pressure was reduced to 60 and then $40 \mathrm{mmHg}$, MCA dilated $5 \pm 2$ and then $7 \pm 3 \%$ (Fig. 6A). When pressure was increased to 100,120 , and then $140 \mathrm{mmHg}, \mathrm{MCA}$ constricted $5 \pm 1,11 \pm 1$, and $15 \pm 2 \%$ (Fig. $6 \mathrm{~A}$ ). After treating MCA with $1 \mu \mathrm{M}$ DPO-1, the arterioles constricted to $85 \pm 1 \mu \mathrm{m}$. Further, in the presence of DPO-1, the dilations to reduced pressure were $3 \pm 1$ and then $4 \pm 2 \%$ (Fig. $6 \mathrm{~A}$ ) and the constrictions to increased pressure were $6 \pm 1,11 \pm 1$, and $17 \pm 2 \%$ (Fig. 6A). Thus, DPO- 1 produces a parallel shift in the relationship between internal pressure and diameter, but myogenic activity is still present. In GA, when pressure was reduced from 80 to 60 and then 40 $\mathrm{mmHg}$, arterioles dilated $4 \pm 1$ and then $6 \pm 1 \%$ (Fig. 6B). When pressure was increased to 100,120 , and then $140 \mathrm{mmHg}, \mathrm{MCA}$ constricted $5 \pm 1,10 \pm 1$, and $14 \pm$ $2 \%$ (Fig. 6B). After treating arterioles with $1 \mu \mathrm{M}$ DPO-1, GA constricted to $93 \pm 4 \mu \mathrm{m}$. Further, in the presence of DPO-1, the dilations to reduced pressure were $1 \pm 2$ and then $4 \pm 2 \%$ (Fig. $6 \mathrm{~B}$ ) and the constrictions to increased pressure were $7 \pm 1,12 \pm 3$, and $17 \pm 4 \%$ (Fig. 6B). Similar to MCA, DPO-1 shifts the pressure-diameter relationship in a parallel fashion in GA, but myogenic activity is still exhibited. 
DPO-1 inhibits endothelium-dependent vasodilation. ACh was used to induce endothelium-dependent vasodilation in MCA and GA. We performed concentrationresponse experiments before and after DPO-1 $(10 \mu \mathrm{M})$ treatment in pressurized arterioles. In this set of experiments, the baseline diameter of MCA was $101 \pm 2 \mu \mathrm{m}(\mathrm{n}=$ 8). MCA relaxed $3 \pm 1,6 \pm 1,12 \pm 1,17 \pm 2,20 \pm 2$, and $25 \pm 1 \%$ in response to 0.001 , $0.01,0.1,1,10$, and $100 \mu \mathrm{M}$ ACh. DPO-1 significantly reduced MCA baseline diameter to $81 \pm 2 \mu \mathrm{m}$ and impaired vasodilation to $\mathrm{ACh}$, When $\mathrm{K}_{v} 1.5$ was inhibited with DPO-1, relaxations to the same ACh concentrations were $-1 \pm 1,1 \pm 2,6 \pm 2,9 \pm 3,8 \pm 4$, and 8 $\pm 5 \%$ (Fig 7A). The baseline diameter for GA in this set of experiments was $103 \pm 3 \mu \mathrm{m}$ $(\mathrm{n}=8)$. GA relaxed $2 \pm 1,5 \pm 3,10 \pm 1,15 \pm 2,20 \pm 2$, and $26 \pm 2 \%$ in response to $0.001,0.01,0.1,1,10$, and $100 \mu \mathrm{M}$ ACh. DPO-1 significantly reduced baseline diameter to $78 \pm 2 \mu \mathrm{m}$ and impaired vasodilation to $\mathrm{ACh}$, significantly reducing responses to $-1 \pm$ $1,0 \pm 3,2 \pm 3,7 \pm 2,7 \pm 2$, and $9 \pm 2 \%$ (Fig. 7B) . 


\section{Discussion}

Our data support the hypothesis that DPO-1-sensitive $\mathrm{K}_{\mathrm{DR}}$ channels regulate the tone and reactivity of resistance-sized vessels from rat brain and skeletal muscle; therefore, suggesting $\mathrm{K}_{\mathrm{V}} 1.5$ subunits are included in microvascular $\mathrm{K}_{\mathrm{DR}}$ channels. This conclusion is based on four lines of evidence. First, we demonstrated that rat MCA and GA expressed $K_{V} 1.5$ protein. Second, we confirmed that DPO-1 is a $K_{V} 1.5$-selective inhibitor (established by inhibitory effects in smooth muscle cells from wild type but not $\mathrm{K}_{\mathrm{V}} 1.5 \mathrm{KO}$ mice). Third, we documented DPO-1-sensitive $\mathrm{K}_{\mathrm{DR}}$ currents in smooth muscle cells isolated from rat MCA and GA. Fourth, pressure myography experiments revealed powerful effects of DPO-1-sensitive $K_{D R}$ channels to control diameter, impact myogenic reactivity, and shape responses to vasoconstrictors and vasodilators. We suggest that $\mathrm{K}_{\mathrm{V}} 1.5$, a DPO-1-sensitive $\mathrm{K}_{\mathrm{DR}}$ channel, plays a major role in determining microvascular tone and the arteriolar response to pressure, vasoconstrictors, and vasodilators. This novel finding supports and extends previous studies indicating roles for $\mathrm{K}_{\mathrm{DR}}$ channels in arteriolar smooth muscle and microvascular tone by examining effects of 4aminopyridine and/or correolide (Table 1).

The information in Table 1 helped firmly establish that $K_{D R}$ channels regulate arteriolar vascular reactivity, but the molecular identity of these channels has remained unclear. Previous studies aimed at determining the molecular correlates of $K_{D R}$ channels are available in smooth muscle from a variety of vascular beds and ranging from conduit arteries to the microcirculation. A general logical framework has evolved for differentiating two major types of $\mathrm{K}_{\mathrm{DR}}$ channels and it centers on sensitivity to tetraethylammonium (TEA) (Cox, 2005). TEA-sensitive $K_{D R}$ channels most likely contain 
$\mathrm{K}_{\mathrm{V}} 2$ or $\mathrm{K}_{\mathrm{V}} 3$ family members, whereas TEA-insensitive $\mathrm{K}_{\mathrm{DR}}$ channels are thought to contain $\mathrm{K}_{\mathrm{v}} 1$ subunits (including $\mathrm{K}_{\mathrm{v}} 1.5$ and perhaps also including $\mathrm{K}_{\mathrm{v}} \beta$ subunits). Both varieties of $K_{D R}$ channels may be present in a single smooth muscle type, but our study addressed only $\mathrm{K}_{\mathrm{V}} 1$-containing $\mathrm{K}_{\mathrm{DR}}$ channels.

In the present study, we observed the expression of $\mathrm{K}_{\mathrm{V}} 1.5$ protein in resistance arterioles of rat brain and skeletal muscle using Western blot techniques (Fig. 1). This agrees with findings of Kang et al., who demonstrated $\mathrm{K}_{\mathrm{V}} 1.5$ expression by Western blot in arterioles from rat gastrocnemius and soleus muscles (Kang et al., 2009). Our data also correspond to immunhistochemical data from three other groups examining $K_{V} 1.5$ expression in arterioles or their cells. Cheong et al. observed $\mathrm{K}_{v} 1.5$ immunostaining in smooth muscle cells of rabbit cerebral arterioles (Cheong, Dedman, \& Beech, 2001). They observed immunoreactivity for $\mathrm{K}_{\mathrm{v}} 1.6$ in smooth muscle as well, but $\mathrm{K}_{\mathrm{v}} 1.2$ had an endothelial-only staining pattern (Cheong, Dedman, \& Beech, 2001). Albarwani et al. demonstrated $\mathrm{K}_{\mathrm{v}} 1.2$ and $\mathrm{K}_{\mathrm{v}} 1.5$ immunoreactivity in single smooth muscle cells isolated from rat cerebral arterioles (Albarwani et al., 2003). McGahon et al. reported $K_{v} 1.5$, but not $\mathrm{K}_{\mathrm{v}} 1.4$, immunoreactivity in smooth muscle cells from rat retinal arterioles (McGahon et al., 2007). They also observed the expression of $K_{v} \square 1$ subunits, which transform $K_{V} 1.5$ currents from the $K_{D R}$ type to an A-type waveform (McGahon et al., 2007). Our data and the studies described above differ dramatically from another effort of Cheong et al. (Cheong, Dedman, Xu, \& Beech, 2001), and suggest there may be species- or vascular bed-specific differences in $\mathrm{K}_{\mathrm{DR}}$ composition. Specifically, in mouse cerebral arterioles, Cheong et al. observed no immunostaining for $\mathrm{K}_{\mathrm{v}} 1.5$; rather they detected $\mathrm{K}_{\mathrm{v}} 1.2$ in endothelium and $\mathrm{K}_{\mathrm{v}} 1.3, \mathrm{~K}_{\mathrm{v}} 1.4$, and $\mathrm{K}_{\mathrm{v}} 1.6$ in smooth muscle and endothelium 
(Cheong, Dedman, $\mathrm{Xu}$, et al., 2001). The lack of $\mathrm{K}_{\mathrm{v}} 1.5$ in mouse cerebral arterioles is at odds with our data showing differences in $\mathrm{K}_{\mathrm{DR}}$ current in aortic smooth muscle between wild type and $\mathrm{K}_{\mathrm{v}}$ 1.5. KO mice (Fig. 2). However, our data complement those of Fountain et al. who demonstrated smooth muscle-specific expression of $\mathrm{K}_{\mathrm{v}} 1.5$ mRNA in mouse aorta, as well as correolide-sensitive $\mathrm{K}_{\mathrm{DR}}$ current in murine aortic myocytes (Fountain et al., 2004).

A major consideration for our study is whether DPO-1 is a $K_{V} 1.5$-specific pharmacological tool. The literature would suggest that it is indeed a selective inhibitor (Lagrutta et al., 2006; Regan et al., 2006; Stump et al., 2005), but we designed a set of experiments to address this point ourselves. Specifically, we isolated smooth muscle cells from the aortae of wild type and $\mathrm{K}_{\mathrm{V}} 1.5 \mathrm{KO}$ mice and used patch clamp techniques to assess drug specificity. DPO-1 inhibited $\mathrm{K}_{\mathrm{DR}}$ current in myocytes from wild type mice (Fig. 2), which suggests that $\mathrm{K}_{\mathrm{V}} 1.5$ subunits are indeed expressed in murine aortic smooth muscle. However, this conclusion would be erroneous if DPO-1 were also found to inhibit $\mathrm{K}_{\mathrm{DR}}$ current in aortic myocytes from $\mathrm{K}_{\mathrm{V}} 1.5 \mathrm{KO}$ mice (i.e., it blocked $\mathrm{K}_{\mathrm{V}}$ channel types other than $\left.\mathrm{K}_{\mathrm{V}} 1.5\right)$. We observed no significant inhibition of $\mathrm{K}_{\mathrm{DR}}$ current by DPO-1 in aortic myocytes of $\mathrm{K}_{\mathrm{V}} 1.5 \mathrm{KO}$, mice (Fig. 2). Thus, we suggest that DPO-1 is $\mathrm{K}_{\mathrm{V}} 1.5-$ selective and our conclusion agrees with findings of Lagrutta et al., who demonstrated DPO-1 selectivity for $\mathrm{K}_{\mathrm{V}} 1.5$ (and native $\mathrm{I}_{\mathrm{Kur}}$ ) over $\mathrm{I}_{\mathrm{to}}, \mathrm{I}_{\mathrm{K} 1}, \mathrm{I}_{\mathrm{Kr}}, \mathrm{I}_{\mathrm{Ks}}$, and $\mathrm{K}_{\mathrm{V}} 3.1$ (Lagrutta et al., 2006). We observed DPO-1-sensitive $K_{D R}$ currents in smooth muscle cells isolated from rat MCA and GA (Fig. 3). We interpret that to mean that these microvascular $K_{D R}$ channels contained $\mathrm{K}_{\mathrm{V}} 1.5$ subunits, which corroborates the expression of $\mathrm{K}_{\mathrm{V}} 1.5$ protein in MCA and GA (Fig. 1). DPO-1 right-shifted the reversal of the whole-cell current- 
voltage relationship (indicating a theoretical depolarization; Fig. 3), which suggests that $\mathrm{K}_{\mathrm{V}}$ 1.5-containing $\mathrm{K}_{\mathrm{DR}}$ channels may help set resting membrane potential and thus control resting vascular tone.

Accordingly, we observed that inhibition of $K_{V} 1.5$-containing $K_{D R}$ channels with DPO-1 significantly constricted MCA and GA, i.e., altered the vascular tone at a typical, physiological distending pressure (Fig. 4). Many of the studies in Table 1 support this idea that $K_{D R}$ channels control resting microvascular tone, but used less selective inhibitors such as 4-AP and correolide (which were the best available tools at the time). None of the studies in Table 1 show that $K_{D R}$ channels control microvascular reactivity to vasoconstrictors, but this is an idea worth testing, as $\mathrm{K}^{+}$channels are known to "dampen' or "buffer" excitation in the microvasculature (Hald et al., 2012). Thus, we tested the reactivity to vasoconstrictors (5-HT and PE for MCA and GA, respectively) before and after inhibition of $\mathrm{K}_{\mathrm{V}} 1.5$-containing $\mathrm{K}_{\mathrm{DR}}$ channels with DPO-1 (Fig. 5). DPO-1 significantly left-shifted the concentration-response curves in both MCA (5-HT) and GA (PE). We interpret this to mean that $\mathrm{K}_{\mathrm{V}} 1$.5-containing $\mathrm{K}_{\mathrm{DR}}$ channels provide a critical, physiological negative feedback against vasoconstriction. While not well documented, this is not entirely surprising, as part of the mechanism of $5-\mathrm{HT}$ vasoconstriction may be inhibition of $\mathrm{K}_{\mathrm{V}} 1.5$ channels (Cogolludo et al., 2006). There are no comparable data showing PE-induced inhibition of $\mathrm{K}_{\mathrm{V}} 1.5$ in the vasculature, but PE inhibits atrial $\mathrm{I}_{\mathrm{Kur}}$ (thought to be $\left.K_{V} 1.5\right)$ (Van Wagoner, Kirian, \& Lamorgese, 1996). Luykenaar and colleagues have previously proposed the idea that vasoconstrictors act, in part, by inhibiting $\mathrm{K}_{\mathrm{DR}}$ currents in cerebral microvascular smooth muscle (Luykenaar, Brett, Wu, Wiehler, \& Welsh, 2004; Luykenaar, El-Rahman, Walsh, \& Welsh, 2009). We suggest 
that $\mathrm{K}_{\mathrm{V}} 1.5$-containing $\mathrm{K}_{\mathrm{DR}}$ channels are important in determining microvascular responses to neural and humoral vasoconstrictors.

Another important adjustment that resistance vessels make is diameter changes in response to distending pressure (i.e., myogenic responses). Several of the studies in Table 1 demonstrate that pharmacological inhibition of microvascular $K_{D R}$ channels augments myogenic reactivity. However, using molecular tools (dominant-negative $\mathrm{K}_{\mathrm{v}} 1.5$ and $\mathrm{K}_{\mathrm{v}} 1.5$ overexpression techniques), it has been more convincingly shown that $\mathrm{K}_{\mathrm{v}} 1.5$ channels can affect the myogenic reactivity of rat cerebral arterioles (Chen et al., 2006). Specifically, Chen et al. have shown that: a) suppression of $K_{V} 1$-containing $K_{D R}$ channels with correolide enhances cerebral myogenic responses (similar to other studies in Table 1); b) dominant-negative $\mathrm{K}_{\mathrm{v}} 1.5$ enhances cerebral myogenic responses; and c) overexpression of wild type $\mathrm{K}_{\mathrm{V}} 1.5$ suppresses cerebral myogenic responses (Chen et al., 2006). Those novel findings led us to investigate the effects of DPO-1 on the myogenic response of MCA and GA (Fig. 6). Inhibition of Kv1.5containing $\mathrm{K}_{\mathrm{DR}}$ channels with DPO-1 decreased the dilation of MCA and GA to lowered pressures and increased the constrictions to higher pressures. Overall, a parallel downward shift in the diameter-pressure relationship was observed. Together these findings indicate that $\mathrm{K}_{\mathrm{V}} 1.5$-containing $\mathrm{K}_{\mathrm{DR}}$ channels act as negative feedback elements to maintain appropriate physiological tone, promoting vasodilation under low pressure and regulating constriction under high pressure.

To test the role of $\mathrm{K}_{\mathrm{V}} 1.5$-containing $\mathrm{K}_{\mathrm{DR}}$ channels as end effectors of vasodilation in MCA and GA, we conducted concentration-response experiments with $\mathrm{ACh}$ in the presence of DPO-1 (Fig. 7). With endothelial stimulation, mediators are released that 
open vascular smooth muscle $\mathrm{K}^{+}$channels, hyperpolarize membrane potential, and dilate the vessel (Waldron \& Cole, 1999). DPO-1 impaired the response to ACh in MCA and $\mathrm{GA}$, suggesting that $\mathrm{K}_{\mathrm{V}} 1.5$-containing $\mathrm{K}_{\mathrm{DR}}$ channels in microvascular smooth muscle are signaling targets in endothelium-dependent vasodilation. An alternative interpretation might be that KV1.5 is also expressed in endothelial cells; therefore, DPO1 might inhibit endothelium-dependent vasodilation by depolarizing the endothelium and decreasing the driving force for $\mathrm{Ca}^{2+}$ entry that is required for production of some relaxing/hyperpolarizing factors. At present, it is unclear what is the individual contribution of nitric oxide, prostaglandins, or other endothelial-derived hyperpolarizing factors, but there is evidence that protein kinase $A$ and $G$ pathways signal to microvascular $\mathrm{K}_{\mathrm{DR}}$ channels (Luykenaar \& Welsh, 2007).

We conclude that DPO-1 inhibits $K_{D R}$ channels in microvascular smooth muscle, indicating that these channels contain $\mathrm{K}_{\mathrm{v}} 1.5$ subunits. Our data indicate that these $\mathrm{K}_{\mathrm{V}}$ 1.5-containing $\mathrm{K}_{\mathrm{DR}}$ channels help set resting arteriolar tone and play an important role in microvascular reactivity to pressure and vasoactive agents. Further investigation of $\mathrm{K}_{\mathrm{V}}$ 1.5-containing $\mathrm{K}_{\mathrm{DR}}$ channels and how they function to regulate arteriolar tone and reactivity could help us understand how systemic blood pressure is maintained as well shed light on how tissue blood flow is controlled. Additionally, further study of $\mathrm{K}_{\mathrm{V}} 1.5$ containing $\mathrm{K}_{\mathrm{DR}}$ channels may reveal therapeutic targets for treating conditions such as hypertension, angina, ischemia, and peripheral artery disease. 


\section{Perspectives}

The present study contributes to an existing body of literature concerning the regulation of arteriolar function by $\mathrm{K}^{+}$channels, which suggests that $\mathrm{K}_{\mathrm{v}} 1$ family members are major components of $\mathrm{K}_{\mathrm{DR}}$ channels in microvascular smooth muscle. We add to this knowledge by demonstrating that a specific member of the $\mathrm{K}_{v} 1$ family, $\mathrm{K}_{\mathrm{v}} 1.5$, is a prominent subunit in microvascular smooth muscle, and moreover, that these $\mathrm{K}_{\mathrm{v}} 1.5$ containing channels regulate resistance vessel tone and reactivity. Information about specific $K_{V}$ channel members in resistance vessels could identify new therapeutic targets in treating cardiovascular diseases. Possibilities include the development of subunit-specific drugs that could be used to modulate inappropriate microvascular tone (e.g., $\mathrm{K}_{\mathrm{V}}$-specific openers to ameliorate hypertension or $\mathrm{K}_{\mathrm{V}}$-specific antagonists to treat hypotension associated with sepsis). 


\section{References}

Albarwani, S., Nemetz, L. T., Madden, J. A., Tobin, A. A., England, S. K., Pratt, P. F., \& Rusch, N. J. (2003). Voltage-gated $\mathrm{K}^{+}$channels in rat small cerebral arteries: molecular identity of the functional channels. [Research Support, Non-U.S. Gov't Research Support, U.S. Gov't, Non-P.H.S.

Research Support, U.S. Gov't, P.H.S.]. The Journal of physiology, 551(Pt 3), 751-763. doi: 10.1113/jphysiol.2003.040014

Butcher, J. T., Goodwill, A. G., \& Frisbee, J. C. (2012). The ex vivo isolated skeletal microvessel preparation for investigation of vascular reactivity. J Vis Exp, 62, e3674, doi:10.3791/3674(62). doi: 10.3791/3674

Chen, T. T., Luykenaar, K. D., Walsh, E. J., Walsh, M. P., \& Cole, W. C. (2006). Key role of Kv1 channels in vasoregulation. [In Vitro

Research Support, Non-U.S. Gov't]. Circulation research, 99(1), 53-60. doi: 10.1161/01.RES.0000229654.45090.57

Cheong, A., Dedman, A. M., \& Beech, D. J. (2001). Expression and function of native potassium channel [Kvalpha1] subunits in terminal arterioles of rabbit. [Research Support, Non-U.S. Gov't]. The Journal of physiology, 534(Pt 3), 691-700.

Cheong, A., Dedman, A. M., Xu, S. Z., \& Beech, D. J. (2001). Kvalpha1 channels in murine arterioles: differential cellular expression and regulation of diameter. Am J Physiol Heart Circ Physiol, 281(3), H1057-1065. 
Cheong, A., Quinn, K., Dedman, A. M., \& Beech, D. J. (2002). Activation thresholds of $\mathrm{K}_{\mathrm{V}}, \mathrm{BK}$ and $\mathrm{Cl}_{\mathrm{Ca}}$ channels in smooth muscle cells in pial precapillary arterioles. $J$ Vasc Res, 39(2), 122-130. doi: 57761

Clement-Chomienne, O., Ishii, K., Walsh, M. P., \& Cole, W. C. (1999). Identification, cloning and expression of rabbit vascular smooth muscle Kv1.5 and comparison with native delayed rectifier $\mathrm{K}^{+}$current. [Comparative Study

Research Support, Non-U.S. Gov't]. The Journal of physiology, 515, 653-667.

Cogolludo, A., Moreno, L., Lodi, F., Frazziano, G., Cobeno, L., Tamargo, J., \& PerezVizcaino, F. (2006). Serotonin inhibits voltage-gated $\mathrm{K}^{+}$currents in pulmonary artery smooth muscle cells: role of $5-\mathrm{HT} 2 \mathrm{~A}$ receptors, caveolin- 1 , and $\mathrm{K}_{\mathrm{v}} 1.5$ channel internalization. [Research Support, Non-U.S. Gov't]. Circulation research, 98(7), 931-938. doi: 10.1161/01.RES.0000216858.04599.e1

Cox, R. H. (2005). Molecular determinants of voltage-gated potassium currents in vascular smooth muscle. Cell Biochem Biophys, 42(2), 167-195. doi: 10.1385/CBB:42:2:167

Dick, G. M., Bratz, I. N., Borbouse, L., Payne, G. A., Dincer, U. D., Knudson, J. D., . . . Tune, J. D. (2008). Voltage-dependent $\mathrm{K}^{+}$channels regulate the duration of reactive hyperemia in the canine coronary circulation. [Research Support, N.I.H., Extramural]. American journal of physiology. Heart and circulatory physiology, 294(5), H2371-2381. doi: 10.1152/ajpheart.01279.2007 
Dick, G. M., \& Tune, J. D. (2010). Role of potassium channels in coronary vasodilation. Exp Biol Med (Maywood), 235(1), 10-22. doi: 10.1258/ebm.2009.009201

Fountain, S. J., Cheong, A., Flemming, R., Mair, L., Sivaprasadarao, A., \& Beech, D. J. (2004). Functional up-regulation of KCNA gene family expression in murine mesenteric resistance artery smooth muscle. J Physiol, 556(Pt 1), 29-42. doi: 10.1113/jphysiol.2003.058594

Gollasch, M., Ried, C., Bychkov, R., Luft, F. C., \& Haller, H. (1996). K ${ }^{+}$currents in human coronary artery vascular smooth muscle cells. Circ Res, 78(4), 676-688.

Hald, B. O., Jacobsen, J. C., Braunstein, T. H., Inoue, R., Ito, Y., Sorensen, P. G., . . . Jensen, L. J. (2012). BKCa and KV channels limit conducted vasomotor responses in rat mesenteric terminal arterioles. Pflugers Arch, 463(2), 279-295. doi: 10.1007/s00424-011-1049-8

Heaps, C. L., \& Bowles, D. K. (2002). Gender-specific $\mathrm{K}^{+}$-channel contribution to adenosine-induced relaxation in coronary arterioles. J Appl Physiol, 92(2), 550558. doi: 10.1152/japplphysiol.00566.2001

Jackson, W. F. (1998). Potassium channels and regulation of the microcirculation. Microcirculation, 5(2-3), 85-90. 
Jackson, W. F. (2005). Potassium channels in the peripheral microcirculation. Microcirculation, 12(1), 113-127. doi: W638WM0317Q8U570 [pii]

$10.1080 / 10739680590896072$

Kang, L. S., Kim, S., Dominguez, J. M., 2nd, Sindler, A. L., Dick, G. M., \& Muller-Delp, J. M. (2009). Aging and muscle fiber type alter $\mathrm{K}^{+}$channel contributions to the myogenic response in skeletal muscle arterioles. J Appl Physiol, 107(2), 389398. doi: 10.1152/japplphysiol.91245.2008

Kerr, P. M., Clement-Chomienne, O., Thorneloe, K. S., Chen, T. T., Ishii, K., Sontag, D. P., . . Cole, W. C. (2001). Heteromultimeric Kv1.2-Kv1.5 channels underlie 4aminopyridine-sensitive delayed rectifier $\mathrm{K}^{+}$current of rabbit vascular myocytes. [Comparative Study

Research Support, Non-U.S. Gov't]. Circulation research, 89(11), 1038-1044.

Knot, H. J., \& Nelson, M. T. (1995). Regulation of membrane potential and diameter by voltage-dependent $\mathrm{K}^{+}$channels in rabbit myogenic cerebral arteries. [Research Support, Non-U.S. Gov't

Research Support, U.S. Gov't, Non-P.H.S.

Research Support, U.S. Gov't, P.H.S.]. The American journal of physiology, 269(1 Pt 2), H348-355.

Lagrutta, A., Wang, J., Fermini, B., \& Salata, J. J. (2006). Novel, potent inhibitors of human $\mathrm{Kv} 1.5 \mathrm{~K}^{+}$channels and ultrarapidly activating delayed rectifier potassium 
current. The Journal of pharmacology and experimental therapeutics, 317(3), 1054-1063. doi: 10.1124/jpet.106.101162

Luykenaar, K. D., Brett, S. E., Wu, B. N., Wiehler, W. B., \& Welsh, D. G. (2004). Pyrimidine nucleotides suppress $\mathrm{K}_{\mathrm{DR}}$ currents and depolarize rat cerebral arteries by activating Rho kinase. Am J Physiol Heart Circ Physiol, 286(3), H1088-1100. doi: 10.1152/ajpheart.00903.2003

00903.2003 [pii]

Luykenaar, K. D., El-Rahman, R. A., Walsh, M. P., \& Welsh, D. G. (2009). Rho-kinasemediated suppression of KDR current in cerebral arteries requires an intact actin cytoskeleton. Am J Physiol Heart Circ Physiol, 296(4), H917-926. doi: 10.1152/ajpheart.01206.2008

Luykenaar, K. D., \& Welsh, D. G. (2007). Activators of the PKA and PKG pathways attenuate RhoA-mediated suppression of the KDR current in cerebral arteries. Am J Physiol Heart Circ Physiol, 292(6), H2654-2663. doi: 01255.2006 [pii]

10.1152/ajpheart.01255.2006

McGahon, M. K., Dawicki, J. M., Arora, A., Simpson, D. A., Gardiner, T. A., Stitt, A. W., . . . Curtis, T. M. (2007). Kv1.5 is a major component underlying the A-type potassium current in retinal arteriolar smooth muscle. Am J Physiol, 292(2), H1001-1008. doi: 10.1152/ajpheart.01003.2006 
National Research Council. (2011). Guide for the Care and Use of Laboratory Animals (8 ed.): The National Academies Press.

Ohanyan, V. A., Bratz, I. N., Guarini, G., Yin, L., \& Chilian, W. M. (2010 (Abstract)). Kv1.5 channels play a critical role in coronary metabolic dilation. Circulation, 122(21).

Plane, F., Johnson, R., Kerr, P., Wiehler, W., Thorneloe, K., Ishii, K., . . . Cole, W. (2005). Heteromultimeric Kv1 channels contribute to myogenic control of arterial diameter. [Comparative Study

Research Support, Non-U.S. Gov't]. Circulation research, 96(2), 216-224. doi: 10.1161/01.RES.0000154070.06421.25

Regan, C. P., Wallace, A. A., Cresswell, H. K., Atkins, C. L., \& Lynch, J. J., Jr. (2006). In vivo cardiac electrophysiologic effects of a novel diphenylphosphine oxide IKur blocker, (2-Isopropyl-5-methylcyclohexyl) diphenylphosphine oxide, in rat and nonhuman primate. The Journal of pharmacology and experimental therapeutics, 316(2), 727-732. doi: 10.1124/jpet.105.094839

Stump, G. L., Wallace, A. A., Regan, C. P., \& Lynch, J. J., Jr. (2005). In vivo antiarrhythmic and cardiac electrophysiologic effects of a novel diphenylphosphine oxide IKur blocker (2-isopropyl-5-methylcyclohexyl) diphenylphosphine oxide. [Comparative Study]. The Journal of pharmacology and experimental therapeutics, 315(3), 1362-1367. doi: 10.1124/jpet.105.092197 
Thorneloe, K. S., Chen, T. T., Kerr, P. M., Grier, E. F., Horowitz, B., Cole, W. C., \& Walsh, M. P. (2001). Molecular composition of 4-aminopyridine-sensitive voltagegated $\mathrm{K}^{+}$channels of vascular smooth muscle. [Research Support, Non-U.S. Gov't]. Circulation research, 89(11), 1030-1037.

Van Wagoner, D. R., Kirian, M., \& Lamorgese, M. (1996). Phenylephrine suppresses outward $\mathrm{K}^{+}$currents in rat atrial myocytes. [Research Support, Non-U.S. Gov't]. The American journal of physiology, 271(3 Pt 2), H937-946.

Volk, K. A., Matsuda, J. J., \& Shibata, E. F. (1991). A voltage-dependent potassium current in rabbit coronary artery smooth muscle cells. J Physiol, 439, 751-768.

Waldron, G. J., \& Cole, W. C. (1999). Activation of vascular smooth muscle $\mathrm{K}^{+}$channels by endothelium-derived relaxing factors. [Research Support, Non-U.S. Gov't Review]. Clinical and experimental pharmacology \& physiology, 26(2), 180-184. 
Table 1. Effects of $\mathrm{K}_{\mathrm{v}}$ channel inhibitors on microvascular smooth muscle

\begin{tabular}{|c|c|c|c|c|}
\hline Reference & Species & Vessel or bed & Inhibitor & Effect \\
\hline Knot and Nelson 1995 & Rabbit & Cerebral arterioles & $\begin{array}{l}\text { 3,4-DAP } \\
\text { 4-AP }\end{array}$ & Depolarize, constrict, alter myogenic reactivity \\
\hline Jackson et al. 1996 & Rat and hamster & Cremasteric arterioles & 4-AP & Block current, depolarize \\
\hline Kirton and Loutzenhiser 1998 & Rat & Renal afferent arterioles & 4-AP & Constrict \\
\hline Platts et al. 1998 & Rat & Cremasteric arterioles & 4-AP & Inhibit dilation \\
\hline Horiuchi et al. 2001 & Rat & Cerebral arterioles & 4-AP & Constrict \\
\hline Cheong et al. 2001 & Rabbit & Cerebral arterioles & $\begin{array}{l}\text { 4-AP } \\
\text { correolide }\end{array}$ & Block current, depolarize, constrict \\
\hline Heaps and Bowles 2002 & Pig & Coronary arterioles & 4-AP & Inhibit dilation \\
\hline Cheong et al. 2002 & Rabbit & Cerebral arterioles & 3,4-DAP & Block current, constrict \\
\hline Albarwani et al. 2003 & Rat & Cerebral arterioles & $\begin{array}{l}\text { Correolide } \\
\text { 4-AP }\end{array}$ & Block current, depolarize \\
\hline Mayhan et al. 2004 & Rat & Cerebral arterioles & 4-AP & Constrict \\
\hline Plane et al. 2005 & Rat & Mesenteric arterioles & $\begin{array}{l}\text { 4-AP } \\
\text { correolide }\end{array}$ & Block current, alter myogenic reactivity \\
\hline Rogers et al. 2006 & $\begin{array}{l}\text { Rat } \\
\text { Dog }\end{array}$ & $\begin{array}{l}\text { Coronary arterioles } \\
\text { Coronary blood flow }\end{array}$ & 4-AP & Inhibit dilation \\
\hline Dick et al. 2008 & Dog & $\begin{array}{l}\text { Coronary arterioles } \\
\text { Coronary blood flow }\end{array}$ & $\begin{array}{l}\text { 4-AP } \\
\text { correolide }\end{array}$ & Inhibit dilation, constrict \\
\hline Kang et al. 2009 & Rat & Skeletal muscle arterioles & 4-AP & Constrict, alter myogenic reactivity \\
\hline
\end{tabular}


Figure 2.1

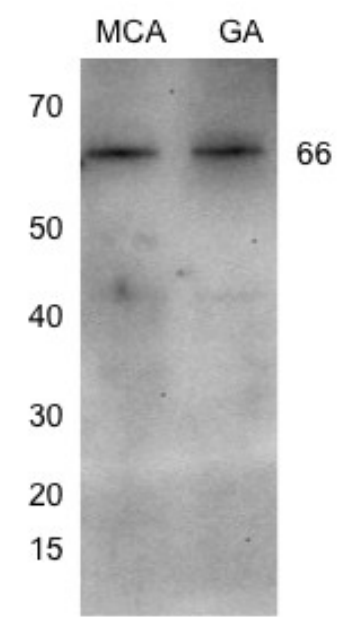


Figure $2.1 \mathrm{~K}_{\mathrm{v}} 1.5$ protein in resistance arteries. A representative Western blot is shown. Whole vessel lysate (15-20 $\mu$ g protein) was loaded. The numbers on the left indicate molecular weights of markers in $\mathrm{kDa}$. A band of $\mathrm{K}_{\mathrm{v}} 1.5$ immunoreactivity was detected near $66 \mathrm{kDa}$ in MCA and GA. A faint, nonspecific band at approximately $42 \mathrm{kDa}$ is also present. 
Figure 2.2

A

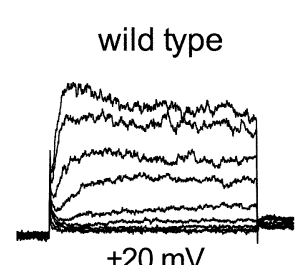

$-80 \mathrm{mV}$

D

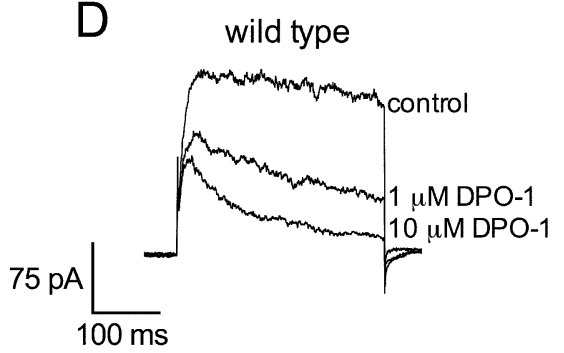

B

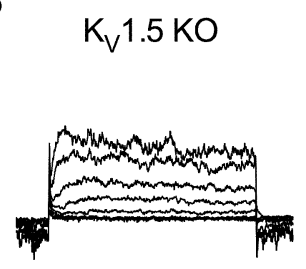

E

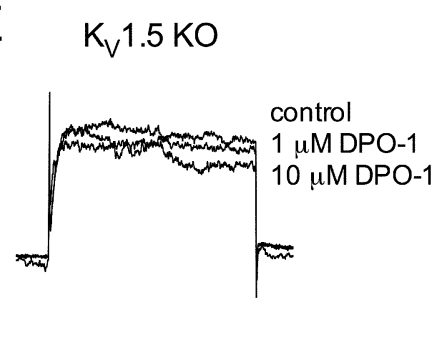

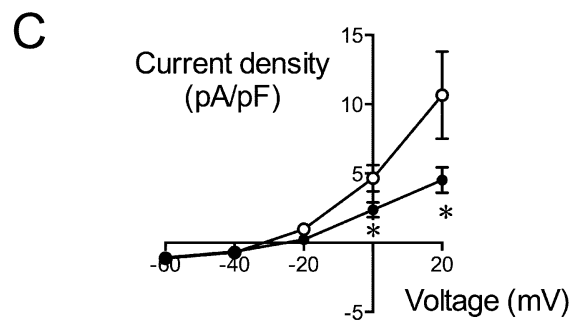

F

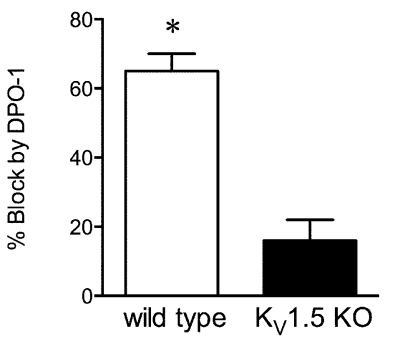


Figure 2.2 DPO-1-sensitive currents are absent in the smooth muscle cells from $\mathrm{K}_{\mathrm{v}} 1.5$ knockout mice. Panels $A$ and $B$ contain current traces from aortic myocytes isolated from wild type and $K_{v} 1.5$ knockout mice. The voltage template is shown below A. Panel C contains group data ( $n=4$ mice in each group) illustrating reduce current density in cells from $\mathrm{K}_{\mathrm{v}} 1.5$ knockout mice. Panels $\mathrm{D}$ and $\mathrm{E}$ contain currents elicited at $+20 \mathrm{mV}$ and the effects of 1 and $10 \mu \mathrm{M}$ DPO-1. Panel $F$ shows group data for inhibition by $1 \mu \mathrm{M}$ DPO-1. 
Figure 2.3

A middle cerebral arterioles

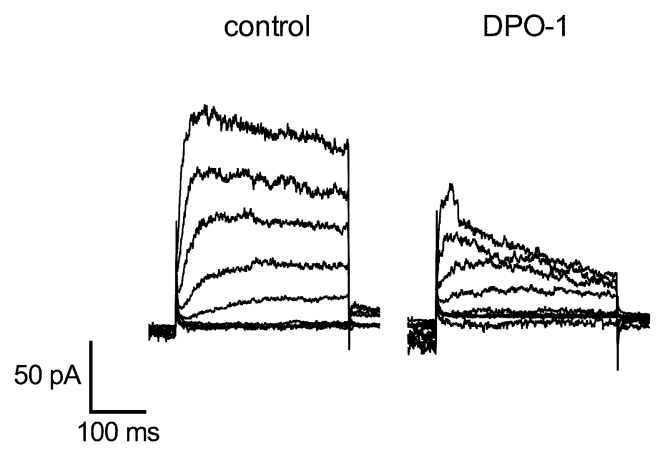

C

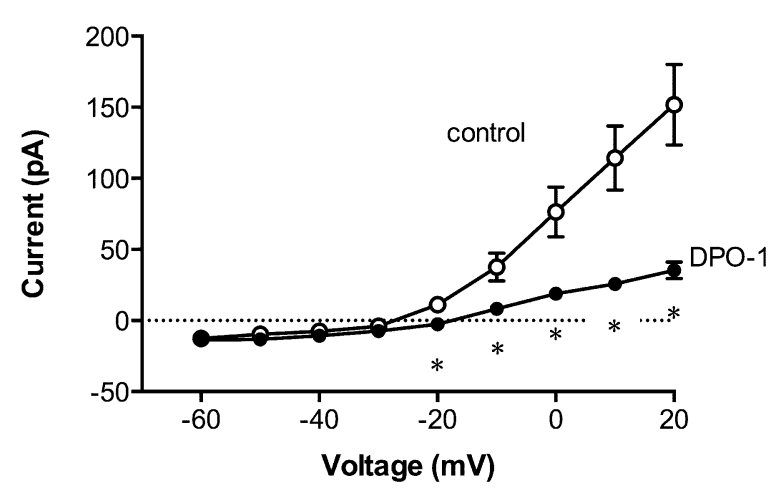

B gracilis arterioles

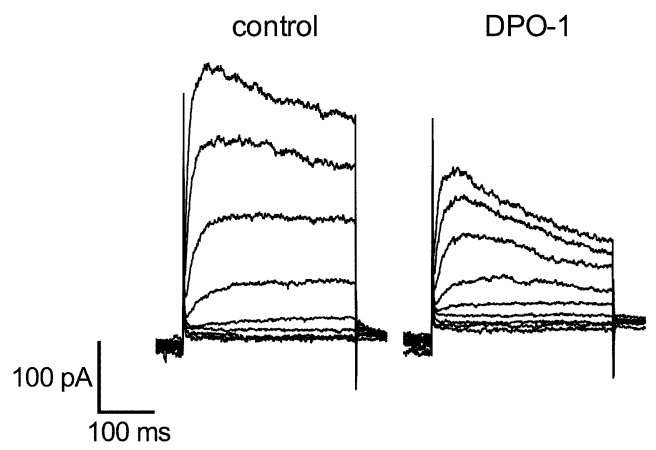

D

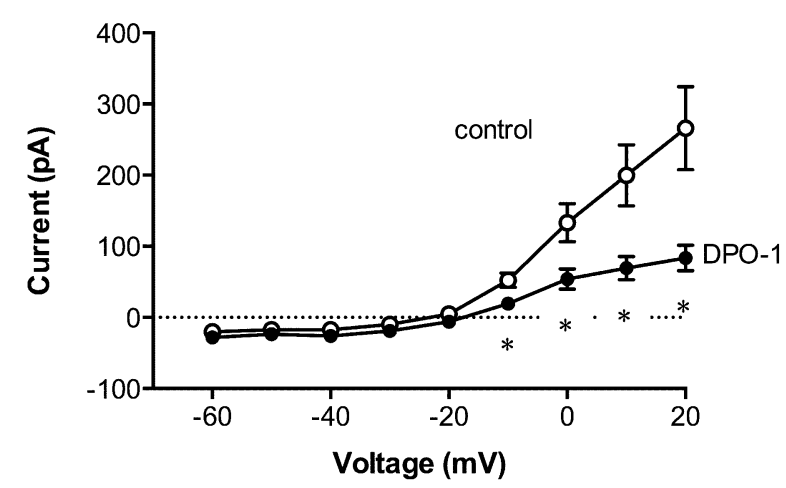


Figure 2.3 DPO-1-sensitive $\mathrm{K}_{\mathrm{DR}}$ current in arteriolar smooth muscle. Current traces from representative smooth muscle cells are shown in panels $A(M C A)$ and $B(G A)$ before and after the addition of $10 \mu \mathrm{M}$ DPO-1. The membrane potential of cells was stepped in $10 \mathrm{mV}$ increments from $-60 \mathrm{mV}$ to $+20 \mathrm{mV}$ (holding potential was $-80 \mathrm{mV}$ ). DPO-1 (10 $\mu \mathrm{M})$ inhibited $\mathrm{K}_{\mathrm{DR}}$ currents in smooth muscle cells from both types of arterioles. Panels C and D contain group I-V data for cells from the MCA $(n=6)$ and GA $(n=4)$. Asterisks indicate voltages at which $10 \mu \mathrm{M}$ DPO-1 significantly reduced $\mathrm{K}_{\mathrm{DR}}$ current. 
Figure 2.4

A middle cerebral arterioles

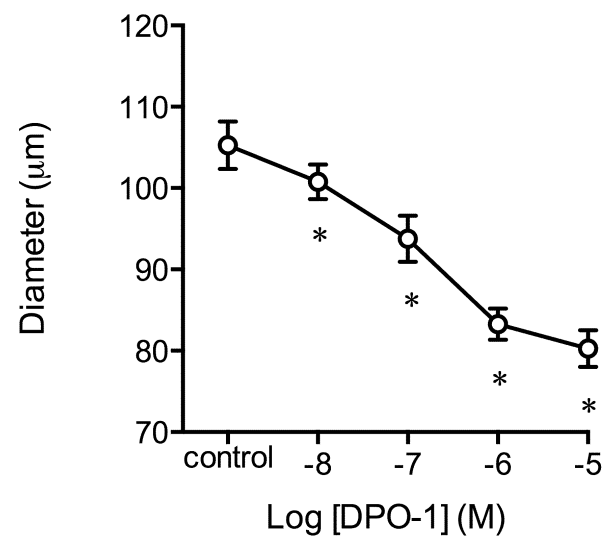

B

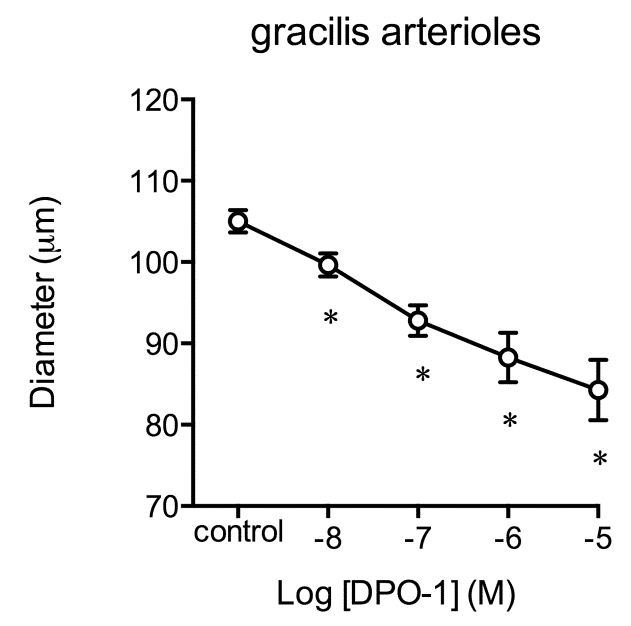


Figure 2.4 Concentration-dependent effect of DPO-1 on arteriolar diameter. MCA (panel $A ; n=4$ ) and $G A$ (panel $B ; n=4$ ) were pressurized to $80 \%$ of mean arterial pressure for video measurements of diameter. Arterioles were treated with increasing concentrations of DPO-1, which elicited constriction. Asterisks indicate concentrations at which DPO-1 significantly reduced arteriolar diameter. 
Figure 2.5

A

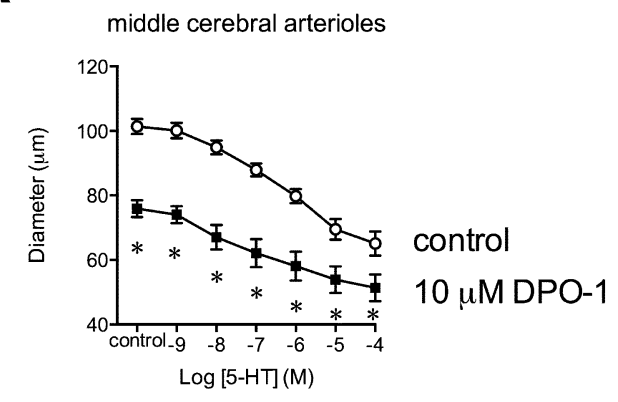

C

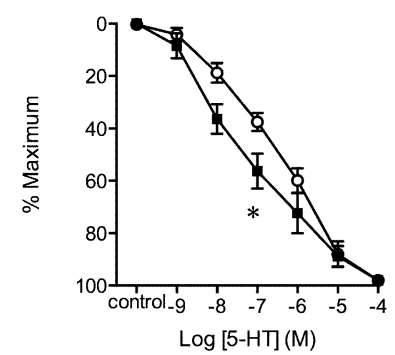

B

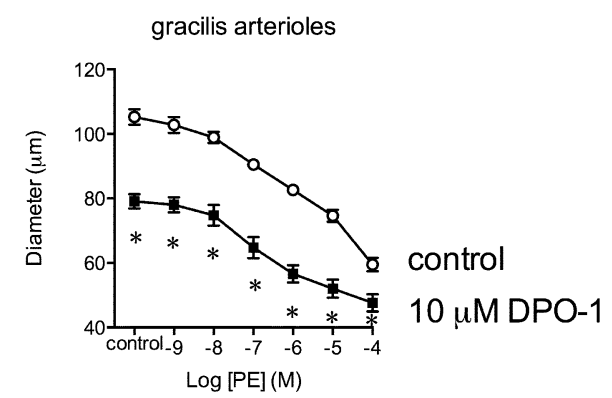

D

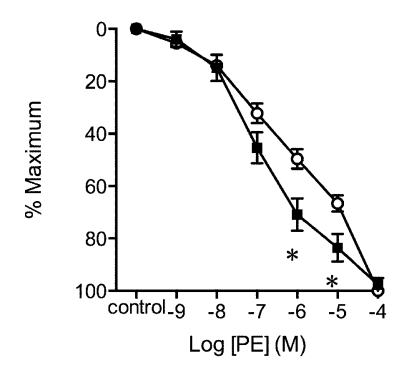


Figure 2.5 DPO-1 augments contractions to serotonin and phenylephrine. Inhibition of $\mathrm{K}_{\mathrm{DR}}$ by DPO-1 $(10 \mu \mathrm{M})$ augmented constriction to $5-\mathrm{HT}$ in MCA (Panel $\left.\mathrm{A} ; \mathrm{n}=8\right)$ and to PE in GA (Panel $B ; n=8)$. In the presence of $10 \mu \mathrm{M}$ DPO-1 both $5-\mathrm{HT}$ and PE significantly decreased diameters from the respective control curve. When normalized to maximum effects, the 5-HT and PE concentration-response curves were significantly left-shifted (Panels C and D). 
Figure 2.6

A

middle cerebral arterioles

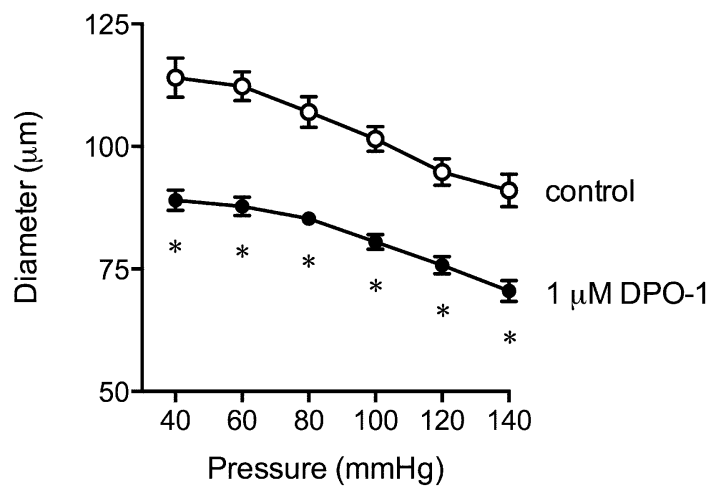

B

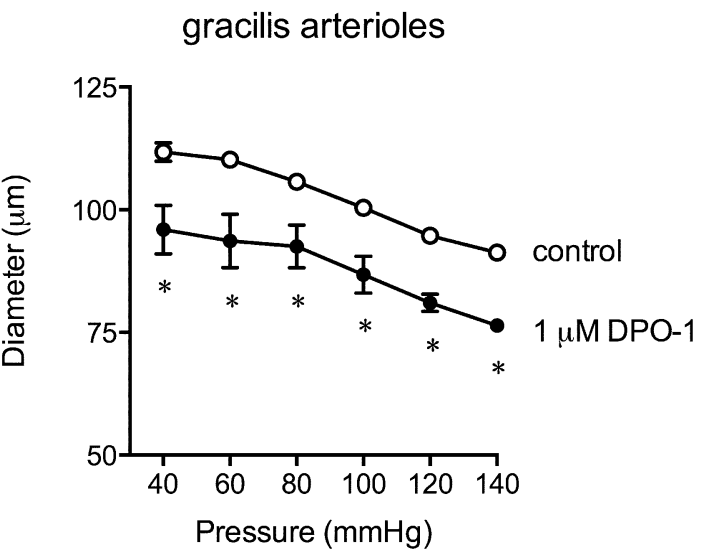


Figure 2.6 DPO-1 shifts the myogenic response. Changes in intraluminal pressure in the presence of DPO-1 cause a shift toward smaller diameters in MCA (Panel A) and GA (Panel B), while keeping the myogenic response intact $(n=4$ in each panel). 
Figure 2.7

A

middle cerebral arterioles

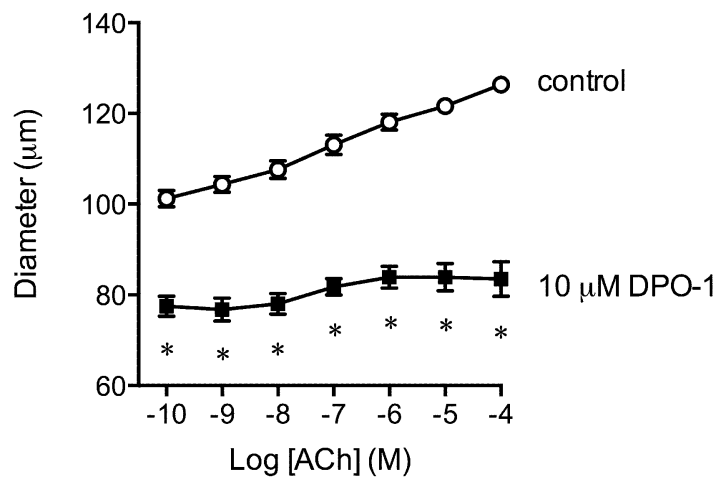

B

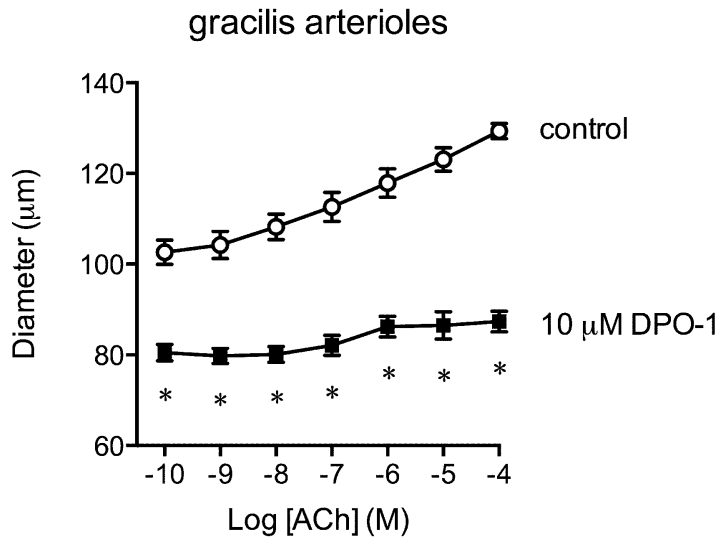


Figure 2.7 Relaxations to acetylcholine are impaired by DPO-1. $N=8$ arterioles for both panels. $10 \mu \mathrm{M}$ DPO-1 significantly reduced vasodilation to each concentration of ACh in MCA (Panel A) and GA (Panel B). 


\section{Chapter 3}

\section{Diphenyl phosphine oxide-1 inhibits $K_{V}$ channels in porcine coronary smooth muscle by accelerating inactivation kinetics}

To be submitted to Channels (September, 2014)

Ibra S. Fancher and Gregory M. Dick

Center for Cardiovascular and Respiratory Sciences

West Virginia University School of Medicine

Short title: DPO-1 accelerates $K_{V}$ channel kinetics

Please address correspondence to:

Gregory M. Dick, Ph.D.

West Virginia University

1 Medical Center Drive

P.O. Box 9105

Morgantown, WV 26506-9105

Phone (304) 293-2542

Fax (304) 293-5513

Email gmdick@hsc.wvu.edu 


\section{Abstract}

Delayed rectifier $\mathrm{K}^{+}\left(\mathrm{K}_{\mathrm{DR}}\right)$ currents help control the contraction of vascular smooth muscle. We recently demonstrated that inhibition of $\mathrm{K}_{\mathrm{DR}}$ channels with diphenyl phosphine oxide-1 (DPO-1) dramatically alters arteriolar reactivity. Importantly, however, it remains unknown how DPO-1 blocks these channels. Our goal was to identify mechanisms involved in DPO-1-induced inhibition of smooth muscle $K_{D R}$ channels. Whole-cell patch clamp experiments were performed on myocytes isolated from the porcine coronary artery. DPO- 1 blocked $\mathrm{K}_{\mathrm{DR}}$ with an $\mathrm{IC}_{50}$ of $212 \pm 28 \mathrm{nM}$. In the presence of DPO-1, the voltage window for channel function diminished, as the voltage of $1 / 2$ inactivation was hyperpolarized $(-11 \pm 1$ vs. $-16 \pm-1 \mathrm{mV})$ and the extent of inactivation more complete (74 \pm 3 vs. $99 \pm 1 \%$ ). During a depolarizing pulse, $\mathrm{K}_{\mathrm{DR}}$ channels inactivated by a process fit with fast and slow time constants $(0.52 \pm 0.07$ and $5.8 \pm 1.1 \mathrm{~s}$, respectively); DPO-1 accelerated both components of inactivation $(0.14 \pm$ 0.01 and $0.6 \pm 0.2 \mathrm{~s}$ ). DPO-1 also prolonged recovery from inactivation (320 \pm 10 vs. $910 \pm 107 \mathrm{~ms}$ ). These findings indicate that DPO-1 blocks $K_{D R}$ channels in coronary vascular smooth muscle by: 1) reducing the voltage window for channel function (i.e., decreasing area under the voltage-dependent activation and inactivation curves); 2) accelerating the transition from the open to closed state in the presence of stimulus; and 3) delaying recovery from voltage-dependent inactivation. These biophysical mechanisms may help explain why DPO-1 so severely impacts smooth muscle reactivity.

Keywords: voltage-dependent $\mathrm{K}^{+}$channels, $\mathrm{K}_{\mathrm{v}} 1.5, \mathrm{KCNA5}$, and vascular smooth muscle 


\section{Introduction}

Voltage-dependent $\mathrm{K}^{+}\left(\mathrm{K}_{\mathrm{V}}\right)$ channels are studied in a variety of cells because they are so important in controlling excitability. This is precisely why so much research focuses on pharmaceutical agents that open and close $K_{V}$ channels, as they have applications for treating conditions including epilepsy (e.g., retigabine), pain (e.g., flupirtine), and atrial fibrillation (e.g., dofetilide). With regard to atrial fibrillation, it was the discovery of rare gain-of-function mutations in several $\mathrm{K}^{+}$channels (e.g. KCNQ1) that provided the therapeutic rationale for treating the condition with $\mathrm{K}^{+}$blockers $(\mathrm{Y} . \mathrm{H}$. Chen et al., 2003). One particularly attractive drug target in treating atrial arrhythmias is $\mathrm{K}_{\mathrm{v}}$ 1.5. This is because: a) $\mathrm{K}_{\mathrm{v}} 1.5$ mediates the atrial ultra-rapid delayed rectifier $\mathrm{K}^{+}$ current ( $\left.\mathrm{I}_{\mathrm{Kur}}\right)$; b) blocking this $\mathrm{I}_{\mathrm{Kur}}$ prolongs the atrial action potential; and c) $\mathrm{I}_{\mathrm{Kur}}$ is not found in the human ventricle (obviating concern about effects on inotropy, etc.) (Brendel \& Peukert, 2003). Thus, the search for $\mathrm{K}_{\mathrm{v}} 1.5$-specific blockers commenced and several candidates emerged, including diphenyl phosphine oxide-1 (DPO-1) (Lagrutta, Wang, Fermini, \& Salata, 2006; Regan, Wallace, Cresswell, Atkins, \& Lynch, 2006; Stump, Wallace, Regan, \& Lynch, 2005). Unfortunately, low oral bioavailability ended the progression of DPO-1 towards clinical trials; however, we are left with a very $\mathrm{K}_{\mathrm{v}} 1.5-$ selective pharmacological tool.

While $\mathrm{I}_{\mathrm{Kur}}$ is not expressed in the human ventricle, the distribution of $\mathrm{K}_{\mathrm{V}} 1.5$ is certainly not limited to atria. In fact, the coronary vessels are strongly positive for $K_{v} 1.5$ immunoreactivity (Mays, Foose, Philipson, \& Tamkun, 1995). Moreover, previous studies have suggested that $\mathrm{K}_{\mathrm{V}} 1.5$ is a component of delayed rectifier $\mathrm{K}^{+}\left(\mathrm{K}_{\mathrm{DR}}\right)$ channels in a variety of vascular smooth muscle cell types (T. T. Chen, Luykenaar, Walsh, Walsh, 
\& Cole, 2006; Kerr et al., 2001; Plane et al., 2005; Thorneloe et al., 2001). We recently demonstrated that inhibition of smooth muscle $K_{D R}$ channels with DPO-1 dramatically alters the reactivity of arterioles from brain and skeletal muscle (Fancher et al., in revision, see Chapter 2). Importantly, however, it remains unknown how DPO-1 blocks these channels; therefore, our goal in the present study was to identify mechanisms involved in DPO-1-induced inhibition of smooth muscle $\mathrm{K}_{\mathrm{DR}}$ channels.

DPO-1 has been suggested as a specific inhibitor of human $\mathrm{K}_{\mathrm{V}} 1.5$ with an $\mathrm{IC}_{50}$ of approximately $160 \mathrm{nM}$ at a pulse frequency of $0.1 \mathrm{~Hz}$ (Lagrutta et al., 2006). Further, at least six hydrophobic residues found in the S6 domain have been shown to play a role in DPO-1-induced inhibition of $\mathrm{K}_{v} 1.5$ (Du et al., 2010). DPO-1 inhibits cloned $\mathrm{K}_{\mathrm{v}} 1.5$ in a frequency- and voltage-dependent manner, indicative of open state block (Du et al., 2010; Lagrutta et al., 2006). DPO-1 increases atrial action potential duration and terminates atrial fibrillation by inhibiting $\mathrm{K}_{\vee} 1.5$-mediated $\mathrm{I}_{\mathrm{Kur}}$. Thus, while the effects of DPO-1 on atrial and cloned $\mathrm{K}_{\mathrm{V}} 1.5$ channels are well documented, the mechanisms of DPO-1 block of $K_{D R}$ channels in vascular smooth muscle have not been investigated previously. We used DPO-1 as a $\mathrm{K}_{\mathrm{v}} 1.5$-selective tool to test the supposition that $\mathrm{K}_{\mathrm{v}} 1.5$ channels contribute to $\mathrm{K}_{\mathrm{DR}}$ current in porcine coronary smooth muscle. Moreover, we examined the effects of DPO-1 on $\mathrm{K}_{\mathrm{DR}}$ current kinetics and other biophysical properties in order to propose a mechanism of block. 


\section{Methods}

Animals. The Institutional Animal Care and Use Committee at Indiana University School of Medicine approved the protocols. All methods conformed to regulations set forth by in the Guide for the Care and Use of Laboratory Animals (National Research Council, 2011). The hearts of anesthetized pigs, subjects of unrelated experiments, were fibrillated and removed. An epicardial segment of the right coronary artery was collected.

Isolation of smooth muscle cells. A small portion $(2-3 \mathrm{~cm})$ of porcine right coronary artery was cleaned of adipose and adventitia in buffer containing (mM) 135 $\mathrm{NaCl}, 5 \mathrm{KCl}, 0.36 \mathrm{CaCl}_{2}, 1 \mathrm{MgCl}_{2}, 10$ glucose, 10 HEPES, 5 Tris-Base, $\mathrm{pH}$ 7.4. The artery was transferred to a tube containing the same low $\mathrm{Ca}^{2+}$ HEPES buffer supplemented with $(\mathrm{mg} / \mathrm{ml}) 2$ collagenase, 1 elastase, 1 soybean trypsin inhibitor and 1 bovine serum albumin. The tube was warmed to $37^{\circ} \mathrm{C}$ for $30-60$ minutes. The artery was passed through the tip of a fire-polished Pasteur pipette to liberate single smooth muscle cells. Cell suspension was centrifuged at $400 \mathrm{~g}$ for 5 min and the resulting pellet was resuspended in fresh low $\mathrm{Ca}^{2+}$ HEPES buffer. Cells were stored on ice and used within $8 \mathrm{hr}$.

Electrophysiology. A drop of cell suspension was placed on an $8 \mathrm{~mm}$ diameter cover glass and cells were allowed $5-10$ min to adhere. This cover glass was then moved to a recording chamber (volume $0.2-0.3 \mathrm{ml}$ ) mounted atop an inverted microscope. Cells were continuously superfused $(2-3 \mathrm{ml} / \mathrm{min})$ with a solution containing (mM) $135 \mathrm{Na}$-isethionate, $5 \mathrm{~K}$-gluconate, $2 \mathrm{MnCl}_{2}, 1 \mathrm{MgCl}_{2}$, 10 glucose, 10 HEPES, 5 Tris-base, $\mathrm{pH}$ 7.4. Cells were approached with borosilicate pipettes having tip 
resistances of 2-5 $\mathrm{M} \Omega$ when filled a solution containing (mM) $140 \mathrm{~K}$-gluconate, $1 \mathrm{MgCl}_{2}$, 3 Mg-ATP, 1 Na-GTP, 10 BAPTA, 10 HEPES, and 5 Tris, pH 7.1. $\mathrm{K}_{\text {DR }}$ was isolated in whole-cell patch configurations because the pipette solution also contained penitrem $\mathrm{A}$ $(1 \mu \mathrm{M})$ to block large conductance $\mathrm{Ca}^{2+}$ activated $\mathrm{K}^{+}$channels, glibenclamide $(10 \mu \mathrm{M})$ to block $\mathrm{K}_{\text {ATP }}$ channels, and BAPTA $(10 \mathrm{mM})$, a $\mathrm{Ca}^{2+}$ chelator. After achieving whole cell access, the appropriate voltage protocol was applied to examine specific aspects of porcine VSM delayed rectifier current and kinetics in the presence or absence of DPO-1 in the bath solution. Currents were low-pass filtered at $1 \mathrm{kH}$ and digitized at $5 \mathrm{kH}$.

Statistics. Data are presented as the mean \pm SE from $n$ cells. Comparisons were made using 2-way repeated measures ANOVA (2RM-ANOVA; with Bonferroni post-hoc when appropriate) or paired $t$-tests as described. For all comparisons, $p<0.05$ was considered statistically significant. Boltzmann fits were used to calculate the $V_{1 / 2}$ of activation and inactivation curves. Mono-exponential fits were used to determine the kinetics of activation as well as the recovery from inactivation. Time-dependent inactivation was fit by a bi-exponential curve. 


\section{Results}

Smooth muscle $K_{D R}$ is inhibited by DPO-1. Fig. 1 shows concentration-dependent inhibition of $K_{D R}$ current by DPO-1 in smooth muscle cells isolated from the pig coronary artery. Results from two voltage protocols of dramatically different length are shown. Results from the first type of voltage protocol (Figs. 1A-D) were obtained with the typical 400 ms duration template we have used previously (Dick et al., 2008). Results from the short voltage template allow one to appreciate that this a $\mathrm{K}_{\mathrm{DR}}$ current (note the fast activation, modest inactivation, deactivating tails, and shape of the I-V relationship). Inhibition of $K_{D R}$ current by DPO-1 was largely reversible upon washout (Fig. 1D). The second type of voltage protocol was more than 10-times longer in duration and lets one more fully appreciate the extent of time-dependent inactivation and even more dramatic effects of DPO-1 (Fig. 1E). By measuring current at the end of the test pulses in the shorter protocol and determining the effects of various concentrations of DPO-1, we calculated an $\mathrm{IC}_{50}$ of $212 \pm 28 \mathrm{nM}$ (Fig. 1F). Note that if current is measured at the end of the long voltage templates and effects are calculated, the apparent IC50 is approximately one log order lower (left shifted; Fig. 1F). We chose to use $1 \mu \mathrm{M}$ DPO-1 for the majority of the subsequent experiments as this concentration is above the calculated $\mathrm{IC}_{50}$ and produces substantial inhibition to study.

Fig. 2 shows activation and inactivation curves for $\mathrm{K}_{\mathrm{DR}}$ current in in smooth muscle cells from the porcine coronary artery. The activation curves were calculated from the peak current at the beginning of the various voltage steps (Figs. $2 A$ and $B$ ). Current was divided by driving force (difference between test voltage and the equilibrium potential for $\mathrm{K}^{+}$) to calculate conductance $(\mathrm{G})$. $\mathrm{G}$ was normalized to its maximum and plotted; these 
activation curves increase from left to right in Fig. 1C. Inactivation was determined by measuring the fraction of available current at $+20 \mathrm{mV}$ following the various test potentials (expanded currents shown in Figs. 2Ai and 2Bi). The inactivation curves decrease from left to right in Fig. 1C. The area beneath the intersection of activation and inactivation curves represents the 'voltage window' for channel function. DPO-1 significantly left shifted the activation curve $\left(\mathrm{V}_{1 / 2}\right.$ was $-4 \pm 1$ vs. $-9 \pm-1 \mathrm{mV}$ before and after DPO-1 respectively). DPO-1 hyperpolarized the $\mathrm{V}_{1 / 2}$ of inactivation $\left(\mathrm{V}_{1 / 2}\right.$ was $-11 \pm$ 1 vs. $-16 \pm-1 \mathrm{mV}$ before and after DPO-1 respectively). Moreover, the extent of inactivation was more complete in the presence of DPO-1 (74 \pm 3 vs. $99 \pm 1 \%$ ). Overall, the effect of DPO-1 on the activation and inactivation curves is to reduce the area under them; therefore, limiting the voltage window for channel operation.

Inhibition of $K_{D R}$ by DPO-1 is modestly voltage-dependent. Studies conducted on cloned $\mathrm{K}_{\mathrm{V}} 1.5$ indicate that DPO-1 blocks the current in a slightly voltage-dependent manner at potentials between 0 and $20 \mathrm{mV}$ (Du et al., 2010). That is, block was more pronounced at more depolarized test potentials. Thus, we investigated the voltagedependence of block by $1 \mu \mathrm{M}$ DPO-1 on $K_{D R}$ current in smooth muscle cells from the porcine coronary artery, voltage-dependent block is a hallmark of open state block. Fig. 3 shows the effect of three concentrations of DPO-1 $(0.1,1$, and $10 \mu \mathrm{M})$ at voltages between -20 and $+20 \mathrm{mV}$. This voltage range was chosen because it represents the steepest portion of the activation curve (dotted line in Fig. 3 is the Boltzman fit from Fig. 2C). There is a modest voltage-dependent block by DPO-1. For example, inhibition by $0.1 \mu \mathrm{M}$ doubles from $17 \pm 3$ to $36 \pm 7 \%$ across this range of potentials (Fig. 3 ). 
Inhibition of smooth muscle $K_{D R}$ by DPO-1 is frequency-dependent. Frequencydependent block of cloned $\mathrm{K}_{\mathrm{v}} 1.5$ with application of DPO-1 has been demonstrated (Du et al., 2010; Lagrutta et al., 2006). This is also known as use- or rate-dependent block and is an ideal characteristic for $\mathrm{K}^{+}$channel inhibitors used to treat atrial fibrillation, as block becomes more effective as the rate of fibrillation increases. We show frequencydependent block of smooth muscle $\mathrm{K}_{\mathrm{DR}}$ by $1 \mu \mathrm{M}$ DPO-1 (Fig. 4). Membrane potential was stepped to $+20 \mathrm{mV}$. Current was steady at the control rate of $0.2 \mathrm{~Hz}$ stimulation and the effect of DPO-1 reached steady state quickly. In the continued presence of DPO-1, increasing the frequency of stimulation to 1 and then $2 \mathrm{~Hz}$ produced significantly more inhibition of current. Reducing stimulation frequency back to $0.2 \mathrm{~Hz}$ relieved the greater degree of channel block.

DPO-1 inhibits smooth muscle $K_{D R}$ in the open state. Open state block of cloned $\mathrm{K}_{\mathrm{v}} 1.5$ by DPO-1 has been shown (Lagrutta et al., 2006). Specifically, Lagrutta et al. demonstrated that when cloned $\mathrm{K}_{\mathrm{V}} 1.5$ channels were treated with DPO-1, they would open and produce current to the untreated level instantaneously; however, when channels were open in the presence of drug, current rapidly decreased. Further, the degree of channel block increased to steady state over the next few trials. Fig. 5 shows what we describe as a 'partial' open state block of $K_{D R}$ by DPO-1 in coronary smooth muscle. The block is 'partial' open state block, because the current elicited by the first stimulus in the presence of DPO-1 is approximately $70 \%$ of the control, untreated peak. Current is not maximally blocked by DPO-1 until several more cycles of stimulation have occurred. Our results are more like those of Du et al. who showed that DPO-1 produced an initial instantaneous block of approximately 30\% (Du et al., 2010). They suggested 
that the initial instantaneous block might represent an extremely fast phase of open channel block followed by a second slow phase of block.

$D P O-1$ affects the kinetics of $K_{D R}$ channels in smooth muscle. Figure 6 shows the effect of $1 \mu \mathrm{M}$ DPO-1 on the activation time constant (т) during a $350 \mathrm{~ms}+20 \mathrm{mV}$ stimulus. DPO-1 induces a small but significant acceleration in activation т ( $8.5 \pm 1.1$ vs. $6.8 \pm 0.6 \mathrm{~ms} ; \mathrm{p}<0.05$; Fig. $6 \mathrm{C}$ ). Figure $6 \mathrm{D}$ shows that $1 \mu \mathrm{M}$ DPO-1 abolished tail currents; therefore, deactivation kinetics could not be analyzed. This also precluded our inspection of tail current 'crossover', another indicator of open state block.

DPO-1 significantly accelerated both the fast and slow components of inactivation (Figure 7C and D; control (fast) $=519 \pm 74 \mathrm{~ms}$ vs. DPO-1 (fast) $=141 \pm 10$ $\mathrm{ms}$, control $($ slow $)=5,757 \pm 1,071 \mathrm{~ms}$ vs. DPO-1 (slow) $=601 \pm 222 \mathrm{~ms} ; \mathrm{p}<0.05)$ during a five-second, $+20 \mathrm{mV}$ pulse (Figure 7A). The two components were fit simultaneously with a bi-exponential equation to produce a fast and slow inactivation $\mathrm{T}$ in the presence and absence of $1 \mu \mathrm{M}$ DPO-1 (Figure 7B).

The recovery currents shown in Figure $8 \mathrm{~A}$ were produced by a five-second +20 $\mathrm{mV}$ conditioning pulse followed by a $300 \mathrm{~ms}$ test pulse. Each new test pulse was another $300 \mathrm{~ms}$ further from the conditioning pulse (denoted by $\Delta \mathrm{t}$ in the voltage template) in order to investigate the time for $\mathrm{K}_{\mathrm{DR}}$ to return after conditioned inactivation in the presence of DPO-1. DPO-1 reduced recovery currents and prolonged reactivation kinetics (320 \pm 10 vs. $910 \pm 107 \mathrm{~ms} ; \mathrm{p}<0.05)$ extrapolated from this protocol. 


\section{Discussion}

The aim of the current study was to investigate porcine VSM $K_{V}$ channel kinetics and current inhibition when challenged with DPO-1 using whole cell voltage clamp electrophysiology and compare our findings to known effects of DPO-1 on cloned $\mathrm{K}_{\mathrm{V}} 1.5$ patch analyses, thereby acknowledging both the specificity of DPO-1 for $\mathrm{K}_{\mathrm{v}} 1.5$ and the presence of $\mathrm{K}_{\mathrm{V}} 1.5$ in porcine coronary VSM. Our data suggest that DPO-1 blocks porcine coronary VSM $I_{D R}$ by shifting activation and inactivation currents to more polarized potentials and affects the kinetics of VSM $I_{D R}$ by binding in the open and inactivated state of $\mathrm{K}_{\mathrm{V}} 1.5$ containing channels.

$\mathrm{K}_{\mathrm{v}} 1.5$ is a popular candidate for setting $\mathrm{E}_{\mathrm{m}}$ and therefore resting arterial tone especially in the pulmonary circulation due to its role in oxygen sensing (Archer et al., 1998; Archer et al., 2004; Grissmer et al., 1994; Moudgil, Michelakis, \& Archer, 2006). However, such a role for $\mathrm{K}_{\mathrm{v}} 1.5$ in other vascular beds, including the coronary circulation, is less established. Resting coronary flow is tightly regulated because the highly aerobic cardiac cells are in constant demand of supply, making $I_{D R}$ channels extremely important end effectors in maintaining sufficient resting tone. These end effectors, most likely $\mathrm{K}_{\mathrm{V}} 1$ channels, also provide hyperpolarizing currents to allow for coronary reserve under increased cardiac metabolic activity (Berwick et al., 2012).

The molecular identities of the $\mathrm{K}_{\mathrm{V}}$ channels that drive $\mathrm{I}_{\mathrm{DR}}$ and therefore govern resting membrane potential and arterial tone remain unclear. This is due, in part, to a lack of specific pharmacology for individual $K_{V}$ channel members, however evidence for the $\mathrm{K}_{\mathrm{v}} 1$ subfamily has been supported through the use of correolide (Albarwani et al., 2003; Archer et al., 2004; Cheong, Dedman, \& Beech, 2001; Dick et al., 2008; Plane et 
al., 2005), which will block all $\mathrm{K}_{\mathrm{v}} 1$ members. In arterial smooth muscle, the expression of $\mathrm{K}_{\mathrm{v}} 1.5$ has been observed in the microvasculature as well as in conduit-like arteries but so too has other $K_{V}$ channels, including other $K_{V} 1$ members (Plane et al., 2005; Thorneloe et al., 2001), making discerning which channels regulate arterial tone in specific vascular beds difficult to interpret.

The present study supports a role for $\mathrm{K}_{\mathrm{V}} 1.5$ in the regulation of coronary VSM based on similarities between our data in native VSM and other analyses of cloned $\mathrm{K}_{\mathrm{V}} 1.5$ channel block by DPO-1. We report a dose-dependent block of porcine coronary VSM $I_{D R}$ by DPO-1 and a left shift in the voltage window of activation. Inhibition of VSM IDR was voltage and frequency dependent, hallmarks of open state block previously shown to be the mechanism of block by DPO-1 on cloned $\mathrm{K}_{\mathrm{v}} 1.5$. However, we report a 'partial' open state block that is not in line with inhibition of cloned $\mathrm{K}_{v} 1.5$ by DPO-1. Our data indicate that the mechanism of DPO-1 inhibition of porcine coronary VSM $I_{D R}$ is by accelerating activation and inactivation kinetics and prolonging reactivation kinetics by binding in the open and inactivated state of channels containing $\mathrm{K}_{v} 1.5$. These findings support the use of DPO-1 as a tool for investigating a role for $\mathrm{K}_{\mathrm{v}} 1.5$ in arterial smooth muscle. Furthermore, we suggest that the disparities between the present data and that of cloned $\mathrm{K}_{\mathrm{V}} 1.5$ support the hypothesis of heteromultimer $\mathrm{K}_{V}$ channel complexes in arterial smooth muscle.

Recently, $\mathrm{K}_{\mathrm{V}} 1.5$ specific drugs such as DPO-1 used in the present study, have been synthesized with the goal of treating atrial fibrillation by blocking the $1 \mathrm{~K}_{\mathrm{ur}}$ component of the atrial action potential. Du et al. showed whole cell patch clamp of cloned human $\mathrm{K}_{\mathrm{v}} 1.5$ channels expressed in xenopus laevis oocytes and pulsed at +40 
mV exhibited an $\mathrm{IC}_{50}$ of approximately $780 \mathrm{nM}$ (Du et al., 2010). However, Lagrutta et al showed in the same expression system that the $\mathrm{IC}_{50}$ of DPO-1 for human cloned $\mathrm{K}_{\mathrm{V}} 1.5$ is approximately $160 \mathrm{nM}$ at a low stimulation frequency (Lagrutta et al., 2006). In our dose-response experiments of whole cell voltage clamp in porcine coronary VSM (Fig. 1), we pulsed at $+20 \mathrm{mV}$ at a stimulation frequency of $0.2 \mathrm{~Hz}$, which produced an $\mathrm{IC}_{50}$ for DPO-1 of $212 \pm 28 \mathrm{nM}$, which is in accordance with Lagrutta and colleagues. Block of porcine coronary VSM by DPO-1 is reversible upon washout and has been shown previously in these studies on cloned human $\mathrm{K}_{\mathrm{v}} 1.5$.

In many studies investigating open state block of $\mathrm{K}_{\mathrm{v}} 1.5$, drugs did not influence the voltage sensitivity with regard to activation (Du et al., 2010; Jeong, Choi, \& Hahn, 2013; Jeong, Choi, Yoon, \& Hahn, 2012; Jeong, Yoon, \& Hahn, 2012) yet we report a significant left shift at 0 and $-10 \mathrm{mV}$ in coronary VSM whole cell patch clamp experiments (Fig 2), which would indicate an increase in voltage sensitivity associated with agonists of voltage sensitive channels. While this may be an artifact of our calculations in correcting for driving force from step potentials in lieu of abolished tail currents, we suggest that DPO-1 exhibits a dose dependent "foot in the door" effect as an open channel blocker. Du et al. show a left shift of $V_{1 / 2}$ activation from $-3.7 \mathrm{mV}$ to $8.1 \mathrm{mV}$ with application of $30 \mu \mathrm{M}$ DPO-1. Similarly, in our studies using $1 \mu \mathrm{M}$ DPO-1, a shift of the $V_{1 / 2}$ activation from $-3.8 \mathrm{mV}$ to $-9.3 \mathrm{mV}$ was observed. This data supports the specificity of DPO-1 for $\mathrm{K}_{\mathrm{V}} 1.5$ in porcine coronary VSM and is similar to activation curves investigating drug-induced tail current crossover of cloned $\mathrm{K}_{\mathrm{v}} 1.5$ (Du et al., 2010). However, we are aware that we cannot show evidence of the "foot in the door" 
effect without first observing tail current crossover (Fig. 6) and plan to repeat these experiments with submicromolar concentrations of DPO-1.

Inactivation curves were produced by a two-pulse protocol to observe the inactivation currents (see the Figure 2 legend for further details). Because our experiments were conducted in native cells, a variety of $\mathrm{K}_{V}$ channel inactivating influences are present and therefore the control inactivation curve does not match $\mathrm{K}_{\mathrm{V}} 1.5$ positive to $+10 \mathrm{mV}$. The application of $1 \mu \mathrm{M}$ DPO-1 significantly left shifts the $\mathrm{V}_{1 / 2}$ from $10.9 \mathrm{mV}$ to $-14.6 \mathrm{mV}$ and induces complete inactivation by approximately $+10 \mathrm{mV}$. The shift of inactivation to more polarized potentials is in accordance with many other $K_{v} 1.5$ open state blockers including lobeline, dapoxetine, and pergolide tested in a series of publications by Hahn and colleagues (Jeong et al., 2013; Jeong, Choi, et al., 2012; Jeong, Yoon, et al., 2012). In addition, DPO-1 has been shown to interact with at least six residues of the $\mathrm{S} 4$ voltage-sensing segment of activated $\mathrm{K}_{\mathrm{v}} 1.5$ channels (Du et al., 2010), supporting the observed effects in voltage sensitive curves and our hypothesis that DPO-1 is inhibiting $\mathrm{K}_{\mathrm{V}} 1.5$ channels in porcine coronary VSM. Together, activation and inactivation curves show that DPO-1 shifts, and in our two-pulse protocol reduces, the voltage window of activation to more polarized potentials (Fig.2), suggesting that DPO-1 may be inhibiting $\mathrm{K}_{\mathrm{V}} 1.5$ channels of porcine coronary VSM in the open and inactivated states.

The voltage dependent block of cloned $\mathrm{K}_{\mathrm{V}} 1.5$ and $\mathrm{IK}_{\mathrm{ur}}$ by DPO-1 is well established (Du et al., 2010; Lagrutta et al., 2006) and was the basis for investigating voltage dependency of DPO-1 in native porcine coronary VSM. In addition, our observations of the decreased and left shifted voltage window of activation (Fig. 2) prompted our 
investigation of coronary VSM voltage dependent block by DPO-1. DPO-1 produced a similar, although left shifted, window of voltage dependent inhibition of coronary VSM (Fig. 3) as compared to previous work by Du et al. where the voltage window of block by $300 \mathrm{nM}$ DPO-1 was $0 \mathrm{mV}$ to $+20 \mathrm{mV}$ in cloned human $\mathrm{K}_{\mathrm{V}} 1.5$ (Du et al., 2010). We suggest this difference in voltage window block may be due to the concentrations used, however, we did not analyze our lower concentration (100 nM) at more positive potentials where we may have observed a similar result to other studies. Our finding that $1 \mu \mathrm{M}$ DPO- 1 exhibits a voltage dependent block in the window of $-20 \mathrm{mV}$ to $0 \mathrm{mV}$ is in line with the voltage window of activation produced by DPO-1 (approximately $-30 \mathrm{mV}$ to $+10 \mathrm{mV}$ ) in the present study (Fig. 2). $\mathrm{K}_{\mathrm{V}} 1.5$ is activated in this range of potentials. Therefore, we interpret the block by DPO- 1 in the activation window of coronary VSM $\mathrm{I}_{\mathrm{DR}}$ as corresponding to block of $\mathrm{K}_{\mathrm{v}} 1.5$, which supports the use of DPO-1 to investigate $\mathrm{K}_{\mathrm{V}} 1.5$ channels in native coronary VSM.

Frequency dependent block by DPO- 1 on cloned $\mathrm{K}_{\mathrm{V}} 1.5$ channels has also been shown to increase the potency of inhibition (Du et al., 2010; Lagrutta et al., 2006). We show a frequency dependent block by DPO-1 in porcine coronary VSM (Fig. 4) similar to that which Lagrutta et al. and Du et al. showed on cloned human $\mathrm{K}_{\mathrm{v}} 1.5$ expressed in $x$. laevis oocytes. In the present study, we used $1 \mu \mathrm{M}$ DPO-1 and a maximum stimulation frequency of $2 \mathrm{~Hz}$ to show the frequency dependent block of coronary VSM $\mathrm{I}_{\mathrm{DR}}$. In the study by Du et al., $300 \mathrm{nM}$ DPO-1 reduced $\mathrm{K}_{\mathrm{V}} 1.5$ currents at only $0.66 \mathrm{~Hz}$ beyond control currents at $3 \mathrm{~Hz}$. In comparison to our data in native smooth muscle, 1 $\mu \mathrm{M}$ DPO-1 at a stimulation frequency of $.2 \mathrm{~Hz}$ does not significantly reduce currents beyond control currents stimulated at $2 \mathrm{~Hz}$. Lagrutta et al. show that $1 \mu \mathrm{M}$ DPO-1 
abolishes $\mathrm{K}_{\mathrm{v}} 1.5$ current at $1 \mathrm{~Hz}$. Under the same conditions in our study, we observe $>60 \%$ block by DPO-1. We interpret the differences between our investigation of DPO-1 on native coronary smooth muscle and that of the studies examining cloned $\mathrm{K}_{\mathrm{V}} 1.5$ to mean that $1 \mu \mathrm{M}$ DPO- 1 is specific to $\mathrm{K}_{\mathrm{V}} 1.5$ over other $\mathrm{K}_{\mathrm{V}}$ currents present in the native system i.e. $1 \mu \mathrm{M}$ DPO-1 does not reduce current to zero at $2 \mathrm{~Hz}$.

We suggest that the voltage and frequency dependent inhibition observed in the present study is due to block of $\mathrm{K}_{\mathrm{V}} 1.5$ currents and that is supported by studies investigating the atrial action potential, including selectivity for $I_{\mathrm{ur}}$ over $I_{\mathrm{to}}, I_{\mathrm{K} 1}, I_{\mathrm{Kr}}, I_{\mathrm{Ks}}$ (Lagrutta et al., 2006). However, DPO-1 has recently been shown to inhibit $\mathrm{K}_{v} 1.3$ channels, also expressed in arterial smooth muscle, in human T cells (Zhao et al., 2013). While we used a concentration less than the calculated $I C_{50}$ of 2-3 $\mu \mathrm{M}$ in the study on $\mathrm{K}_{\mathrm{v}} 1.3$, we acknowledge that we may be inhibiting other $\mathrm{K}_{\mathrm{V}} 1$ channels at $1 \mu \mathrm{M}$ DPO-1. Currently, a more collective knowledge regarding the effect of DPO-1 on non$\mathrm{K}_{\mathrm{v}} 1.5 \mathrm{~K}_{\mathrm{v}} 1$ delayed rectifier current is lacking, however, it remains a useful tool for the investigation of VSM delayed rectifying current. Furthermore, it is our supposition that at lesser concentrations DPO- 1 is an appropriate tool to exclusively study $\mathrm{K}_{\mathrm{v}} 1.5$ in native cells including VSM.

Open state block of $\mathrm{K}_{\mathrm{V}}$ channels by a variety of drugs is well established and DPO-1 exhibits such a mechanism on $\mathrm{K}_{\mathrm{v}} 1.5$ as supported by the voltage and frequency dependent block, as well as tail current crossover, shown in previous studies (Du et al., 2010; Lagrutta et al., 2006). A more direct approach for investigating the open state block of human cloned $\mathrm{K}_{\mathrm{v}} 1.5$ by DPO- 1 was performed by Lagrutta et al. in outside-out patch experiments. Application of $1 \mu \mathrm{M}$ DPO-1 for five minutes after recording control 
currents revealed that the subsequent pulse reached control peak current levels. Additional pulses showed complete block by DPO-1. We repeated this experiment in whole cell patches of porcine coronary VSM in the present study (Fig. 5). After five minutes incubation with $1 \mu \mathrm{M}$ DPO-1 we observed an approximately $30 \%$ block from control currents with the initial pulse, which is at odds with Lagrutta et al. in cloned $\mathrm{K}_{\mathrm{V}} 1.5$ outside-out patches. Furthermore, the subsequent pulses did not immediately reach full block as in the comparison study. While these differences between our current study and those conducted by Lagrutta et al. are unlikely due to patch configurations, we do however acknowledge the possibility of native $\beta$ auxiliary subunits or heterotetrameric complexes containing $\mathrm{K}_{\mathrm{v}} 1.5$. Evidence for such complexes have been supported in a series of publications by Cole and colleagues and suggests that the underlying molecular identity of $\mathrm{I}_{\mathrm{DR}}$ conducting $\mathrm{K}_{\mathrm{V}}$ channels in arterial smooth muscle is likely that of $\mathrm{K}_{\mathrm{v}} 1.5$ and $\mathrm{K}_{\mathrm{v}} 1.2$ containing channels (Kerr et al., 2001; Plane et al., 2005; Thorneloe et al., 2001). It could therefore be possible that heterotetrameric channels could change the interaction of DPO- 1 with $\mathrm{K}_{\mathrm{v}} 1.5$ and thusly modify the conditions of open state block, complicating our investigation of open state block by DPO-1 in native arterial smooth muscle. Our group is considering further examination of the effects of DPO-1 on cloned $\mathrm{K}_{\mathrm{v}} 1.5-\mathrm{K}_{\mathrm{V}} 1.2$ complexes.

The effects of DPO-1 on porcine coronary VSM IDR kinetics were extrapolated from whole-cell patch clamp data in the present study and include activation, fast and slow inactivation, and recovery from inactivation. To our knowledge, the effect of DPO-1 on $\mathrm{K}_{\mathrm{V}} 1.5$ activation $\mathrm{T}$ has not been investigated. We show that DPO-1 accelerates the activation T of porcine coronary VSM (Fig. 6). Similarly, studies investigating the effects 
of polyunsaturated fatty acids on $\mathrm{K}_{\mathrm{v}} 1.5$ have shown increased activation kinetics coupled to the inhibition of current (Guizy et al., 2008; McKay \& Worley, 2001). These studies suggest that polyunsaturated fatty acids may be reducing the free energy needed for $K_{v} 1.5$ to open thus accelerating channel opening. This would correspond to a left shift in the $V_{1 / 2}$, and may explain the mechanism as to how DPO-1 is accelerating activation of $I_{D R}$ channels in our study. We also observed accelerated components of inactivation. Co-expression of $\mathrm{K}_{\mathrm{v}} \beta 1.3$ with $\mathrm{K}_{\mathrm{v}} 1.5$ results in a fast and slow component of inactivation (Tipparaju et al., 2012) and this association is plausible as $K_{v} \beta 1.3$ is expressed in arterial smooth muscle (Thorneloe et al., 2001). We successfully fit a biexponential function to the traces in the current study during inactivation of $\mathrm{K}_{\mathrm{V}}$ channels, perhaps supporting evidence of auxiliary $\beta$ subunit association with $\mathrm{K}_{\mathrm{v}} 1.5 \alpha$ pore. Both the fast and slow $\mathrm{T}$ of inactivation were robustly and significantly accelerated by DPO-1 and we suggest this to be the prominent mechanism of VSM IDR inhibition. $\mathrm{K}_{\mathrm{V}} 1.5$ exhibits a $\mathrm{P} / \mathrm{C}$ type inactivation where $\mathrm{N}$-terminal $\mathrm{T}$-domains are expected to promote slow inactivation of the channel (Kurata et al., 2002). Modulation of residues of the T-domain results in the switching from P/C to U-type inactivation (Kurata, Doerksen, Eldstrom, Rezazadeh, \& Fedida, 2005). While the expected residues of DPO-1 interaction with $\mathrm{K}_{\mathrm{v}} 1.5$ have been shown to be in the $\mathrm{S} 4$ voltage-sensing segment (Du et al., 2010), the left shift of inactivation curves upon application of DPO-1 also appears to mimic T-domain modulation. Based on this observation, we hypothesize a mode of inhibition by DPO-1 where slow inactivation components of the T-domain are prevented from usual gating mechanics. 


\section{References}

Albarwani, S., Nemetz, L. T., Madden, J. A., Tobin, A. A., England, S. K., Pratt, P. F., \& Rusch, N. J. (2003). Voltage-gated K+ channels in rat small cerebral arteries: molecular identity of the functional channels. J Physiol, 551(Pt 3), 751-763. doi: 10.1113/jphysiol.2003.040014

Archer, S. L., Souil, E., Dinh-Xuan, A. T., Schremmer, B., Mercier, J. C., El Yaagoubi, A., . . Hampl, V. (1998). Molecular identification of the role of voltage-gated K+ channels, Kv1.5 and Kv2.1, in hypoxic pulmonary vasoconstriction and control of resting membrane potential in rat pulmonary artery myocytes. J Clin Invest, 101(11), 2319-2330. doi: 10.1172/JCI333

Archer, S. L., Wu, X. C., Thebaud, B., Nsair, A., Bonnet, S., Tyrrell, B., . . Michelakis, E. D. (2004). Preferential expression and function of voltage-gated, O2-sensitive $\mathrm{K}+$ channels in resistance pulmonary arteries explains regional heterogeneity in hypoxic pulmonary vasoconstriction: ionic diversity in smooth muscle cells. Circ Res, 95(3), 308-318. doi: 10.1161/01.RES.0000137173.42723.fb

Berwick, Z. C., Dick, G. M., Moberly, S. P., Kohr, M. C., Sturek, M., \& Tune, J. D. (2012). Contribution of voltage-dependent $\mathrm{K}(+)$ channels to metabolic control of coronary blood flow. J Mol Cell Cardiol, 52(4), 912-919. doi: 10.1016/j.yjmcc.2011.07.004 
Brendel, J., \& Peukert, S. (2003). Blockers of the Kv1.5 channel for the treatment of atrial arrhythmias. Curr Med Chem Cardiovasc Hematol Agents, 1(3), 273-287.

Chen, T. T., Luykenaar, K. D., Walsh, E. J., Walsh, M. P., \& Cole, W. C. (2006). Key role of Kv1 channels in vasoregulation. Circ Res, 99(1), 53-60. doi: 10.1161/01.RES.0000229654.45090.57

Chen, Y. H., Xu, S. J., Bendahhou, S., Wang, X. L., Wang, Y., Xu, W. Y., . . Huang, W. (2003). KCNQ1 gain-of-function mutation in familial atrial fibrillation. Science, 299(5604), 251-254. doi: 10.1126/science.1077771

Cheong, A., Dedman, A. M., \& Beech, D. J. (2001). Expression and function of native potassium channel $[\mathrm{K}(\mathrm{V})$ alpha1] subunits in terminal arterioles of rabbit. $J$ Physiol, 534(Pt 3), 691-700.

Dick, G. M., Bratz, I. N., Borbouse, L., Payne, G. A., Dincer, U. D., Knudson, J. D., . . . Tune, J. D. (2008). Voltage-dependent $\mathrm{K}+$ channels regulate the duration of reactive hyperemia in the canine coronary circulation. Am J Physiol Heart Circ Physiol, 294(5), H2371-2381. doi: 10.1152/ajpheart.01279.2007

Du, Y. M., Zhang, X. X., Tu, D. N., Zhao, N., Liu, Y. J., Xiao, H., . . Liao, Y. H. (2010). Molecular determinants of Kv1.5 channel block by diphenyl phosphine oxide-1. J Mol Cell Cardiol, 48(6), 1111-1120. doi: 10.1016/j.yjmcc.2010.02.010 
Grissmer, S., Nguyen, A. N., Aiyar, J., Hanson, D. C., Mather, R. J., Gutman, G. A., . . Chandy, K. G. (1994). Pharmacological characterization of five cloned voltagegated $\mathrm{K}+$ channels, types $\mathrm{Kv} 1.1,1.2,1.3,1.5$, and 3.1 , stably expressed in mammalian cell lines. Mol Pharmacol, 45(6), 1227-1234.

Guizy, M., David, M., Arias, C., Zhang, L., Cofan, M., Ruiz-Gutierrez, V., . . . Valenzuela, C. (2008). Modulation of the atrial specific Kv1.5 channel by the $n-3$ polyunsaturated fatty acid, alpha-linolenic acid. J Mol Cell Cardiol, 44(2), 323335. doi: 10.1016/j.yjmcc.2007.11.004

Jeong, I., Choi, B. H., \& Hahn, S. J. (2013). Pergolide block of the cloned Kv1.5 potassium channels. Naunyn Schmiedebergs Arch Pharmacol, 386(2), 125-133. doi: $10.1007 / \mathrm{s} 00210-012-0776-5$

Jeong, I., Choi, B. H., Yoon, S. H., \& Hahn, S. J. (2012). Carvedilol blocks the cloned cardiac Kv1.5 channels in a beta-adrenergic receptor-independent manner. Biochem Pharmacol, 83(4), 497-505. doi: 10.1016/j.bcp.2011.11.019

Jeong, I., Yoon, S. H., \& Hahn, S. J. (2012). Effects of dapoxetine on cloned Kv1.5 channels expressed in $\mathrm{CHO}$ cells. Naunyn Schmiedebergs Arch Pharmacol, 385(7), 707-716. doi: 10.1007/s00210-012-0754-y

Kerr, P. M., Clement-Chomienne, O., Thorneloe, K. S., Chen, T. T., Ishii, K., Sontag, D. P., . . Cole, W. C. (2001). Heteromultimeric Kv1.2-Kv1.5 channels underlie 4- 
aminopyridine-sensitive delayed rectifier $\mathrm{K}(+)$ current of rabbit vascular myocytes. Circ Res, 89(11), 1038-1044.

Kurata, H. T., Doerksen, K. W., Eldstrom, J. R., Rezazadeh, S., \& Fedida, D. (2005). Separation of $\mathrm{P} / \mathrm{C}$ - and U-type inactivation pathways in $\mathrm{Kv} 1.5$ potassium channels. J Physiol, 568(Pt 1), 31-46. doi: 10.1113/jphysiol.2005.087148

Kurata, H. T., Soon, G. S., Eldstrom, J. R., Lu, G. W., Steele, D. F., \& Fedida, D. (2002). Amino-terminal determinants of U-type inactivation of voltage-gated $\mathrm{K}+$ channels. J Biol Chem, 277(32), 29045-29053. doi: 10.1074/jbc.M111470200

Lagrutta, A., Wang, J., Fermini, B., \& Salata, J. J. (2006). Novel, potent inhibitors of

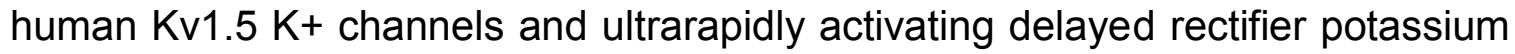
current. J Pharmacol Exp Ther, 317(3), 1054-1063. doi: 10.1124/jpet.106.101162

Mays, D. J., Foose, J. M., Philipson, L. H., \& Tamkun, M. M. (1995). Localization of the Kv1.5 K+ channel protein in explanted cardiac tissue. J Clin Invest, 96(1), 282292. doi: $10.1172 / \mathrm{JCl} 118032$

McKay, M. C., \& Worley, J. F., 3rd. (2001). Linoleic acid both enhances activation and blocks Kv1.5 and Kv2.1 channels by two separate mechanisms. Am J Physiol Cell Physiol, 281(4), C1277-1284. 
Moudgil, R., Michelakis, E. D., \& Archer, S. L. (2006). The role of k+ channels in determining pulmonary vascular tone, oxygen sensing, cell proliferation, and apoptosis: implications in hypoxic pulmonary vasoconstriction and pulmonary arterial hypertension. Microcirculation, 13(8), 615-632. doi: $10.1080 / 10739680600930222$

National Research Council. (2011). Guide for the Care and Use of Laboratory Animals: Eighth Edition: The National Academies Press.

Plane, F., Johnson, R., Kerr, P., Wiehler, W., Thorneloe, K., Ishii, K., . . . Cole, W. (2005). Heteromultimeric Kv1 channels contribute to myogenic control of arterial diameter. Circ Res, 96(2), 216-224. doi: 10.1161/01.RES.0000154070.06421.25

Regan, C. P., Wallace, A. A., Cresswell, H. K., Atkins, C. L., \& Lynch, J. J., Jr. (2006). In vivo cardiac electrophysiologic effects of a novel diphenylphosphine oxide IKur blocker, (2-Isopropyl-5-methylcyclohexyl) diphenylphosphine oxide, in rat and nonhuman primate. J Pharmacol Exp Ther, 316(2), 727-732. doi: 10.1124/jpet.105.094839

Stump, G. L., Wallace, A. A., Regan, C. P., \& Lynch, J. J., Jr. (2005). In vivo antiarrhythmic and cardiac electrophysiologic effects of a novel diphenylphosphine oxide IKur blocker (2-isopropyl-5-methylcyclohexyl) diphenylphosphine oxide. J Pharmacol Exp Ther, 315(3), 1362-1367. doi: 10.1124/jpet.105.092197 
Thorneloe, K. S., Chen, T. T., Kerr, P. M., Grier, E. F., Horowitz, B., Cole, W. C., \& Walsh, M. P. (2001). Molecular composition of 4-aminopyridine-sensitive voltagegated $\mathrm{K}(+)$ channels of vascular smooth muscle. Circ Res, 89(11), 1030-1037.

Tipparaju, S. M., Li, X. P., Kilfoil, P. J., Xue, B., Uversky, V. N., Bhatnagar, A., \& Barski, O. A. (2012). Interactions between the C-terminus of Kv1.5 and Kvbeta regulate pyridine nucleotide-dependent changes in channel gating. Pflugers Arch, 463(6), 799-818. doi: 10.1007/s00424-012-1093-z

Zhao, N., Dong, Q., Du, L. L., Fu, X. X., Du, Y. M., \& Liao, Y. H. (2013). Potent suppression of Kv1.3 potassium channel and IL-2 secretion by diphenyl phosphine oxide-1 in human $\mathrm{T}$ cells. PLoS One, 8(5), e64629. doi: 10.1371/journal.pone.0064629 
Figure 3.1

A
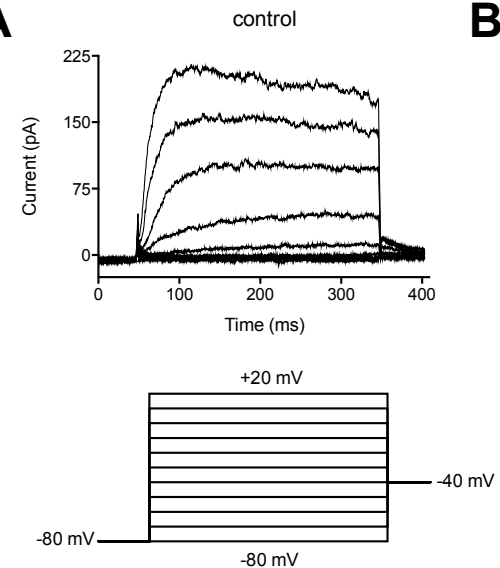

D

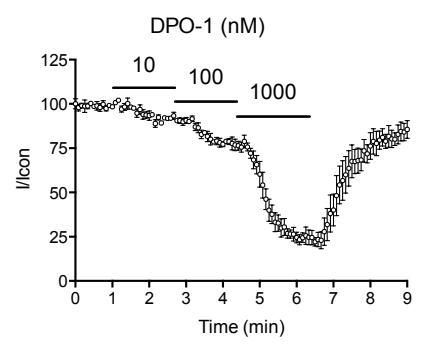

E
B
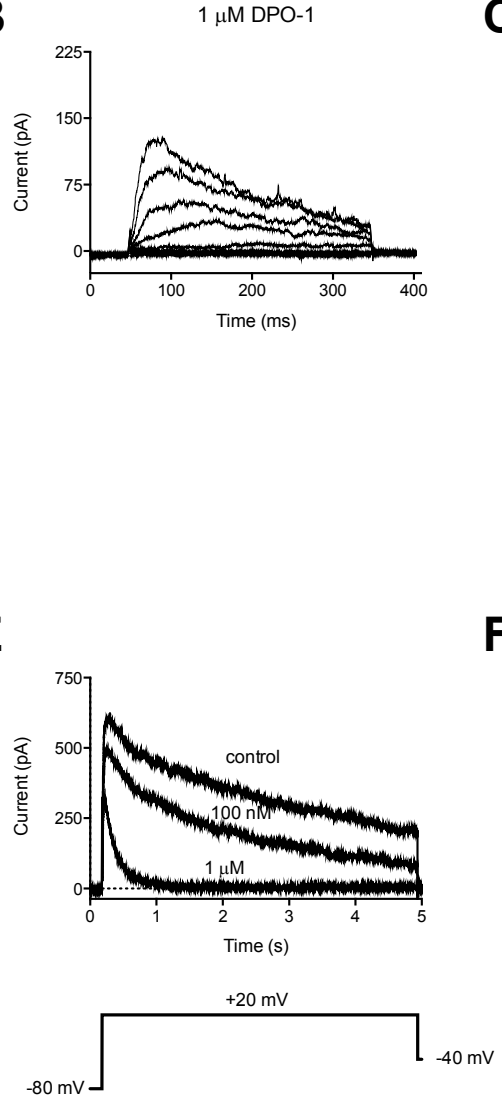

C

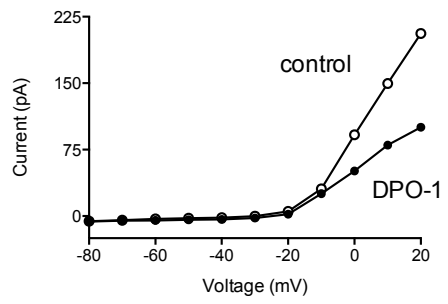

F

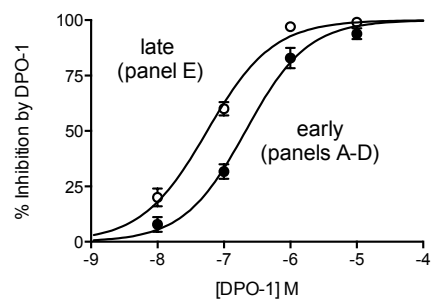


Figure 3.1 DPO-1 blocks $\mathrm{K}_{\mathrm{DR}}$ channels in a concentration-dependent manner. Panel $\mathrm{A}$ contains $\mathrm{K}_{\mathrm{DR}}$ current traces from a representative coronary smooth muscle cell when depolarized to $+20 \mathrm{mV}$. This $5 \mathrm{~s}$ trace illustrates the time-dependent inactivation of $K_{D R}$ current. Panel B shows group data $(n=5)$ demonstrating the concentration-dependent effect of DPO-1 to inhibit $K_{D R}$ current. Note that the effect of DPO-1 is largely reversible upon washout. Panel $\mathrm{C}$ holds group data $(n=3-8)$ for the concentration-response curve. 
Figure 3.2

A
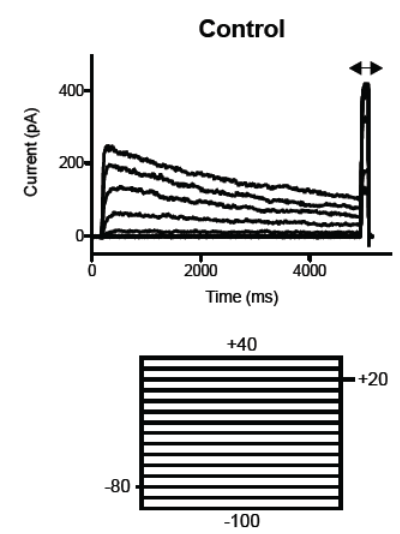

B
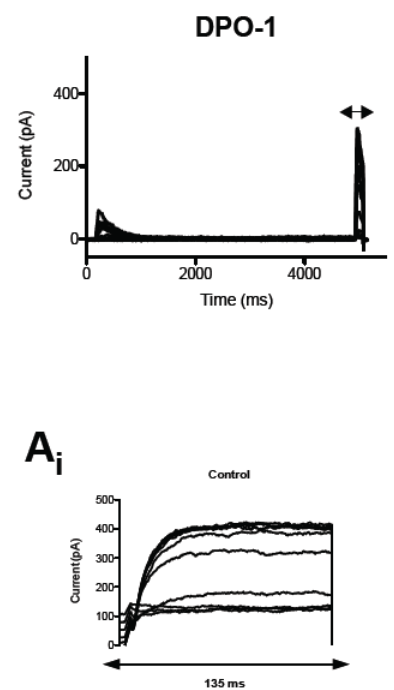

C
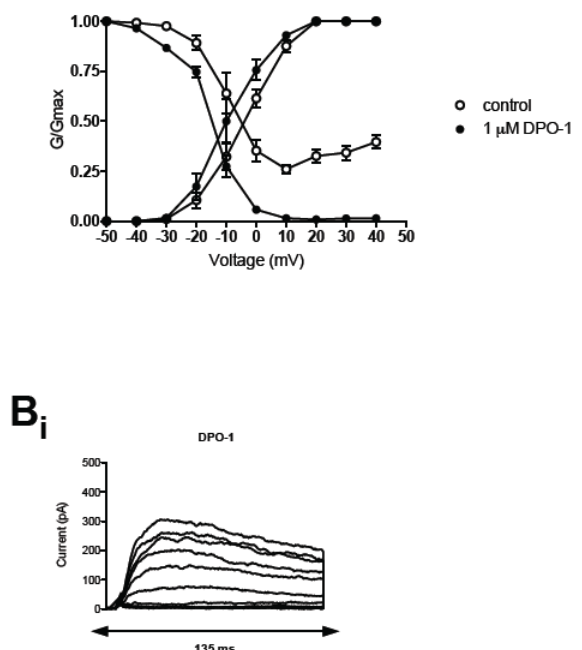
Figure 3.2 DPO-1 reduces the voltage window for the function of $K_{D R}$ channels. Panels A and B contain current traces from a representative coronary smooth muscle cell before and after treatment with $1 \mu \mathrm{M}$ DPO-1. The voltage protocol was designed to demonstrate voltage-dependent activation and inactivation. Activation was determined from the peak current near the beginning of the voltage stimuli (current was converted to conductance by considering voltage and the equilibrium potential for $\mathrm{K}^{+}$). The extent of voltage-dependent inactivation was determined by measuring current at the end of the voltage template when potential was $+20 \mathrm{mV}$. Panels $\mathrm{Ai}$ and $\mathrm{Bi}$ show the current at $+20 \mathrm{mV}$ on an expanded scale. Panel $\mathrm{C}$ contains the activation curves (rising from left to right) and inactivation curves (falling from left to right) before and after treatment with DPO-1. Note that DPO-1 produced a slight hyperpolarizing shift in the activation curve, which would serve to increase the voltage window. Importantly, however, this effect is overshadowed by a dramatic rightward shift and downward shift in the inactivation curve caused by DPO-1. That is, DPO-1 caused $K_{D R}$ channels to inactivate at more negative potentials and produced a much larger degree of inactivation. 
Figure 3.3

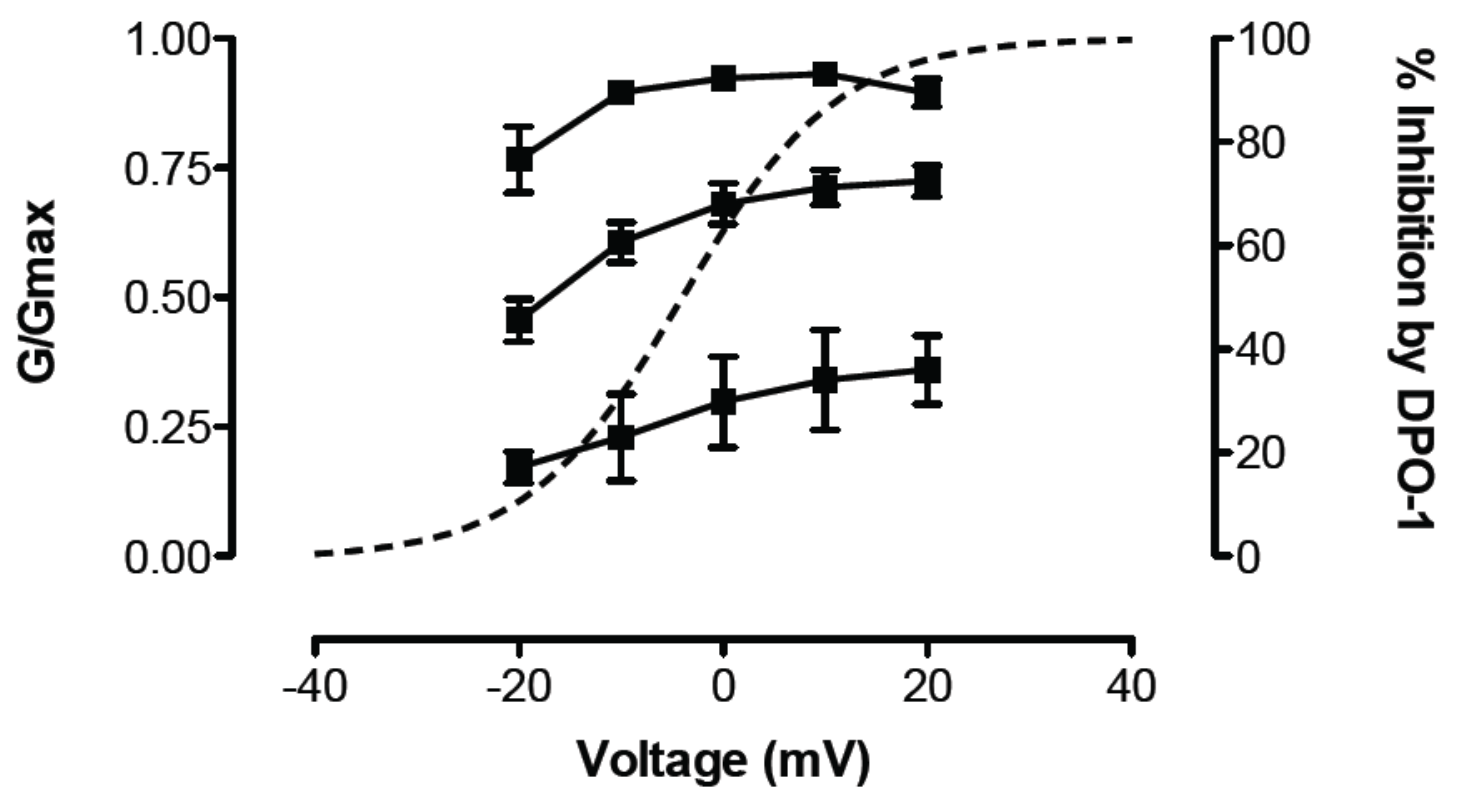


Figure 3.3 Modest voltage-dependence in the block of KDR channels by DPO-1. The percent inhibition for different concentrations (bottom to top: $100 \mathrm{nM}, 1 \mu \mathrm{M}$, and $10 \mu \mathrm{M}$ ) of DPO-1 is plotted on the activation curve of porcine coronary $K_{D R}$. Both $1 \mu \mathrm{M}$ and 10 $\mu \mathrm{M}$ DPO-1, but not $100 \mathrm{nM}$ DPO-1, show steep inhibition in the voltage window of -20 to $+20 \mathrm{mV}$. The curvilinear response at these concentrations indicates voltage dependent inhibition by DPO-1 in this range of potentials. 
Figure 3.4

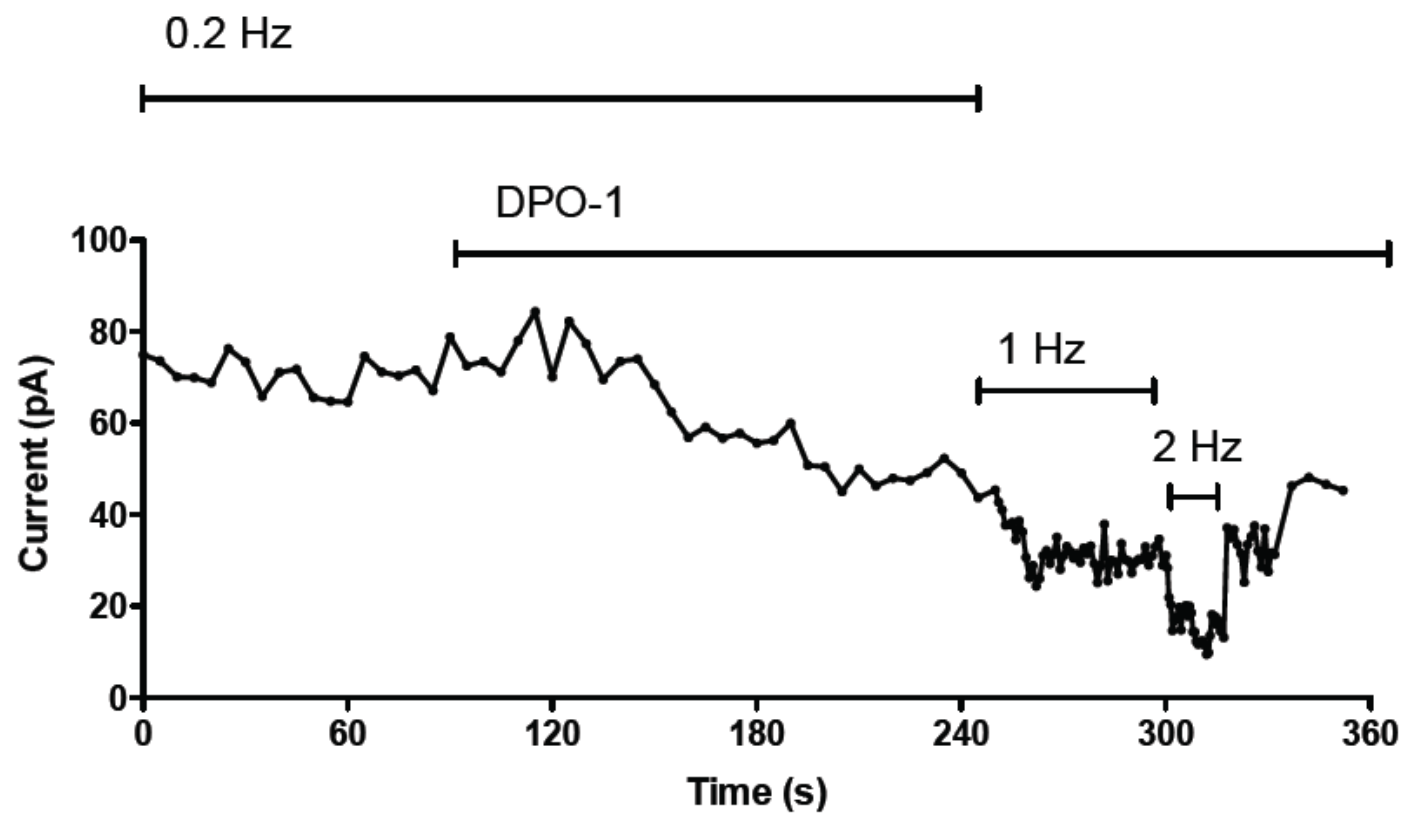


Figure 3.4 The degree to which DPO-1 inhibits $\mathrm{K}_{\mathrm{DR}}$ depends on stimulation rate. Increasing the frequency of $+20 \mathrm{mV}$ pulse appears to increase the ability of DPO-1 to block porcine KDR. This is in accordance with an open state block mechanism previously shown to occur with DPO- 1 and cloned $\mathrm{K}_{\mathrm{v}} 1.5$ channels. 
Figure 3.5

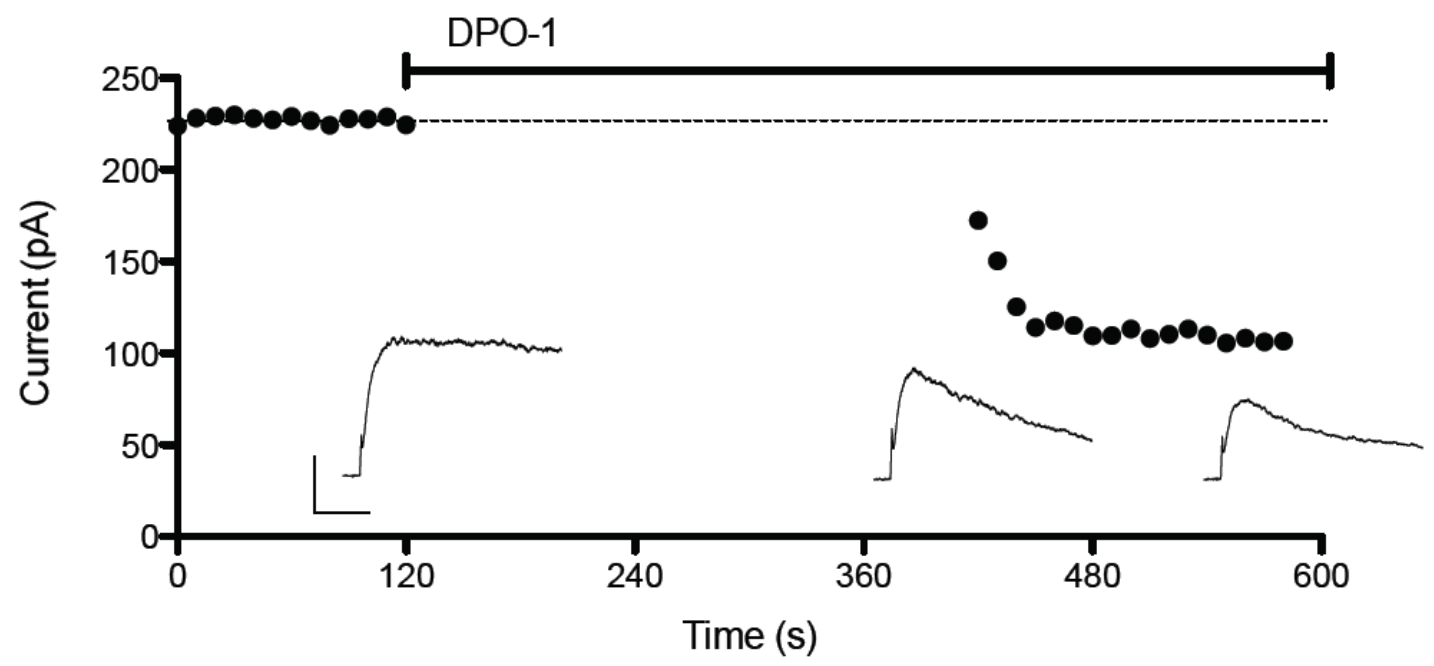


Figure 3.5 The block by DPO-1 requires, to some degree, that $K_{D R}$ channels open. We repeated the experiment performed by Lagrutta et al. in whole-cell patches of smooth muscle cells isolated from porcine coronary artery. Our data indicate that $1 \mu \mathrm{M}$ DPO-1 blocks a population of $\mathrm{K}_{\mathrm{DR}}$ channels in the open state. However, we do not observe a return to peak current after the initial stimulus following DPO-1 application suggesting a more complicated scenario in the native vs. cloned systems. 
Figure 3.6

A

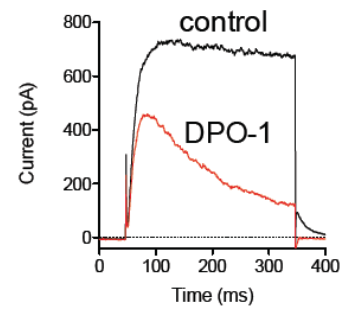

$20 \mathrm{mV}$

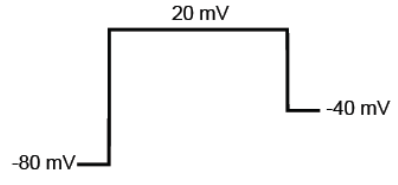

B

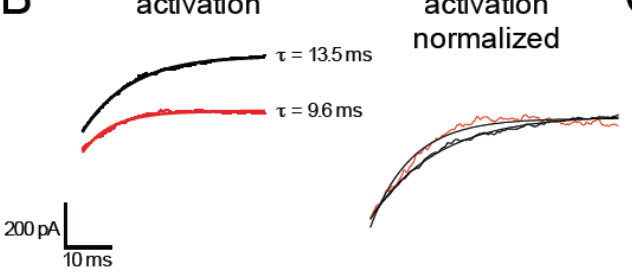

D deactivation

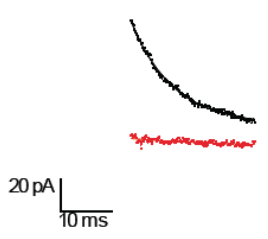


Figure 3.6 DPO-1 appears to increase the rate of time-dependent activation and abolishes $K_{D R}$ channel deactivation. Panel A shows a representative trace of $K_{D R}$ before and after DPO-1 application during a $+20 \mathrm{mV}$ pulse. $\mathrm{K}_{\mathrm{DR}}$ activation was fitted with a mono-exponential function to extrapolate the kinetics of channel opening. Panel B shows the representative ( $\mathrm{T}=13.5$ vs. $9.6 \mathrm{~ms})$ and normalized fits from Panel A. Panel $C$ is the group data and shows $1 \mu \mathrm{M}$ DPO- 1 accelerates activation kinetics $(p<0.05)$. This concentration of DPO-1 abolishes tail currents and therefore deactivation could not be compared (Panel D). 
Figure 3.7

A
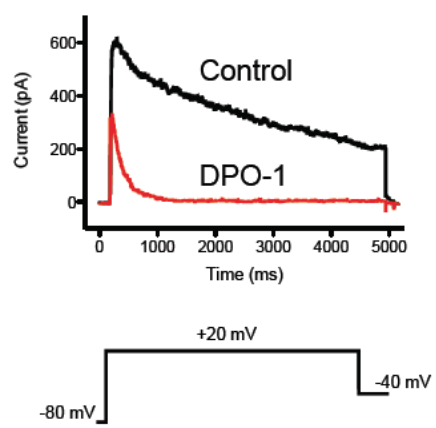

B

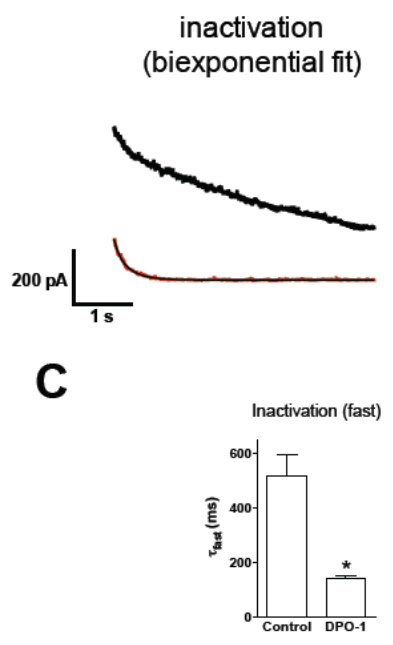

D

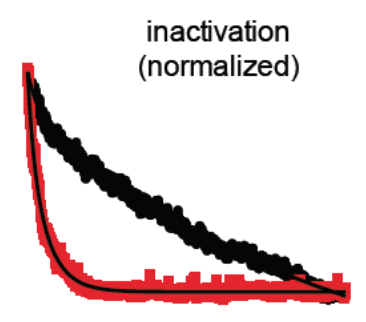

E

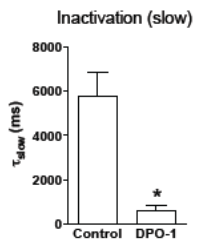


Figure 3.7 DPO-1 accelerates both components of time-dependent inactivation. Panel A shows a representative trace of a 5 second protocol used to observe the inactivation of porcine coronary smooth muscle $K_{D R}$ before and after $1 \mu \mathrm{M} D P O-1 . K_{D R}$ inactivation was fitted with a bi-exponential function to extrapolate both fast and slow components. 
Figure 3.8

A
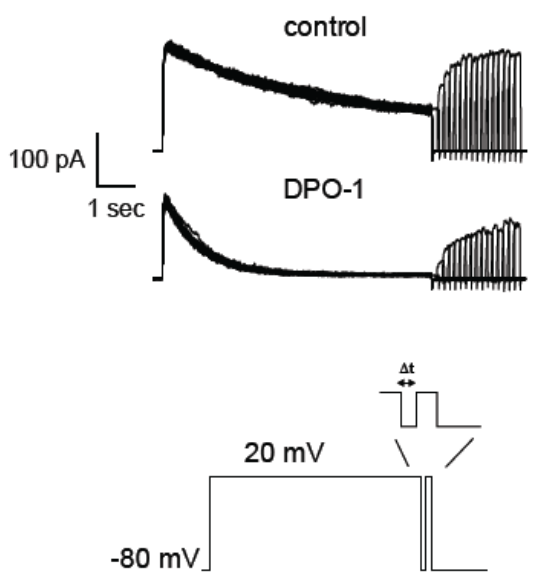

B

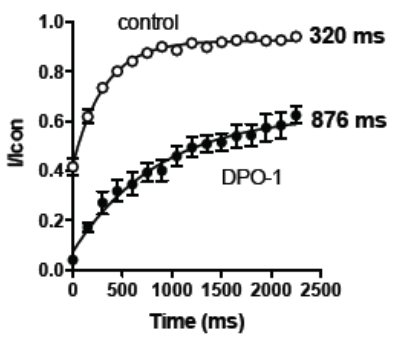

C

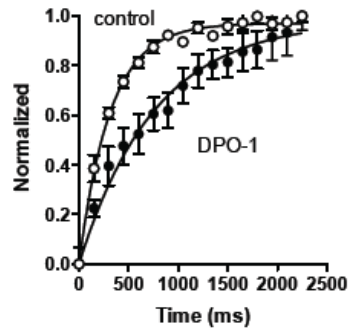


Figure 3.8 DPO-1 slows the recovery from inactivation. Panel A shows a representative trace where the voltage protocol allowed the investigation of the recovery from inactivation before and after $1 \mu \mathrm{M}$ DPO-1. Panel B shows the group data normalized to control currents and fit with a mono-exponential function to determine the kinetics of recovery $(320 \pm$ vs. $876 \pm \mathrm{ms})$. Panel $\mathrm{C}$ shows the within group normalized data and indicates DPO-1 significantly prolongs the recovery from inactivation $(p<0.05)$. 


\section{Chapter 4}

\section{Bisphenol A activates BK channels through effects on $\alpha$ and $\beta 1$ subunits}

As published in Channels (2014)

Trey S. Rottgen ${ }^{1 *}$, Ibra S. Fancher ${ }^{1 *}$, Shinichi Asano ${ }^{1}$, Theodore S. Widlanski ${ }^{2}$, and Gregory M. Dick ${ }^{1}$

${ }^{1}$ Department of Exercise Physiology

Center for Cardiovascular and Respiratory Sciences

West Virginia University School of Medicine

${ }^{2}$ Department of Chemistry

Indiana University

*These authors contributed equally

Short title: BPA-MS activates BK channels

Please address correspondence to:

Gregory M. Dick, Ph.D.

West Virginia University

1 Medical Center Drive

P.O. Box 9105

Morgantown, WV 26506-9105

Phone (304) 293-2542

Fax (304) 293-5513

Email gmdick@hsc.wvu.edu 


\section{Abstract}

We demonstrated previously that $\mathrm{BK}\left(\mathrm{K}_{\mathrm{Ca}} 1.1\right)$ channel activity $\left(\mathrm{NP}_{\mathrm{o}}\right)$ increases in response to bisphenol $\mathrm{A}$ (BPA). Moreover, $\mathrm{BK}$ channels containing regulatory $\beta 1$ subunits were more sensitive to the stimulatory effect of BPA. How BPA increases BK channel $\mathrm{NP}_{\mathrm{o}}$ remains mostly unknown. Estradiol activates $\mathrm{BK}$ channels by binding to an extracellular site, but neither the existence nor location of a BPA binding site has been demonstrated. We tested the hypothesis that an extracellular binding site is responsible for activation of BK channels by BPA. We synthesized membrane-impermeant BPAmonosulfate (BPA-MS) and used patch clamp electrophysiology to study channels composed of $\alpha$ or $\alpha+\beta 1$ subunits in cell-attached (C-A), whole-cell (W-C), and insideout (I-O) patches. In C-A patches, bath application of BPA-MS $(100 \mu \mathrm{M})$ had no effect on the $\mathrm{NP}_{\circ}$ of $\mathrm{BK}$ channels, regardless of their subunit composition. Importantly, however, subsequent addition of membrane-permeant BPA $(100 \mu \mathrm{M})$ increased the $\mathrm{NP}_{\mathrm{o}}$ of both $\alpha$ and $\alpha+\beta 1$ channels in C-A patches. The C-A data indicate that in order to alter $\mathrm{BK}$ channel $\mathrm{NP}_{\mathrm{o}}$, BPA must interact with the channel itself (or some closely associated partner) and diffusible messengers are not involved. In W-C patches, 100 $\mu \mathrm{M}$ BPA-MS activated current in cells expressing $\alpha$ subunits, whereas cells expressing $\alpha+\beta 1$ subunits responded similarly to a log-order lower concentration $(10 \mu \mathrm{M})$. The W-C data suggest that an extracellular activation site exists, but do not eliminate the possibility that an intracellular site may also be present. In I-O patches, where the cytoplasmic face was exposed to the bath, BPA-MS had no effect on the NPo of BK $\alpha$ subunits, but BPA increased it. BPA-MS increased the $\mathrm{NP}_{0}$ of $\alpha+\beta 1$ channels in I-O patches, but not as much as BPA. We conclude that BPA activates BK $\alpha$ via an 
extracellular site and that BPA-sensitivity is increased by the $\beta 1$ subunit, which may also constitute part of an intracellular binding site.

Keywords: $\mathrm{K}_{\mathrm{Ca}} 1.1$; KCNMA1; KCNMB1; endocrine disruptor; estrogen; non-genomic 


\section{Introduction}

Large conductance $\mathrm{Ca}^{2+} /$ voltage-activated $\mathrm{K}^{+}(\mathrm{BK})$ channels are expressed in the plasma membranes and intracellular organelles of numerous cell types.(Singh, Stefani, \& Toro, 2012) BK channels are important physiological regulators whose functions are impacted by and/or underlie disease.(Du et al., 2005; McGahon, Zhang, Scholfield, Curtis, \& McGeown, 2007) These channels are composed of pore-forming $\alpha$ subunits encoded by the KCNMA1 gene.(Butler, Tsunoda, McCobb, Wei, \& Salkoff, 1993) The minimal BK channel is an assembly of $4 \alpha$ subunits around a central axis. Each $\alpha$ subunit has an extracellular $\mathrm{N}$-terminus, 7 transmembrane segments, and an intracellular C-terminus containing numerous regulatory domains and sites.(Hill, Yang, Ella, Davis, \& Braun, 2010) $\alpha$-only tetramers are fully functional $\mathrm{K}^{+}$-selective channels with inherent $\mathrm{Ca}^{2+}$ - and voltage-sensitivity. Variations in $\alpha$ subunit properties result from alternative splicing of KCNMA1.(Soom, Gessner, Heuer, Hoshi, \& Heinemann, 2008) However, a variety of important post-translational modifications also regulate BK channel properties, including their trafficking and anchoring to the membrane.(Kyle, Hurst, Swayze, Sheng, \& Braun, 2013; Tian, McClafferty, Knaus, Ruth, \& Shipston, 2012) Other differences in BK channels can be due to co-assembly with regulatory $\beta$ subunits, 4 of which have been identified.(Sun, Zaydman, \& Cui, 2012) $\beta$ subunits can dramatically change channel properties including gating kinetics, $\mathrm{Ca}^{2+} / \mathrm{voltage}-$ sensitivity, and pharmacology.(Sweet \& Cox, 2009) Interestingly, it has been demonstrated recently that the $\mathrm{N}$-terminus of intermediate conductance $\mathrm{Ca}^{2+}$-activated $\mathrm{K}^{+}$channels reduces $\mathrm{BK}$ channel $\mathrm{NP}_{\mathrm{o}}$ by the same open channel block underlying $\beta 2-$ and $\beta 3$-induced inactivation.(Thompson \& Begenisich, 2009) $\beta$ subunits can also 
influence the response of BK channels to pharmacological blockers and openers.(Asano et al., 2012; Bukiya, Liu, Toro, \& Dopico, 2007; Dick, Rossow, Smirnov, Horowitz, \& Sanders, 2001; Meera, Wallner, \& Toro, 2000)

BK channels are activated by estradiol (Valverde et al., 1999) and xenoestrogens.(Dick, Hunter, \& Sanders, 2002; Dick et al., 2001; Dick \& Sanders, 2001) Regulation by estrogenic substances, in multiple cases, involves $\beta$ subunits.(Dick et al., 2001; Dick \& Sanders, 2001; Valverde et al., 1999) We demonstrated previously that BPA increases the open probability $\left(\mathrm{NP}_{\mathrm{o}}\right)$ of $\mathrm{BK}$ channels without affecting single channel conductance.(Asano, Tune, \& Dick, 2010) BPA appears to have less of an effect on BK channels lacking the $\beta 1$ subunit, as a 10 -fold higher concentration of BPA was needed to activate BK $\alpha$ subunits alone.(Asano et al., 2010) Thus, effects of BPA, like those of other xenoestrogens, seem to be modulated by $\beta$ subunits. However, a particular extracellular or intracellular binding site for the molecule has not been identified; BPA is lipophilic and it would be reasonable to suggest sites on either side of the membrane. It is possible that BPA binds to the $\alpha$ subunit, but this interaction is made much more efficient by addition of the $\beta 1$ subunit.(Asano et al., 2010) Another possibility may be that two different BPA binding sites exist when the $\beta$ I subunit is present.(Asano et al., 2010) Whether these sites are intracellular, extracellular, or both remains unclear. In this study, we test the hypothesis that an extracellular binding site is responsible for activation of BK channels by BPA. In order to examine this possibility, we synthesized membrane-impermeant BPA-monosulfate (BPA-MS). This novel reagent allows us to determine whether an intracellular or extracellular binding site exists (under the presumptions that BPA-MS: 1) can bind to the same site(s) as BPA 
and 2) similarly increase channel activity). W-C, C-A, and I-O recordings were made on cells expressing BK channels composed of $\alpha$ or $\alpha+\beta 1$ subunits. 


\section{Results}

We recorded BK currents in AD 293 cells expressing $\alpha$ or $\alpha+\beta 1$ subunits (Fig. 1). Our goal was to determine whether BPA-MS, a membrane-impermeant derivative of BPA, increased whole-cell BK current. Further, if BPA-MS were to have an effect, we were interested in determining whether the presence of the $\beta 1$ subunit influenced it. In cells expressing BK $\alpha$ subunits, whole-cell current was unaffected by $10 \mu \mathrm{M}$ BPA-MS (Fig. 1A and B). Specifically, in cells expressing $\alpha$ subunits alone, current in the presence of BPA-MS was $106 \pm 4 \%$ of control $(n=5)$. There was no BK current in nontransfected cells (data not shown) and the current in transfected cells was identified as BK through its sensitivity to $1 \mu \mathrm{M}$ penitrem A (93 $\pm 4 \%$ block).(Asano et al., 2012) In cells expressing BK $\alpha+\beta 1$ subunits, current magnitude was increased by $10 \mu \mathrm{M}$ BPAMS (Fig. 1C and D). Specifically, at $+100 \mathrm{mV}$, BPA-MS increased current $34 \pm 4 \%$ (an increase of $712 \pm 103 p A ; n=7$ ) when the $\beta 1$ subunit was present. These data are very much like what we reported previously for the effect of BPA on whole-cell BK current and the role of the $\beta 1$ subunit (ref. (Asano et al., 2010)); however, these experiments with BPA-MS further indicate that the stimulatory effect of BPA is probably mediated, at least in part, by an extracellular binding site.

In our previous report, we demonstrated that a 10 -fold higher concentration of BPA $(100 \mu \mathrm{M})$ could activate BK channels composed of $\alpha$ subunits alone.(Asano et al., 2010) Thus, in the present study, we determined whether a log order higher concentration of membrane-impermeant BPA-MS $(100 \mu \mathrm{M})$ could also activate BK $\alpha$ subunits (Fig 2). Bath application of $100 \mu \mathrm{M}$ BPA-MS to W-C patches increased BK $\alpha$ current (Fig. 2A). Specifically, at $+100 \mathrm{mV}, 100 \mu \mathrm{M}$ BPA-MS increased BK $\alpha$ current 36 
$\pm 4 \%$ (an increase of $1151 \pm 187 \mathrm{pA} ; \mathrm{n}=6)$. These data support what we demonstrated previously regarding the role of the $\beta 1$ subunit in determining sensitivity to BPA. Further, these data lead us to suggest that the lower affinity site for activation of BK $\alpha$ by BPA/BPA-MS is extracellular.

We performed additional W-C experiments to further characterize the concentration-dependence of BPA-MS effects (Fig. 3). In cells expressing BK $\alpha+\beta 1$ subunits, BPA-MS increased current in a concentration-dependent manner (Fig. 3A). The increase in BK $\alpha+\beta 1$ current by BPA-MS (Fig. 3B) was qualitatively similar to effects of BPA we reported previously.(Asano et al., 2010) Quantitatively, in cells expressing BK $\alpha+\beta 1$ subunits, the magnitude of BPA-MS-activated current was less than that elicited by BPA (Fig. 3B). However, the current activated by BPA-MS was greater in cells expressing BK $\alpha+\beta 1$ subunits than cells expressing BK $\alpha$ alone (Fig. 3B). These data may indicate that effects of BPA-MS are less than BPA because intracellular and extracellular binding sites exist, but bath-applied, membraneimpermeant BPA-MS is restricted to acting on only the extracellular site. Further, the data may indicate that BPA-MS is a more potent and efficacious agonist of BK channels when the $\beta 1$ subunit is present.

Our next set of experiments was designed to demonstrate that BPA-MS is, indeed, membrane-impermeant. Our rationale was that: a) the W-C data suggest a low affinity extracellular site for BPA exists; 2) BPA is membrane-permeant and should activate channels in C-A patches through extracellular sites and intracellular sites (if any exist); 3) BPA-MS, if membrane-impermeant, should be unable to activate BK channels ( $\alpha$ or $\alpha+\beta 1$ ) physically isolated from the test solutions by the pipette glass and plasma 
membrane. Results from C-A patches are shown in Fig. 4. In C-A patches on cells expressing $\mathrm{BK} \alpha+\beta 1$, adding $10 \mu \mathrm{M}$ BPA-MS to the bath had no effect on NPo (Fig. 4A). In contrast, adding $10 \mu \mathrm{M}$ BPA to the bath increased $\mathrm{NP}_{\circ} 695 \pm 325 \%$ ( $n=8$; Fig. $4 \mathrm{~A}$ and $\mathrm{B})$. We performed additional experiments with a higher concentration of BPAMS $(100 \mu \mathrm{M})$ to more rigorously test whether it might cross the membrane and activate channels. In C-A patches on cells expressing BK $\alpha+\beta 1$, adding $100 \mu \mathrm{M}$ BPA-MS to the bath had no effect on channel activity $\left(\mathrm{NP}_{\circ}\right.$ was $132 \pm 9 \%$ of control; $\left.n=4\right)$. In contrast, adding $100 \mu \mathrm{M}$ BPA to bath solution in these experiments increased $\mathrm{NP}_{\circ} 521 \pm 154 \%(\mathrm{p}$ $<0.05)$. These data demonstrating differential effects of BPA and BPA-MS on NP。 reassure us that the latter is likely membrane-impermeant (and that our preparation of BPA-MS is not contaminated with significant amounts of BPA). Further, the data also lead us to suggest that AD 293 cells do not metabolize BPA-MS by defsulfation to produce BPA, as can be observed in cells expressing estrone sulfatase activity.(Stowell et al., 2006)

We excised I-O patches from cells expressing BK channels composed of $\alpha$ or $\alpha$ $+\beta 1$ subunits and determined the effect of bath-applied BPA-MS (Fig. 5). Our goal was to determine whether BPA-MS increased $\mathrm{BK}$ channel $\mathrm{NP}_{\mathrm{o}}$ at the intracellular face of the membrane. Further, if BPA-MS were to activate BK channels, we were interested in determining whether the presence of the $\beta 1$ subunit influenced this effect. In I-O patches from cells expressing BK $\alpha$ alone, adding $100 \mu \mathrm{M}$ BPA-MS to the bath had no significant effect on $\mathrm{NP}_{\mathrm{o}}(156 \pm 15 \%$ of control, $\mathrm{n}=8$; Fig. $5 \mathrm{~A}$ and $\mathrm{B})$. However, adding $100 \mu \mathrm{M}$ BPA to the bath increased $\mathrm{NP}_{\circ} 462 \pm 147 \%$ (Fig. 5A and $\mathrm{B}$ ). The response to intracellular BPA-MS was much different when BK channels contained the $\beta 1$ subunit 
(Fig. 5C). In I-O patches from cells expressing BK $\alpha+\beta 1$ subunits, adding $10 \mu \mathrm{M}$ BPAMS to the bath increased NPo $403 \pm 97 \%$ ( $n=15$; Fig. 5C and D). Replacing BPA-MS with BPA increased NPo $910 \pm 247 \%$ (Fig. 5C and D). Thus, BPA-MS can activate BK channels from the cytoplasmic face of the membrane only if the $\beta 1$ subunit is present. These data lead us to suggest that the $\beta 1$ subunit may comprise or complete an intracellular binding site for BPA.

Until this point, all of our single channel experiments had been performed at only one voltage, $+40 \mathrm{mV}$ on the membrane. We were interested in determining the effect of BPA-MS on BK channel activity at a variety of voltages. Rather than repeat the experiments outlined above at constant holding potentials, we opted to construct activation curves for channels in I-O patches (Fig. 6). Thus, I-O patches were excised from cells expressing BK $\alpha$ or $\alpha+\beta 1$ and stepped to voltages between -40 and +140 $\mathrm{mV}$ in symmetrical $140 \mathrm{mM} \mathrm{K}^{+}$with $500 \mathrm{nM} \mathrm{Ca}^{2+}$. Currents were recorded under control conditions and with bath application of $100 \mu \mathrm{M}$ BPA-MS or $100 \mu \mathrm{M}$ BPA. Conductance (G) was calculated by dividing current by voltage; $G$ was then normalized to the maximum for each patch $\left(G_{\max }\right)$. When BK channels were composed of $\alpha$ subunits alone, BPA-MS had no effect on the voltage at which $50 \%$ of the channels were activated $\left(\mathrm{V}^{1} 1 / 2=98 \pm 2\right.$ and $98 \pm 2 \mathrm{mV}, \mathrm{n}=8$; Fig. $\left.6 \mathrm{~A}-\mathrm{C}\right)$. However, bath application of membrane-permeant BPA did increase channel activity at lower voltages $\left(\mathrm{V}^{1} / 2=82 \pm 2\right.$ $\mathrm{mV})$. The BPA-induced hyperpolarizing shift was parallel, as the slope factor (k) was not significantly altered (16 \pm 2 for all 3 curves). When BK channels contained the $\beta 1$ subunit, BPA-MS hyperpolarized the $\mathrm{V} 1 \frac{1}{2}$ (from $54 \pm 2$ to $34 \pm 2 \mathrm{mV}, \mathrm{n}=12$; Fig. $6 \mathrm{D}-\mathrm{F}$ ). Bath application of membrane-permeant BPA increased channel activity further $(\mathrm{V} 1 / 2=$ 
$17 \pm 3 \mathrm{mV}$ ). The BPA-induced hyperpolarizing shift was parallel, as $\mathrm{k}$ was not significantly altered $(20 \pm 2,18 \pm 2$, and $22 \pm 3$ for control, BPA-MS, and BPA, respectively). Data from these activation curves support the single channel experiments in that: a) BPA, but not BPA-MS, activates BK $\alpha$ in I-O patches; b) in I-O patches, BPAMS activates BK channels containing the $\beta 1$ subunit; c) membrane-permeant BPA activates BK $\alpha+\beta 1$ more than BPA-MS. Further, these data indicate that BPA and BPA-MS activate BK channels over a much wider range of voltages than we had examined in the previous experiments.

Effects of BPA-MS on $\mathrm{NP}_{\mathrm{o}}$ are reversible (Fig. 7). The results in Fig. 7A are from a single I-O patch pulled from a cell expressing $\mathrm{BK} \alpha+\beta 1$. $\mathrm{NP}_{\mathrm{o}}$ at $+40 \mathrm{mV}$ is plotted vs. time. BPA-MS increased channel activity, but channel activity returned to baseline upon washout. Thus, effects of BPA-MS mediated at the intracellular face of the membrane are reversible. Data from a representative $\mathrm{W}-\mathrm{C}$ experiment are shown in Figs. 7B and C. These data indicate that effect of BPA-MS to increase BK current from extracellular face of the membrane is also reversible. We reported previously that BPA had no effect on BK channel unitary conductance.(Asano et al., 2010) It appears that BPA-MS, at least from the cytoplasmic side, does not alter unitary conductance either (see Fig. 5; also a lack of effect can be inferred from Fig. 6, where $G$ is unaffected). However, to determine whether BPA-MS affected unitary conductance from the extracellular side of the membrane, we performed experiments in outside-out patches. Extracelllular BPAMS had no effect on BK channel amplitude, as channels demonstrated conductances of $240 \pm 10$ and $241 \pm 10 \mathrm{pS}$ before and during exposure to $100 \mu \mathrm{M}$ BPA-MS, respectively $(n=4)$. 


\section{Discussion}

BPA, a component of polycarbonate plastic used in food and beverage containers, is an estrogenic endocrine disruptor found in the urine of $>95 \%$ of Americans.(Calafat, Ye, Wong, Reidy, \& Needham, 2008) We and others have demonstrated that a wide variety of ion channels (GABA receptors, nicotinic receptors, voltage-gated $\mathrm{Na}^{+}$channels, voltage-gated $\mathrm{Ca}^{2+}$ channels, and $\mathrm{BK}$ channels) are targets of BPA. (Aoshima, Hossain, Imamura, \& Shingai, 2001; Asano et al., 2010; Choi et al., 2007; Deutschmann, Hans, Meyer, Haberlein, \& Swandulla, 2013; Nakazawa \& Ohno, 2001; O'Reilly et al., 2012; Wang et al., 2011) Specifically, we have shown previously that BPA activates BK channels; however, channels containing regulatory $\beta 1$ subunits were approximately one log-order more sensitive to BPA.(Asano et al., 2010) In the present study, we tested the hypothesis that an extracellular binding site is responsible for activation of BK channels by BPA. This hypothesis was based on previous studies indicating that membrane-impermeant estrogen and estrogen receptor modulators activate BK channels by binding to an extracellular site.(Dick et al., 2002; Valverde et al., 1999) In order to test the hypothesis, we synthesized membraneimpermeant BPA-MS and used patch clamp electrophysiology to study BK channels composed of $\alpha$ or $\alpha+\beta 1$ subunits in C-A, W-C, and I-O patches. Our 4 major findings included: 1) BK $\alpha$ was activated by extracellular $100 \mu \mathrm{M}$ BPA-MS (Fig. 2); 2) the $\beta 1$ subunit made BK channels 10x more sensitive to extracellular BPA-MS (Fig. 1); 3) BK channels containing the $\beta 1$ subunit were activated by intracellular BPA-MS, whereas $\alpha$ only BK channels were not (Figs. 5 and 6); and 4) BPA was a more efficacious activator of BK $\alpha+\beta 1$ than was BPA-MS (Fig. 3, 5, and 6). These data lead us to conclude that 
the hypothesis is supported. That is, an extracellular binding site appears to be responsible, at least in part, for the activation of BK channels by BPA (and BPA-MS). Importantly, however, we did not predict that BPA-MS would activate BK $\alpha+\beta 1$ channels from the cytoplasmic face of the membrane or that a difference would exist in the magnitude of $\mathrm{NP}_{0}$ responses to intracellular BPA and BPA-MS. These surprising findings lead us to suggest that the $\beta 1$ subunit may also constitute at least a part of an intracellular binding site.

The idea that that the $\beta 1$ subunit may contribute to an intracellular binding site gains support from a substantial and integrative body of work from Dopico and colleagues on lithocholate, a cholane-derived steroid.(Bukiya et al., 2007; Bukiya et al., 2013; Bukiya, Singh, Parrill, \& Dopico, 2011; Bukiya, Vaithianathan, Toro, \& Dopico, 2008, 2009) Lithocholate activates smooth muscle BK channels from wild type, but not $\beta 1$ subunit knockout mice.(Bukiya et al., 2007) The second transmembrane domain of $\beta 1$ is critical for conferring sensitivity to lithocholate, especially residues $T 169, L 172$, and L173.(Bukiya et al., 2011; Bukiya et al., 2008, 2009) Membrane topology and computational modeling place these 3 residues in an intracellular-facing region where hydrogen bonding and hydrophobic interactions form a binding site. Whether this pocket is responsible for our observed effects of intracellular BPA on BK channels remains to be determined. However, this is our prediction as, this site also mediates responses to the nonsteroidal BK channel opener HENA (3-hydroxyolean-12-en-30-oate).(Bukiya et al., 2013)

There is a clear case for wanting to understand the effects of lithocholate on BK channels, as bile acids can be found in the circulation high micromolar concentrations, 
dilate arterioles (including ileal vessels, which facilitates adsorption of fat), and reduce blood pressure.(Bomzon \& Ljubuncic, 1995) There is no such thing as a "physiological" level of BPA, so the need to understand the effects of BPA on ion channels comes from a toxicology point of view. BPA, with an annual production over six billion pounds, is one of the highest volume chemicals worldwide.(Vandenberg, Maffini, Sonnenschein, Rubin, \& Soto, 2009) BPA is used to manufacture polycarbonate plastics, including those for food and beverage containers, which represent the major sources of exposure for most people. In fact, the body fluids of $>95 \%$ of Americans test positive for BPA. (Calafat et al., 2008) This may be cause for concern, because BPA has been identified as an estrogenic endocrine disruptor. Insight into the biologically relevant mechanisms of BPA began in 1993 with the observation that it was released from polycarbonate plastics during autoclaving and interfered with estrogen binding proteins in yeast.(Krishnan, Stathis, Permuth, Tokes, \& Feldman, 1993) The structure of BPA allows it to bind receptors in the human body normally occupied by steroids to exert its anti-androgenic and estrogenic effects. BPA interacts with nuclear estrogen receptors (ER) $\alpha$ and $\beta$, albeit with low affinity.(Matthews, Twomey, \& Zacharewski, 2000) By doing so, BPA exerts its nuclear (i.e., genomic) effects. BPA also possesses the ability to alter estrogen signaling through two less conventional pathways.(Nadal et al., 2000) Specifically, BPA can bind to membrane-bound ERa and a G protein-coupled ER (GPER).(Bouskine, Nebout, Brucker-Davis, Benahmed, \& Fenichel, 2009) Both membrane-bound ER $\alpha$ and GPER couple to non-genomic signaling pathways that have multiple effects, most of which have only recently become appreciated.(Watson, Bulayeva, Wozniak, \& Alyea, 2007) Ion channels are also targets for BPA 
effects.(Aoshima et al., 2001; Asano et al., 2010; Choi et al., 2007; Deutschmann et al., 2013; Nakazawa \& Ohno, 2001; O'Reilly et al., 2012; Wang et al., 2011) Whether these ion channel effects contribute to the association of BPA exposure with disease remains to be determined.(Lang et al., 2008)

The first identified ion channel target for BPA was recombinant $\mathrm{GABA}_{\mathrm{A}}$ receptors in 2001.(Aoshima et al., 2001) Complex effects were demonstrated, as low concentrations of BPA potentiated responses to low concentrations of GABA, but high concentrations of BPA inhibited GABA responses. Later, BPA was shown to elicit postsynaptic current in CA3 pyramidal neurons, likely mediated by $\mathrm{GABA}_{\mathrm{A}}$ channels.(Choi et al., 2007) The activation of $\mathrm{GABA}_{A}$ channels by BPA may be interestingly related to mechanisms responsible for BK channel activation by BPA, as both channels are also potentiated by ethanol.(Liu, Bukiya, Kuntamallappanavar, Singh, \& Dopico, 2013) Effects of BPA on the other identified ion channel targets share a common feature, as BPA uniformly inhibits a variety of voltage-gated $\mathrm{Na}^{+}$channels (tetrodotoxin-sensitive and -resistant) and voltage-gated $\mathrm{Ca}^{2+}$ channels $(\mathrm{L}-, \mathrm{N}-, \mathrm{P} / \mathrm{Q}-$, and T-type).(Deutschmann et al., 2013; O'Reilly et al., 2012; Wang et al., 2011) In contrast, we show that BPA activates BK channels, which, interestingly, share some structural and regulatory features of voltage-gated $\mathrm{Na}^{+}$and $\mathrm{Ca}^{2+}$ channels.

Whether these non-genomic effects of BPA on BK channels (as well as other ion channels) are relevant to human disease remains to be determined. Genomic effects of BPA ion channel expression are also possible and merit investigation. The present study, however, focused on non-genomic mechanisms and we have shown that $100 \mu \mathrm{M}$ BPA-MS activated current in cells expressing $\alpha$ subunits, 
whereas cells expressing $\alpha+\beta 1$ subunits responded equally to $10 \mu \mathrm{M}$ BPA-MS. The W-C data suggest that an extracellular site exists for BPA on the $\alpha$ subunit. Our data show that in I-O patches, where the cytoplasmic face was exposed to the bath, BPA-MS had no effect on the $\mathrm{NP}_{\mathrm{o}}$ of channels containing $\alpha$ alone; however, BPA-MS increased the $\mathrm{NP}_{\mathrm{o}}$ of $\mathrm{BK}$ channels composed of $\alpha+\beta 1$ subunits. These I-O data suggest that the $\beta 1$ subunit completes or comprises an intracellular binding site for BPA. Together, the data lead us to conclude that BPA activates BK channels via an extracellular binding site and via an intracellular binding site that depends on the presence of the $\beta 1$ subunit. We predict that the intracellular binding site may be the same one identified for interactions with lithocholate and HENA. 


\section{Methods}

Cell Culture and Transfection. The techniques used here were similar to those we have used previously.(Asano et al., 2010) AD 293 cells (Agilent Technologies, Santa Clara, CA) were grown in Dulbecco's modified Eagle's medium (DMEM) supplemented with $10 \%$ fetal bovine serum, $100 \mathrm{U} / \mathrm{ml}$ penicillin, and $100 \mu \mathrm{g} / \mathrm{ml}$ streptomycin. Culture flasks were incubated in a $5 \% \mathrm{CO}_{2}$ incubator, humidified, and kept at $37^{\circ} \mathrm{C}$. Plasmids encoding hSlo $\alpha$ and hSlo $\alpha+\beta 1$ were kindly provided by $\mathrm{Dr}$. Jonathan Lippiat (University of Leeds, Leeds, UK).(Lippiat, Standen, Harrow, Phillips, \& Davies, 2003) Cells were transiently transfected with pIRES-hSloa or pIRES-hSloa $\beta 1$ and pmaxGFP (AMAXA, Gaithersburg, MD) using Lipofectamine LTX with PLUS reagent (Invitrogen, Carlsbad, CA). Cells at $50-70 \%$ confluence in $35-\mathrm{mm}$ dishes were transfected with 0.5 $2.5 \mu \mathrm{g}$ of DNA. Transfected cells were selected in DMEM supplemented with $0.5 \mathrm{mg} / \mathrm{ml}$ G418, $1 \%$ fetal bovine serum, $100 \mathrm{U} / \mathrm{ml}$ penicillin, and $100 \mu \mathrm{g} / \mathrm{ml}$ streptomycin. Currents were recorded from cells expressing green fluorescent protein (GFP) 1-3 days later.

Electrophysiology. BK channel currents were recorded at room temperature from inside-out (I-O), cell-attached (C-A), and whole-cell (W-C) patches as described previously.(Asano et al., 2012; Asano et al., 2010) The bath flowed at a rate of approximately $2-3 \mathrm{ml} / \mathrm{min}$ into a into a chamber with a volume of approximately $0.2-0.3$ $\mathrm{ml}$ throughout the recordings. For W-C recordings, bath solution contained (mM) 135 $\mathrm{NaCl}, 5 \mathrm{KCl}, 2 \mathrm{CaCl}_{2}, 1 \mathrm{MgCl}_{2}, 10$ glucose, 10 HEPES, and 5 Tris; $\mathrm{pH}$ 7.4. Chemicals were purchased from Fisher Scientific (Pittsburgh, PA) or Sigma-Aldrich (St. Louis, MO). For $\mathrm{W}-\mathrm{C}$ recordings, pipette solution contained (mM) $140 \mathrm{KCl}, 1 \mathrm{MgCl}_{2}, 1 \mathrm{EGTA}$, $0.281 \mathrm{CaCl}_{2}, 1 \mathrm{Mg}-\mathrm{ATP}, 0.1 \mathrm{Na}-\mathrm{GTP}, 10 \mathrm{HEPES}$, and 5 Tris; pH 7.1; pCa 7. I-O and C- 
A recordings were made in symmetrical $(\mathrm{mM}) 140 \mathrm{KCl}, 1 \mathrm{MgCl}_{2}, 1$ EGTA, 10 HEPES, and 5 Tris; $\mathrm{pH}$ 7.1. $\mathrm{CaCl}_{2}$ was added to these solutions to achieve free $\mathrm{Ca}^{2+}$ concentrations of $100 \quad \mathrm{nM} \quad(\mathrm{pCa} \quad 7 ;$ calculated using Maxchelator; http://www.stanford.edu/ cpatton/maxc.html) or $500 \mathrm{nM} \mathrm{(pCa} \mathrm{6.3;} \mathrm{calculated} \mathrm{in} \mathrm{ref}$ (Bers, 1982)) as indicated for individual experiments. Because $\mathrm{Cl}^{-}$was symmetrical in all recording conditions, no adjustments were made for the negligible junction potentials. W-C and single channel pipettes were fashioned from borosilicate glass and had tip resistances of 2-3 and 5-10 M $\Omega$, respectively. In W-C recordings, cell capacitance and series resistance were compensated as completely as possible by circuitry of the amplifier (Axopatch 200B; Molecular Devices, Sunnyvale, CA). Currents were low pass filtered at $1 \mathrm{kHz}$ and digitized at $5 \mathrm{kHz}$. pClamp 9 software was used for data acquisition and analysis (Molecular Devices).

Synthesis of BPA-MS. BPA-MS was synthesized from BPA and $\mathrm{SO}_{3}$-pyridinium complex, as described previously.(Stowell et al., 2006) BPA and 1.1 equivalents of $\mathrm{SO}_{3}$ were stirred in dry pyridine under Ar for $36 \mathrm{hr}$. Solvent was removed under reduced pressure and the crude reaction mixture was purified by column chromatography $(10 \%$ methanol in $\mathrm{CH}_{2} \mathrm{Cl}_{2}$ ). The pyridinium salt was dissolved in water and passed down a Dowex $50 \mathrm{~W}$ X-8 cation exchange column, sodium form. ${ }^{1} \mathrm{H}-\mathrm{NMR}\left(\mathrm{CD}_{3} \mathrm{OD}, 300 \mathrm{MHz}\right): \delta$ $7.18(\mathrm{~s}, 4 \mathrm{H}), 7.02(2 \mathrm{H}, \mathrm{d}, \mathrm{J}=8.8 \mathrm{~Hz}), 6.67(2 \mathrm{H}, \mathrm{d}, \mathrm{J}=8.8 \mathrm{~Hz}), 1.6(6 \mathrm{H}, \mathrm{s}),{ }^{13} \mathrm{C}-\mathrm{NMR}$ $\left(\mathrm{CD}_{3} \mathrm{OD}, 101 \mathrm{MHz}\right): \delta 156.2,151.5,149.2,142.7,126.7,128.4,121.9,115.6,42.8$ 31.5. ESIMS (negative ion mode) 291 (BPA-MS monoanion).

Statistics. Data are presented as the mean \pm standard error of $n$ number of patches. Current-voltage relationships were analyzed by two-way repeated measures 
analysis of variance (2RM-ANOVA). NP o values under control conditions and with BPAMS and BPA stimulation (i.e., 3 values) in C-A and I-O patches were compared by oneway repeated measures analysis of variance (1RM-ANOVA). Bonferroni post hoc tests followed 1RM-ANOVA and 2RM-ANOVA when appropriate to determine where differences existed. When only two values were compared, a paired Student's t-test was used. In all tests, $p<0.05$ was considered significant. 


\section{Acknowledgements}

Ibra Fancher and Dr. Asano were supported by NIH T-32 training grant HL090610. A Research Funds Development Grant from West Virginia University, the WV-INBRE program, and NIGMS P20 grant GM103434 supported this work. 


\section{References}

Aoshima, H., Hossain, S. J., Imamura, H., \& Shingai, R. (2001). Effects of bisphenol A and its derivatives on the response of $\operatorname{GABA}(\mathrm{A})$ receptors expressed in Xenopus oocytes. Biosci Biotechnol Biochem, 65(9), 2070-2077.

Asano, S., Bratz, I. N., Berwick, Z. C., Fancher, I. S., Tune, J. D., \& Dick, G. M. (2012).

Penitrem $\mathrm{A}$ as a tool for understanding the role of large conductance $\mathrm{Ca}(2+) /$ voltage-sensitive $\mathrm{K}(+)$ channels in vascular function. J Pharmacol Exp Ther, 342(2), 453-460. doi: 10.1124/jpet.111.191072

Asano, S., Tune, J. D., \& Dick, G. M. (2010). Bisphenol A activates Maxi-K (K(Ca)1.1) channels in coronary smooth muscle. [Research Support, Non-U.S. Gov't]. British journal of pharmacology, 160(1), 160-170. doi: 10.1111/j.14765381.2010.00687.x

Bers, D. M. (1982). A simple method for the accurate determination of free [Ca] in CaEGTA solutions. Am J Physiol, 242(5), C404-408.

Bomzon, A., \& Ljubuncic, P. (1995). Bile acids as endogenous vasodilators? Biochem Pharmacol, 49(5), 581-589.

Bouskine, A., Nebout, M., Brucker-Davis, F., Benahmed, M., \& Fenichel, P. (2009). Low doses of bisphenol A promote human seminoma cell proliferation by activating 
PKA and PKG via a membrane G-protein-coupled estrogen receptor. Environ Health Perspect, 117(7), 1053-1058. doi: 10.1289/ehp.0800367

Bukiya, A. N., Liu, J., Toro, L., \& Dopico, A. M. (2007). Beta1 (KCNMB1) subunits mediate lithocholate activation of large-conductance $\mathrm{Ca} 2+$-activated $\mathrm{K}+$ channels and dilation in small, resistance-size arteries. Mol Pharmacol, 72(2), 359-369. doi: $10.1124 / \mathrm{mol} .107 .034330$

Bukiya, A. N., McMillan, J. E., Fedinec, A. L., Patil, S. A., Miller, D. D., Leffler, C. W., . . Dopico, A. M. (2013). Cerebrovascular dilation via selective targeting of the cholane steroid-recognition site in the BK channel beta1-subunit by a novel nonsteroidal agent. Mol Pharmacol, 83(5), 1030-1044. doi: 10.1124/mol.112.083519

Bukiya, A. N., Singh, A. K., Parrill, A. L., \& Dopico, A. M. (2011). The steroid interaction site in transmembrane domain 2 of the large conductance, voltage- and calciumgated potassium (BK) channel accessory beta1 subunit. Proc Natl Acad Sci U S A, 108(50), 20207-20212. doi: 10.1073/pnas.1112901108

Bukiya, A. N., Vaithianathan, T., Toro, L., \& Dopico, A. M. (2008). The second transmembrane domain of the large conductance, voltage- and calcium-gated potassium channel beta(1) subunit is a lithocholate sensor. FEBS Lett, 582(5), 673-678. doi: 10.1016/j.febslet.2008.01.036 
Bukiya, A. N., Vaithianathan, T., Toro, L., \& Dopico, A. M. (2009). Channel beta2-4 subunits fail to substitute for beta1 in sensitizing BK channels to lithocholate. Biochem Biophys Res Commun, 390(3), 995-1000. doi:

10.1016/j.bbrc.2009.10.091

Butler, A., Tsunoda, S., McCobb, D. P., Wei, A., \& Salkoff, L. (1993). mSlo, a complex mouse gene encoding "maxi" calcium-activated potassium channels. Science, 261(5118), 221-224.

Calafat, A. M., Ye, X., Wong, L. Y., Reidy, J. A., \& Needham, L. L. (2008). Exposure of the U.S. population to bisphenol A and 4-tertiary-octylphenol: 2003-2004. Environ Health Perspect, 116(1), 39-44. doi: 10.1289/ehp.10753

Choi, I. S., Cho, J. H., Park, E. J., Park, J. W., Kim, S. H., Lee, M. G., . . Jang, I. S. (2007). Multiple effects of bisphenol A, an endocrine disrupter, on GABA(A) receptors in acutely dissociated rat CA3 pyramidal neurons. Neurosci Res, 59(1), 8-17. doi: 10.1016/j.neures.2007.05.003

Deutschmann, A., Hans, M., Meyer, R., Haberlein, H., \& Swandulla, D. (2013). Bisphenol A inhibits voltage-activated $\mathrm{Ca}(2+)$ channels in vitro: mechanisms and structural requirements. Mol Pharmacol, 83(2), 501-511. doi:

10.1124/mol.112.081372 
Dick, G. M., Hunter, A. C., \& Sanders, K. M. (2002). Ethylbromide tamoxifen, a membrane-impermeant antiestrogen, activates smooth muscle calcium-activated large-conductance potassium channels from the extracellular side. Mol Pharmacol, 61(5), 1105-1113.

Dick, G. M., Rossow, C. F., Smirnov, S., Horowitz, B., \& Sanders, K. M. (2001). Tamoxifen activates smooth muscle BK channels through the regulatory beta 1 subunit. J Biol Chem, 276(37), 34594-34599. doi: 10.1074/jbc.M104689200

Dick, G. M., \& Sanders, K. M. (2001). (Xeno)estrogen sensitivity of smooth muscle BK channels conferred by the regulatory beta 1 subunit: a study of beta1 knockout mice. J Biol Chem, 276(48), 44835-44840. doi: 10.1074/jbc.M106851200

Du, W., Bautista, J. F., Yang, H., Diez-Sampedro, A., You, S. A., Wang, L., . . Wang, Q. K. (2005). Calcium-sensitive potassium channelopathy in human epilepsy and paroxysmal movement disorder. Nat Genet, 37(7), 733-738. doi: 10.1038/ng1585

Hill, M. A., Yang, Y., Ella, S. R., Davis, M. J., \& Braun, A. P. (2010). Large conductance, Ca2+-activated $\mathrm{K}+$ channels (BKCa) and arteriolar myogenic signaling. FEBS Lett, 584(10), 2033-2042. doi: S0014-5793(10)00149-3 [pii]

10.1016/j.febslet.2010.02.045

Krishnan, A. V., Stathis, P., Permuth, S. F., Tokes, L., \& Feldman, D. (1993). BisphenolA: an estrogenic substance is released from polycarbonate flasks during 
autoclaving. [Research Support, U.S. Gov't, P.H.S.]. Endocrinology, 132(6), 2279-2286.

Kyle, B. D., Hurst, S., Swayze, R. D., Sheng, J., \& Braun, A. P. (2013). Specific phosphorylation sites underlie the stimulation of a large conductance, $\mathrm{Ca}(2+)-$ activated $\mathrm{K}(+)$ channel by cGMP-dependent protein kinase. FASEB J, 27(5), 2027-2038. doi: 10.1096/fj.12-223669

Lang, I. A., Galloway, T. S., Scarlett, A., Henley, W. E., Depledge, M., Wallace, R. B., \& Melzer, D. (2008). Association of urinary bisphenol A concentration with medical disorders and laboratory abnormalities in adults. JAMA, 300(11), 1303-1310. doi: 10.1001/jama.300.11.1303

Lippiat, J. D., Standen, N. B., Harrow, I. D., Phillips, S. C., \& Davies, N. W. (2003). Properties of $\mathrm{BK}(\mathrm{Ca})$ channels formed by bicistronic expression of hSloalpha and beta1-4 subunits in HEK293 cells. J Membr Biol, 192(2), 141-148. doi: $10.1007 / \mathrm{s} 00232-002-1070-0$

Liu, J., Bukiya, A. N., Kuntamallappanavar, G., Singh, A. K., \& Dopico, A. M. (2013). Distinct sensitivity of slo1 channel proteins to ethanol. Mol Pharmacol, 83(1), 235-244. doi: 10.1124/mol.112.081240

Matthews, J. B., Twomey, K., \& Zacharewski, T. R. (2000). In Vitro and in Vivo Interactions of Bisphenol A and Its Metabolite, Bisphenol A Glucuronide, with 
Estrogen Receptors $\alpha$ and $\beta$. Chemical Research in Toxicology, 14(2), 149-157. doi: $10.1021 / \mathrm{tx} 0001833$

McGahon, M. K., Zhang, X., Scholfield, C. N., Curtis, T. M., \& McGeown, J. G. (2007). Selective downregulation of the BKbeta1 subunit in diabetic arteriolar myocytes. Channels (Austin), 1(3), 141-143.

Meera, P., Wallner, M., \& Toro, L. (2000). A neuronal beta subunit (KCNMB4) makes the large conductance, voltage- and $\mathrm{Ca} 2+$-activated $\mathrm{K}+$ channel resistant to charybdotoxin and iberiotoxin. Proc Natl Acad Sci U S A, 97(10), 5562-5567. doi: 10.1073/pnas. 100118597

Nadal, A., Ropero, A. B., Laribi, O., Maillet, M., Fuentes, E., \& Soria, B. (2000). Nongenomic actions of estrogens and xenoestrogens by binding at a plasma membrane receptor unrelated to estrogen receptor alpha and estrogen receptor beta. Proc Natl Acad Sci U S A, 97(21), 11603-11608. doi:

10.1073/pnas.97.21.11603

Nakazawa, K., \& Ohno, Y. (2001). Modulation by estrogens and xenoestrogens of recombinant human neuronal nicotinic receptors. Eur J Pharmacol, 430(2-3), 175-183.

O'Reilly, A. O., Eberhardt, E., Weidner, C., Alzheimer, C., Wallace, B. A., \& Lampert, A. (2012). Bisphenol A binds to the local anesthetic receptor site to block the human 
cardiac sodium channel. PLoS One, 7(7), e41667. doi:

10.1371/journal.pone.0041667

Singh, H., Stefani, E., \& Toro, L. (2012). Intracellular BK(Ca) (iBK(Ca)) channels. J Physiol, 590(Pt 23), 5937-5947. doi: 10.1113/jphysiol.2011.215533

Soom, M., Gessner, G., Heuer, H., Hoshi, T., \& Heinemann, S. H. (2008). A mutually exclusive alternative exon of slo1 codes for a neuronal BK channel with altered function. Channels (Austin), 2(4), 278-282.

Stowell, C. L., Barvian, K. K., Young, P. C., Bigsby, R. M., Verdugo, D. E., Bertozzi, C. R., \& Widlanski, T. S. (2006). A role for sulfation-desulfation in the uptake of bisphenol a into breast tumor cells. Chem Biol, 13(8), 891-897. doi: 10.1016/j.chembiol.2006.06.016

Sun, X., Zaydman, M. A., \& Cui, J. (2012). Regulation of Voltage-Activated K(+) Channel Gating by Transmembrane beta Subunits. Front Pharmacol, 3, 63. doi: 10.3389/fphar.2012.00063

Sweet, T. B., \& Cox, D. H. (2009). Measuring the influence of the BKCa \{beta\}1 subunit on Ca2+ binding to the BKCa channel. J Gen Physiol, 133(2), 139-150. doi: 10.1085/jgp.200810129 
Thompson, J., \& Begenisich, T. (2009). Mechanistic details of BK channel inhibition by the intermediate conductance, Ca2+-activated K channel. Channels (Austin), 3(3), 194-204.

Tian, L., McClafferty, H., Knaus, H. G., Ruth, P., \& Shipston, M. J. (2012). Distinct acyl protein transferases and thioesterases control surface expression of calciumactivated potassium channels. J Biol Chem, 287(18), 14718-14725. doi: 10.1074/jbc.M111.335547

Valverde, M. A., Rojas, P., Amigo, J., Cosmelli, D., Orio, P., Bahamonde, M. I., . . . Latorre, R. (1999). Acute activation of Maxi-K channels (hSlo) by estradiol binding to the beta subunit. Science, 285(5435), 1929-1931.

Vandenberg, L. N., Maffini, M. V., Sonnenschein, C., Rubin, B. S., \& Soto, A. M. (2009). Bisphenol-A and the great divide: a review of controversies in the field of endocrine disruption. Endocr Rev, 30(1), 75-95. doi: er.2008-0021 [pii] 10.1210/er.2008-0021

Wang, Q., Cao, J., Zhu, Q., Luan, C., Chen, X., Yi, X., ... Xiao, H. (2011). Inhibition of voltage-gated sodium channels by bisphenol $\mathrm{A}$ in mouse dorsal root ganglion neurons. Brain Res, 1378, 1-8. doi: 10.1016/j.brainres.2011.01.022 
Watson, C. S., Bulayeva, N. N., Wozniak, A. L., \& Alyea, R. A. (2007). Xenoestrogens are potent activators of nongenomic estrogenic responses. Steroids, 72(2), 124134. doi: $10.1016 /$ j.steroids.2006.11.002 
Figure 4.1

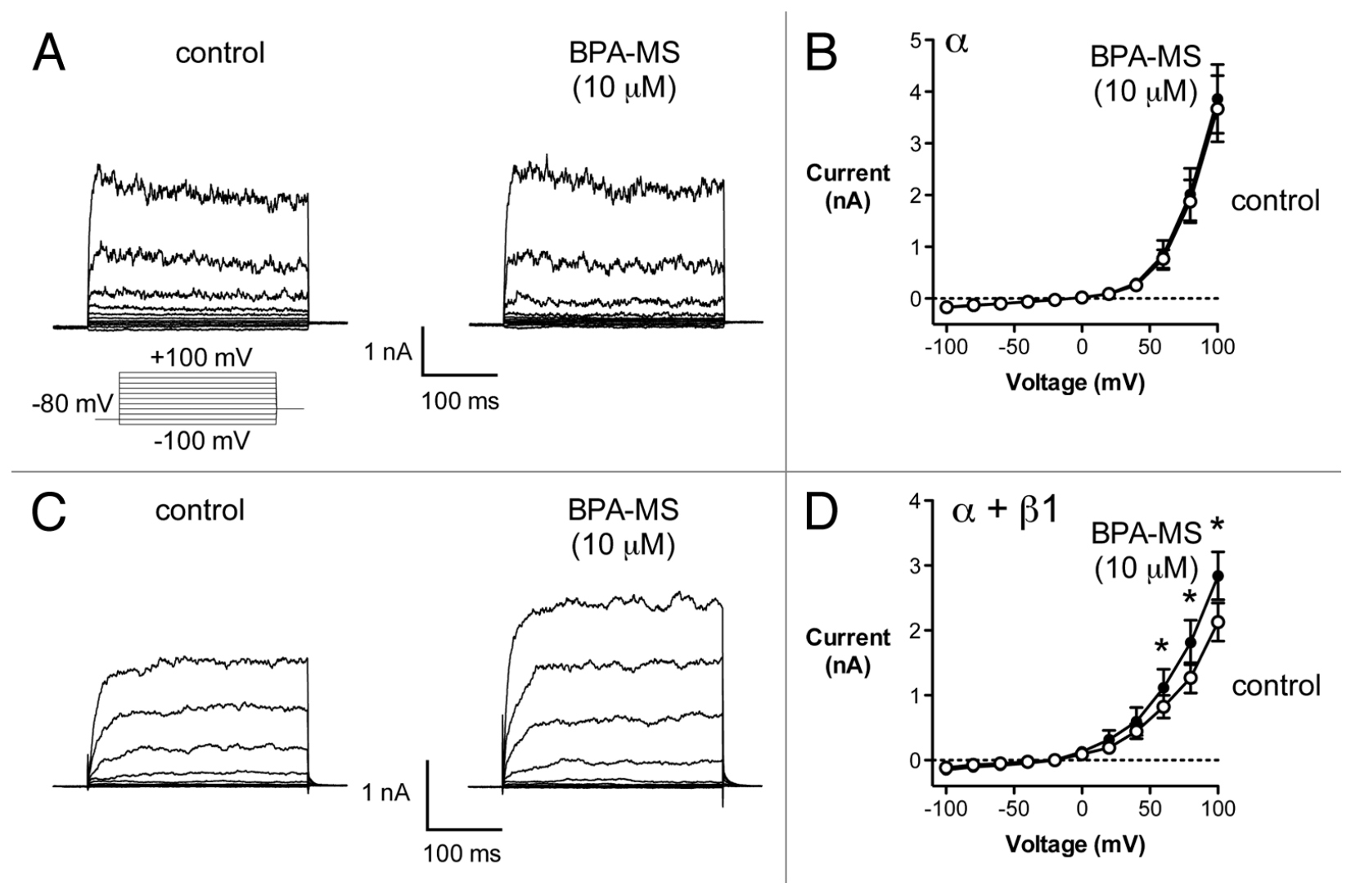


Figure 4.1 BPA-MS $(10 \mu \mathrm{M})$ activates BK channels in W-C patches in a $\beta 1$ subunitdependent manner. Panel A contains families of current traces from a representative cell expressing BK $\alpha$ subunits. The voltage template is shown below; cells were held at $80 \mathrm{mV}$ and stepped from -100 to $+100 \mathrm{mV}$ in $20 \mathrm{mV}$ increments. The addition of $10 \mu \mathrm{M}$ BPA-MS had no effect on current in cells expressing BK $\alpha$ subunits alone. Panel B shows group data $(n=5)$ illustrating the lack of effect of $10 \mu M$ BPA-MS on BK channels composed of $\alpha$ only ( $p=0.99$ by 2RM-ANOVA). $\underline{\text { Panel } \mathrm{C}}$ contains families of current traces from a representative cell expressing BK $\alpha+\beta 1$ subunits. BPA-MS (10 $\mu \mathrm{M})$ increased current in cells expressing BK channels composed of $\alpha+\beta 1$ subunits. Panel $\mathrm{D}$ shows group data $(n=7)$ illustrating the increase in BK $\alpha+\beta 1$ current elicited by $10 \mu \mathrm{M}$ BPA-MS (asterisks indicate $\mathrm{p}<0.05$ by 2 RM-ANOVA with Bonferroni post test). 
Figure 4.2

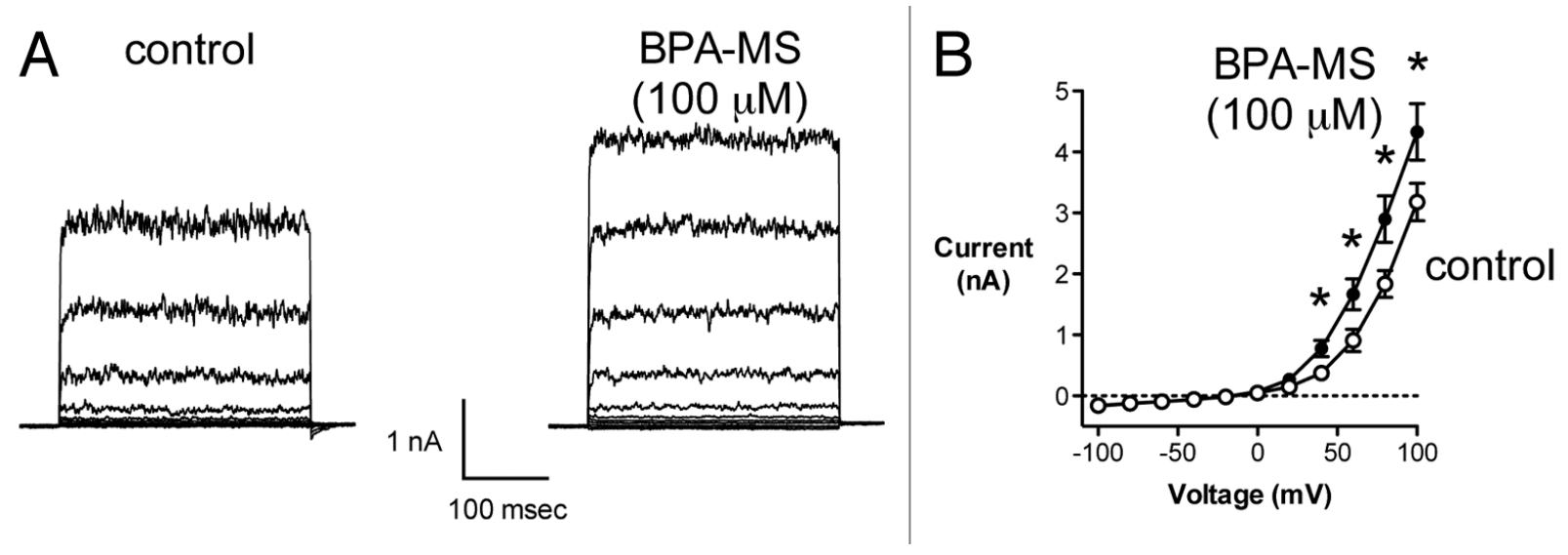


Figure 4.2 A higher concentration of BPA-MS $(100 \mu \mathrm{M})$ activates current in cells expressing BK $\alpha$ subunits. Panel A contains families of current traces from a representative cell expressing BK $\alpha$ subunits. BPA-MS $(100 \mu \mathrm{M}$; note this is $10 x$ higher than Fig. 1) increased current in cells expressing BK channels composed of $\alpha$ subunits only. The voltage template shown in Fig. 1 was used here also. Panel B shows group data $(n=7)$ illustrating the increase in BK $\alpha$ current elicited by $100 \mu$ M BPA-MS (asterisks indicate $p<0.05$ by 2RM-ANOVA with Bonferroni post test). 
Figure 4.3

A

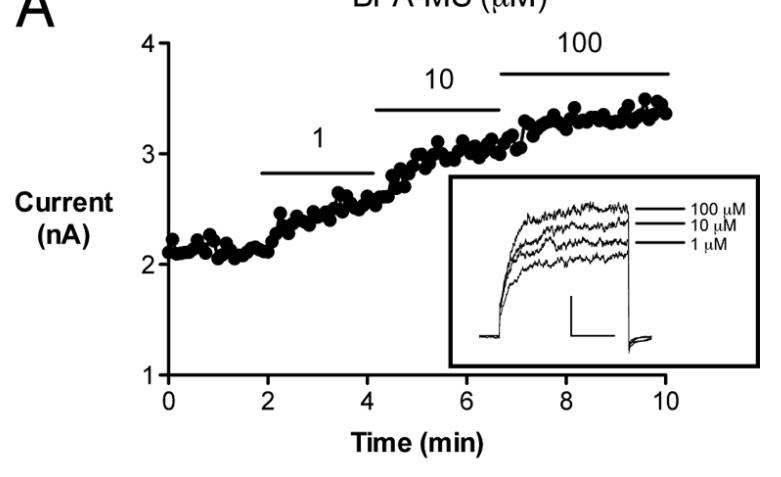

B

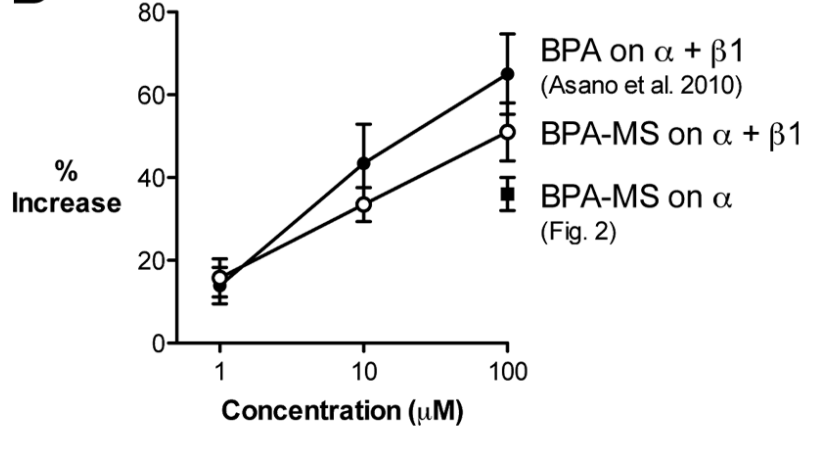


Figure 4.3 Concentration-dependence of effects of BPA-MS. Panel A contains data from a representative $\mathrm{W}-\mathrm{C}$ experiment on a cell expressing BK $\alpha$ and $\alpha+\beta 1$. BPA-MS increased current in a concentration-dependent manner. Inset shows currents under control conditions and in the presence of 1,10 , and $100 \mu \mathrm{M}$ BPA-MS. Panel B contains group data for the experiment described in A $(n=9)$ and offers a comparison of BPAMS to results obtained previously with BPA in cells expressing BK $\alpha+\beta 1$ (ref. (Asano et al., 2010)). Further, the results from Fig. 2 are replotted here to compare effects of BPAMS on channels composed of BK $\alpha$ or $\alpha+\beta 1$. 
Figure 4.4
A
control
$10 \mu \mathrm{M}$ BPA-MS
$10 \mu \mathrm{M}$ BPA

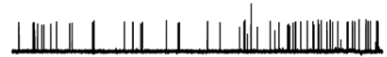

1

$\mathrm{NP}_{\mathrm{o}}=0.0095$

$\mathrm{NP}_{\mathrm{o}}=0.0191$

$10 \mathrm{pA} L_{5} \quad \mathrm{NP}_{0}=0.0359$

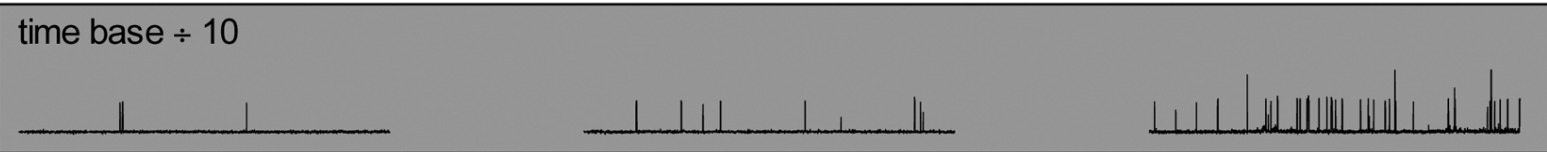

B
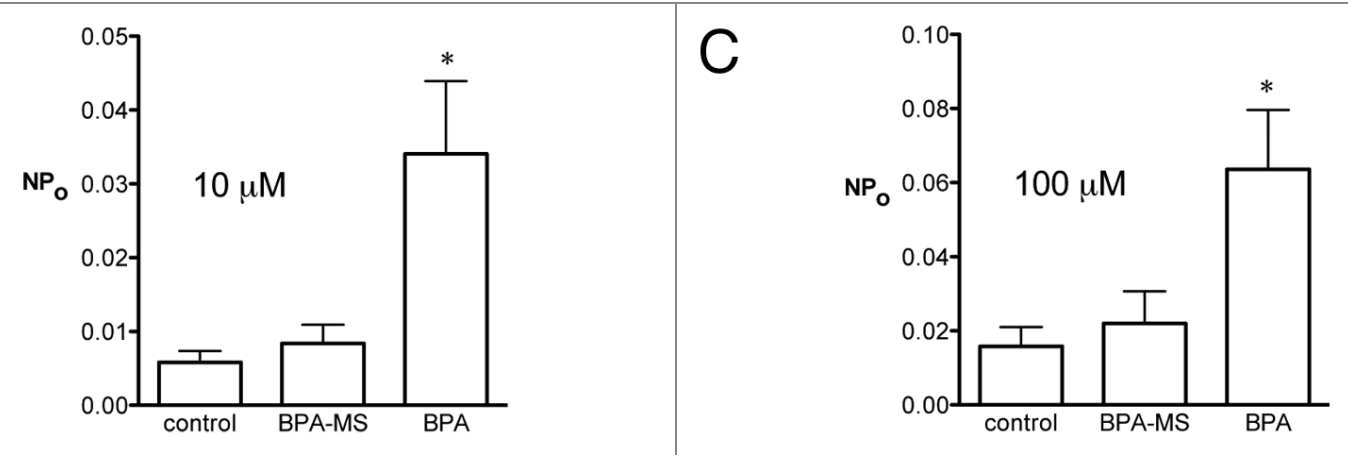
Figure 4.4 BPA-MS is membrane-impermeant as shown by results in C-A patches. Panel A contains current traces from a representative cell expressing BK $\alpha+\beta 1$ subunits. Currents were recorded in C-A mode in symmetrical $\mathrm{K}^{+}(\mathrm{pCa} 7)$ at a patch potential of $+40 \mathrm{mV}$. BPA-MS had no effect on $\mathrm{NP}_{0}$, but BPA increased $\mathrm{NP}_{\mathrm{o}}$. Panel $\mathrm{B}$ shows group data $(n=8)$ illustrating the effect of BPA, but not BPA-MS, to increase NP。 in $\mathrm{C}-\mathrm{A}$ patches of $\mathrm{BK} \alpha+\beta 1$. Asterisk indicates $\mathrm{p}<0.05$ by 1RM-ANOVA with Bonferroni post test. $\underline{\text { Panel } \mathrm{C}}$ indicates that similar results were obtained using a 10 -fold higher concentration of BPA and BPA-MS $(n=5)$. 
Figure 4.5

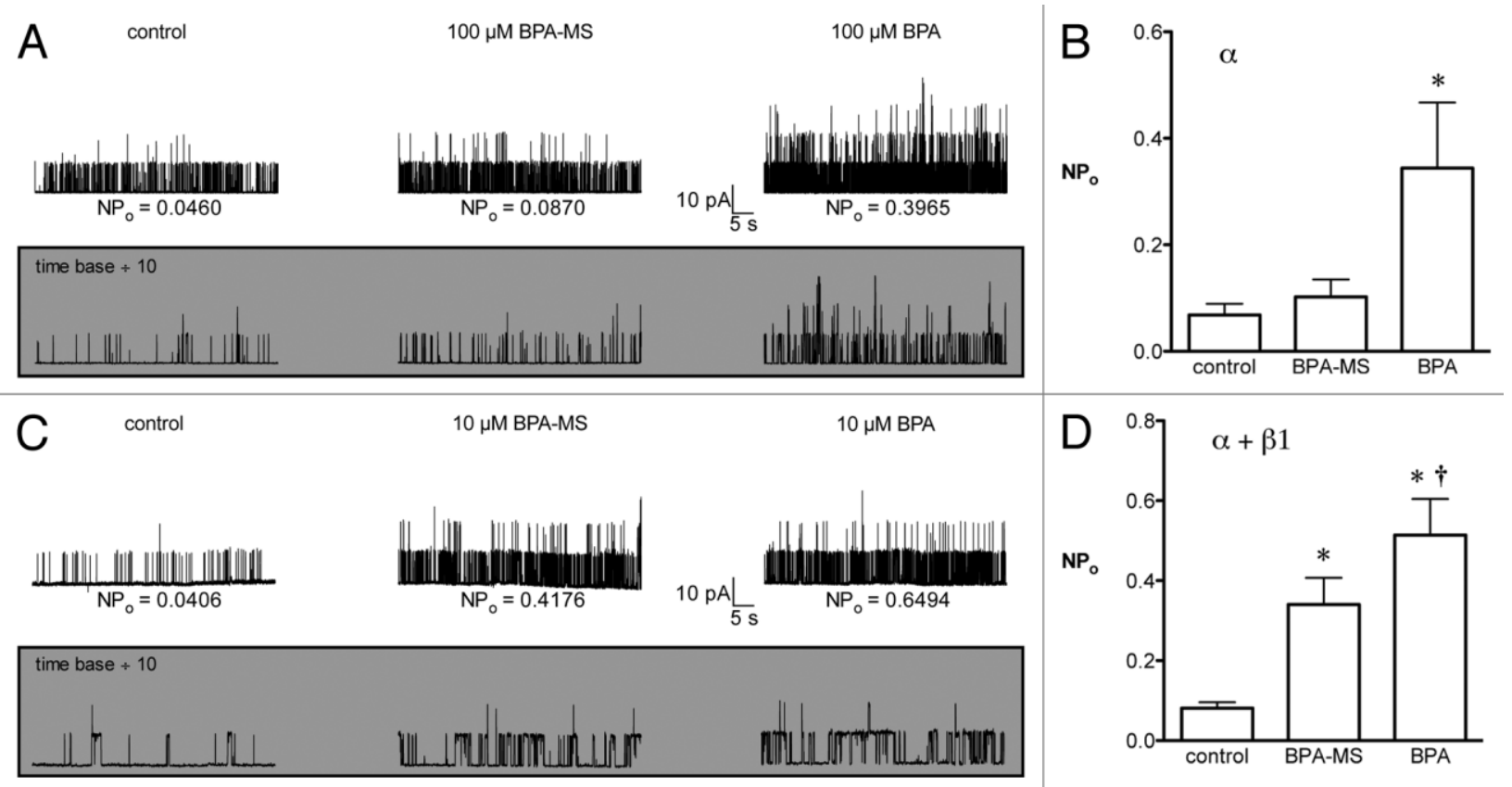


Figure 4.5 When BK channels contain $\beta 1$ subunits, BPA-MS can activate from the cytoplasmic face of the membrane. Panel A shows a family current traces at $+40 \mathrm{mV}$ in a representative I-O patch with BK $\alpha$ (symmetrical $140 \mathrm{mM} \mathrm{K}^{+} ; \mathrm{pCa}$ 6.3). The shaded inset shows a portion of the same current traces on an expanded time scale. Panel B contains group data $(n=8)$ and shows that $100 \mu \mathrm{M}$ BPA-MS does not significantly increase the $\mathrm{NP}_{\circ}$ of $\mathrm{BK} \alpha$. In contrast, $100 \mu \mathrm{M}$ BPA significantly increases $\mathrm{NP}_{\circ}$. Asterisk indicates $p<0.05$ vs. control by 1 RM-ANOVA with Bonferroni post test. Panel C shows a family of current traces at $+40 \mathrm{mV}$ from a representative $\mathrm{I}-\mathrm{O}$ patch of $\mathrm{BK} \alpha+\beta 1$ (symmetrical $140 \mathrm{mM} \mathrm{K}^{+} ; \mathrm{pCa}$ 7). The shaded inset shows a portion of the same traces on an expanded time scale. Panel $D$ contains group data $(n=15)$ showing a significant increase in $\mathrm{NP}_{\mathrm{o}}$ elicited by BPA-MS and BPA. Asterisk indicates $p<0.05$ vs. control by 1RM-ANOVA with Bonferroni post test. Dagger indicates $p<0.05$ vs. control and BPAMS by 1RM-ANOVA with Bonferroni post test. 
Figure 4.6

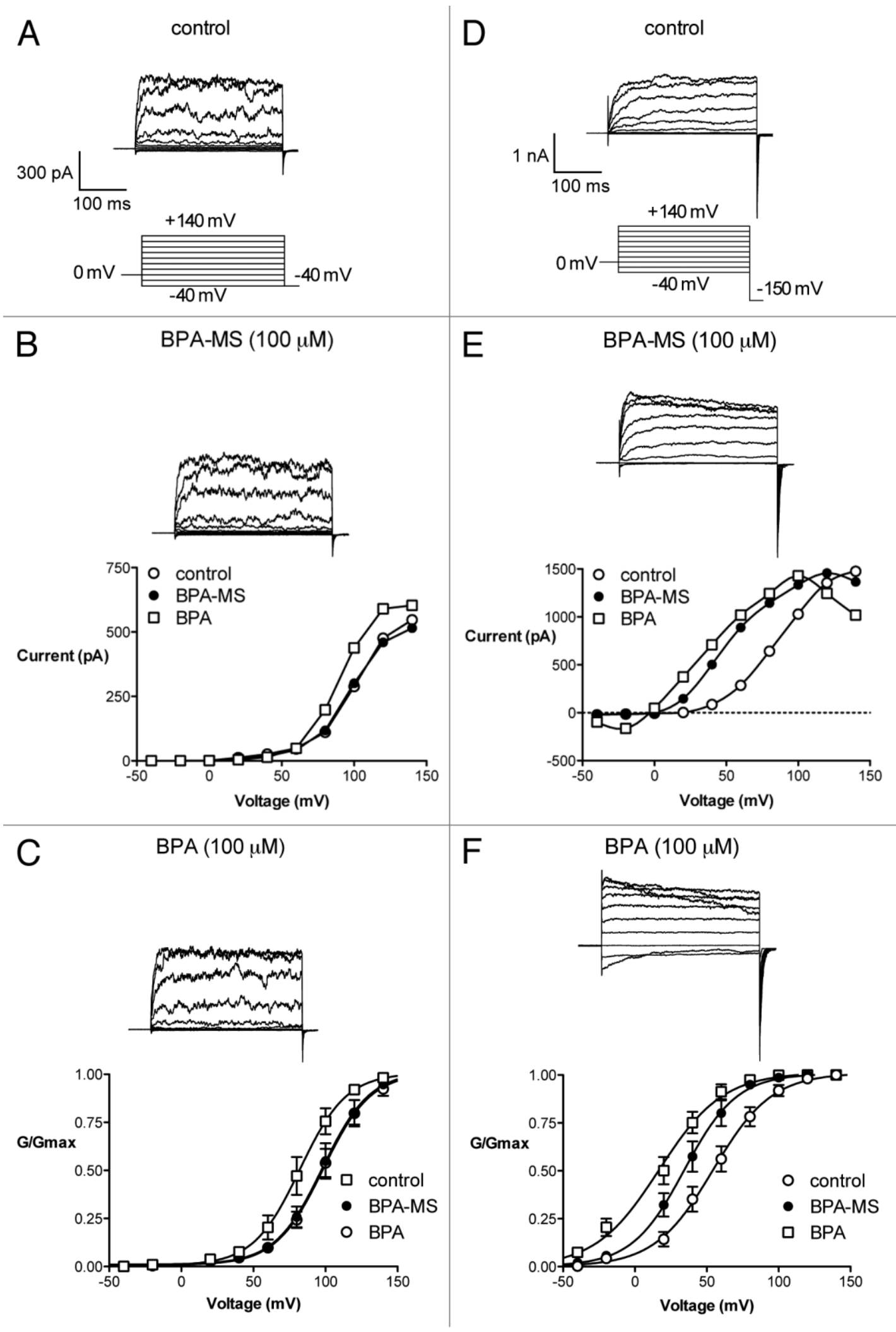


Figure 4.6 BPA-MS activates BK channels containing the $\beta 1$ subunit over a wide range of voltages. Panel A shows families of current traces from a representative I-O patch taken from a cell expressing BK $\alpha$ (symmetrical $140 \mathrm{mM} \mathrm{K}^{+}$; pCa 6.3). The voltage template is shown below. Panel B contains the I-V relationship for this single patch. BPA $(100 \mu \mathrm{M})$, but not BPA-MS $(100 \mu \mathrm{M})$, appears to affect current. Panel C contains group data $(n=8)$ showing that BPA-MS does not shift the midpoint $\left(V^{1} / 2\right)$ of the activation curve. Panel $\mathrm{D}$ shows families of current traces from a representative $\mathrm{I}-\mathrm{O}$ patch taken from a cell expressing BK $\alpha+\beta 1$ (symmetrical $140 \mathrm{mM} \mathrm{K}^{+} ; \mathrm{pCa} 6.3$ ). A slightly different voltage template is shown below. Panel E contains the I-V relationship for this single patch. Both BPA-MS $(100 \mu \mathrm{M})$ and BPA $(100 \mu \mathrm{M})$ appear to affect current. Panel F contains group data $(n=12)$ showing that BPA-MS and BPA both hyperpolarize the $\mathrm{V} 1 \frac{1}{2}$, with BPA being more effective. See text for statistical analyses of $\mathrm{V} 1 / 2$ and $k$ for each set of experiments. 
Figure 4.7

A
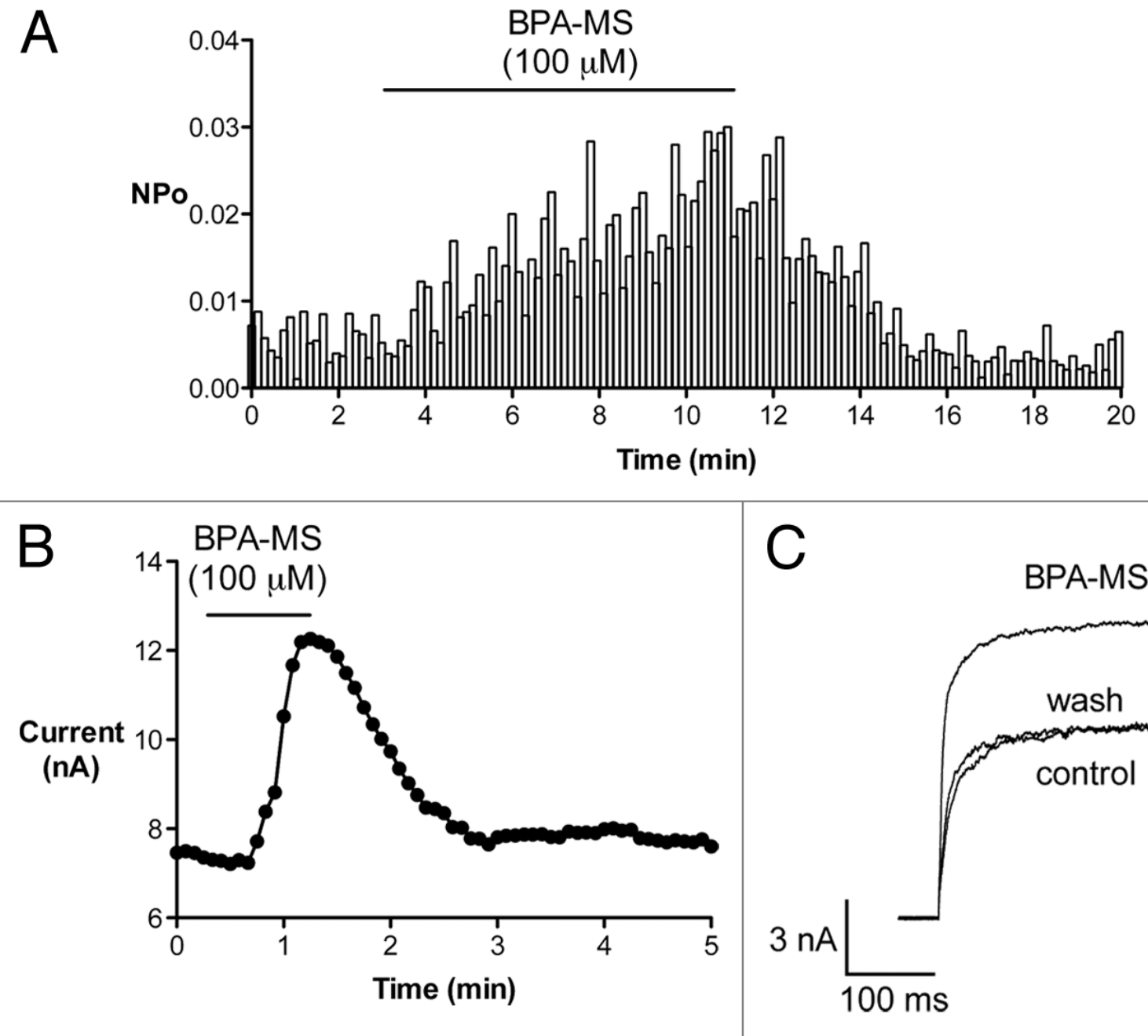

C

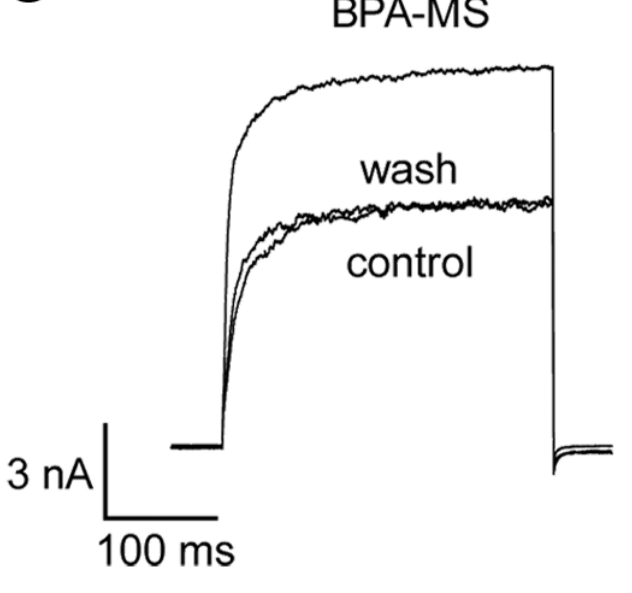


Figure 4.7 The effect of BPA-MS on $\mathrm{NP}_{\mathrm{o}}$ is rapid and reversible. Panel $\mathrm{A} N \mathrm{~N}_{\mathrm{o}}$ vs. time is plotted for a single I-O patch pulled from a cell expressing BK $\alpha+\beta 1$ (symmetrical 140 $\mathrm{mM} \mathrm{K}^{+}$; pCa 7; patch potential $+40 \mathrm{mV}$ ). Cytoplasmic BPA-MS significantly activates BK $\alpha+\beta 1$. Washing out BPA-MS rapidly returns $\mathrm{NP}_{\mathrm{o}}$ towards baseline. Panel $\mathrm{B}$ shows current vs. time for a representative W-C experiment. Bath-applied BPA-MS increases current in a reversible manner. $\underline{\text { Panel } \mathrm{C}}$ contains current traces from experiment plotted in B. 


\section{Chapter 5}

\section{General discussion}

$K_{v} 1$ and $D P O-1$

The regulation of arterial tone by vascular smooth muscle depends, in large part, on a controlled influx of extracellular $\mathrm{Ca}^{2+}$. The magnitude of this $\mathrm{Ca}^{2+}$ influx depends upon the efflux of intracellular $\mathrm{K}^{+}$ions and the resulting negative membrane potential. Voltage-sensitive $\mathrm{Ca}^{2+}$ channels (L-type) are activated by depolarized membrane potential $\left(E_{m}\right)$; therefore, depolarization promotes $\mathrm{Ca}^{2+}$ influx and vasoconstriction. $\mathrm{A}$ variety of $\mathrm{K}^{+}$channels allow $\mathrm{K}^{+}$efflux and thus oppose vasoconstriction. An unknown population of constitutively active $\mathrm{K}^{+}$channels is responsible for resting arterial tone and maintains a polarized membrane potential that inhibits L-type $\mathrm{Ca}^{2+}$ channels. Support for a number of different $\mathrm{K}^{+}$channels exists but a standout candidate remains unclear (see Chapter 1 for a review of putative candidates). It is our supposition that the delayed rectifier $\mathrm{K}^{+}$current $\left(\mathrm{K}_{\mathrm{DR}}\right)$, specifically from the $\mathrm{K}_{\mathrm{V}} 1$ subfamily, is the main contributor to $\mathrm{E}_{\mathrm{m}}$ and arterial tone.

We used the novel $\mathrm{K}_{\mathrm{v}} 1$ antagonist diphenyl phosphine oxide-1 (DPO-1) to examine the effects on $K_{D R}$ channels in smooth muscle from three different vascular beds. DPO1 is reported to have a higher affinity for $\mathrm{K}_{\mathrm{v}} 1.5$ than other $\mathrm{K}_{\mathrm{v}}$ channels (Lagrutta, Wang, Fermini, \& Salata, 2006; Regan, Wallace, Cresswell, Atkins, \& Lynch, 2006; Stump, Wallace, Regan, \& Lynch, 2005) and we demonstrated this in whole-cell patch clamp experiments of aortic smooth muscle cells from $\mathrm{K}_{\mathrm{v}} 1.5$ knockout mice. We investigated the effects of DPO-1 in rat microvessels from brain and skeletal muscle (Chapter 2) as well as $K_{D R}$ channels from porcine right coronary artery (Chapter 3 ). Our goals were to 
investigate the role of $\mathrm{K}_{\mathrm{v}} 1.5$ channels in vascular smooth muscle to determine mechanisms of $K_{D R}$ channel block by DPO-1. In doing so we hope to shed light on the role $\mathrm{K}_{\mathrm{v}} 1.5$ may have in regulating arterial tone and reactivity. Our overall hypothesis was that DPO-1 inhibits $K_{D R}$ channels in smooth muscle cells from both resistance vessels and conduit arteries. Furthermore, we look to support a role for $\mathrm{K}_{\mathrm{V}} 1.5$ in vascular smooth muscle with regard to arterial tone in each study.

The MCA is a widely studied resistance vessel in the cerebral circulation with important physiological implications as these small arteries feed the hemispheres of the brain. The GA feeds the gracillis muscle and would therefore have importance vasoactive responses to exercise. These particular vessels were chosen from vascular beds with different physiological requirements to entertain the possibility of a conserved mechanism of resting arterial tone. In the first study (Chapter 2), we used pressure myography to examine the middle cerebral artery (MCA) and gracilis artery (GA) and their response to inhibition of $K_{D R}$ channels with DPO-1. We also used whole-cell patch clamp techniques to document effects of DPO-1 on $K_{D R}$ channels in smooth muscle cells isolated from these resistance vessels. The goal of this study was to determine a role for $\mathrm{K}_{\mathrm{v}} 1.5$ in vascular tone and reactivity in resistance type vessels from cerebral and skeletal muscle vascular beds. To accomplish that goal, we first had to identify both the expression of $\mathrm{K}_{\mathrm{v}} 1.5$ protein in each vessel and the specificity of DPO-1 for $\mathrm{K}_{\mathrm{v}} 1.5$ in our hands (i.e., with $\mathrm{K}_{\mathrm{v}} 1.5 \mathrm{KO}$ mouse experiments). Western blots confirmed the presence of $\mathrm{K}_{\mathrm{V}} 1.5$ protein in MCA and $\mathrm{GA}$ and this is in accordance with previous studies interested in $\mathrm{K}_{\mathrm{V}}$ channel expression in resistance vessels (Albarwani et al., 2003; Archer et al., 1998; Archer, Weir, Reeve, \& Michelakis, 2000; Cheong, Dedman, 
\& Beech, 2001; Hald et al., 2012; Kang et al., 2009; Plane et al., 2005). Kv1.5 knockout mice had less overall current than their wild-type counterparts in whole-cell patch clamp of smooth muscle cells isolated from aorta. Furthermore, the DPO-1-sensitive current was reduced in knockout mice. We interpret this as support for our hypothesis in two ways: 1) $\mathrm{K}_{\mathrm{V}} 1.5$ is responsible for a significant amount of overall current in arterial smooth muscle and 2) DPO-1 only inhibited currents from cells that contained $\mathrm{K}_{\mathrm{v}} 1.5$. Because $\mathrm{K}_{\mathrm{v}} 1.5$ is expressed in MCA and GA and we confirmed the specificity of DPO-1 for $\mathrm{K}_{\mathrm{v}} 1.5$ in arterial smooth muscle, we felt confident moving forward with using DPO-1 to define a role for $\mathrm{K}_{\mathrm{V}} 1.5$ in regulating arterial tone in the microvasculature.

We determined that DPO-1 inhibits $K_{D R}$ by blockade of $K_{V} 1.5$-containing channels in whole-cell patch clamp of isolated smooth muscle cells from both MCA and GA. Previous electrophysiological recordings in atrial myocytes show DPO compounds preferentially block the ultra rapid activating current ( $\mathrm{IK}_{\mathrm{ur}}$ ) produced by $\mathrm{K}_{\mathrm{v}} 1.5$ (Lagrutta et al., 2006; Regan et al., 2006; Stump et al., 2005). Therefore, we further support the use of DPO-1 as a tool to investigate $\mathrm{K}_{\mathrm{v}} 1.5$ in native cells. We also determined that DPO-1 affects MCA and GA tone and reactivity in a series of pressurized myograph experiments: 1) DPO-1 potently constricted MCA and GA at rest; 2) DPO-1 increased the sensitivity of MCA and GA to vasoconstrictors; 3) DPO-1 shifted the myogenic response of MCA and GA to decreased diameters; and 4) DPO-1 abolished endothelium-dependent vasodilation in MCA and GA. These data support our hypothesis that DPO-1 blocks $\mathrm{K}_{\mathrm{v}} 1.5$-containing $\mathrm{K}_{\mathrm{DR}}$ channels in arterial smooth muscle of resistance vessels and that these channels are important for vascular function. Furthermore, we suggest $\mathrm{K}_{\mathrm{V}} 1.5$ containing channels are open at rest and act as buffers 
to arterial constriction and end effectors in vasodilation. In addition, we support other work suggesting $\mathrm{K}_{\mathrm{V}} 1.5$ channels as major contributors to resting tone and negative feedback against vasoconstriction in microvessels (Archer et al., 2004; Chen, Luykenaar, Walsh, Walsh, \& Cole, 2006; Cheong et al., 2001; Gelband \& Gelband, 1997).

We should note, however, that while we suggest our data shows the inhibition of arterial smooth muscle $\mathrm{K}_{\mathrm{v}} 1.5$ channels, the abolishment of vasodilation due to Ach by DPO-1 might indicate inhibition of other intracellular mechanisms (i.e. inhibition of the sGC/cGMP/PKG pathway). It is well known that $\mathrm{K}^{+}$channels are very important in mediating smooth muscle relaxation by nitric oxide (NO); however, it is also well known that phosphorylation status of myosin light chain kinase/phosphatase (MLCK/P) and intracellular $\mathrm{Ca}^{2+}$ can be influenced by membrane potential-independent cell signaling (Bolotina, Najibi, Palacino, Pagano, \& Cohen, 1994; Khan, Mathews, \& Meisheri, 1993; Somlyo, Wu, Walker, \& Somlyo, 1999). Membrane potential-independent ligand binding to specific G-protein coupled receptors (GPCR) promotes cyclic nucleotide formation followed by direct and indirect (protein kinases) downstream activation of MLCP and/or inhibition of MLCK. Inhibiting these pathways physiologically or pharmacologically results in vasoconstriction, which is also independent of membrane potential or ion channel activity. This complex system of intracellular cross-talk allows for many regulatory pathways of vascular tone and demands careful consideration when investigating novel pharmacological mechanisms. Interestingly, my mentor showed that sodium azide $\left(\mathrm{NaN}_{3}\right)$, which increases cGMP, induces vasodilation dependent on membrane potential yet independent of $\mathrm{K}^{+}$channels, providing pharmaco-mechanical 
evidence that $\mathrm{K}^{+}$channels are not the only driving force for vasodilation, even when membrane potential is a factor (Swafford et al., 2005). Therefore, we cannot exclude a possible off target effect of DPO-1 in our studies regarding MLCK/P phosphorylation status, release of intracellular Ca2+ stores, or sGC/cGMP/PKG intracellular signaling in intact vessels independent of $\mathrm{K}^{+}$channel inhibition. Additional pressure myograph experiments by which reduction of DPO-1-induced vasoconstriction by $\mathrm{K}^{+}$channel independent vasodilators $\left(\mathrm{NaN}_{3}, \mathrm{ML}-7\right.$ to inhibit $\mathrm{MLCK}$, and Rho kinase inhibitors to prevent intracellular $\mathrm{Ca}^{2+}$ release) are required individually and in conjunction to make a conclusion regarding a role for $\mathrm{K}_{\mathrm{V}} 1.5$ (or other $\mathrm{K}^{+}$channels) in microvessel tone and reactivity. Should challenging intact vessels with such pharmacology not promote a vasodilatory effect in the presence of DPO- 1 , then our hypothesis that DPO-1 is a $\mathrm{K}_{\mathrm{V}} 1.5$ specific antagonist will be refuted. If so, DPO-1 should not be used to investigate a role for $\mathrm{K}_{\mathrm{V}} 1.5$ in arterial tone and a new mechanism of DPO-1-induced vasoconstriction will be considered. We also cannot exclude inhibition of endothelial $K_{v} 1.5$, which we also predict would induce similar responses. The use of denuded microvessels and/or an NO donor in place of Ach in additional pressure myograph experiments will shed light on this issue.

Tentative considerations can still be made regarding a role for $\mathrm{K}_{\mathrm{v}} 1.5$ in regulating MCA and GA arterial tone. First, the mechanism of open state block of $\mathrm{K}_{\mathrm{v}} 1.5$ by DPO-1 (discussed in detail in Chapter 3 ) is documented and indicates that channels must be open for DPO-1 to have an effect (Du et al., 2010; Lagrutta et al., 2006). Our data showing that DPO-1 constricts resistance vessels maintaining active tone suggests inhibition of $\mathrm{K}_{\mathrm{v}} 1.5$-containing channels open at rest. Blocking channels responsible for 
the resting $E_{m}$ would depolarize smooth muscle and activate L-type $\mathrm{Ca}^{2+}$ channels, resulting in the observed vasoconstriction in these experiments. Second, we conclude that $\mathrm{K}_{\mathrm{v}} 1.5$ regulates arterial tone by opposing vasoconstriction, but does not control processes such as the myogenic response. This is especially evident in our data showing that blockade of $\mathrm{K}_{\mathrm{V}} 1.5$ by DPO-1 conserves the myogenic response at decreased diameters. Therefore, $\mathrm{K}_{\mathrm{DR}}$ channels prevent an exaggerated vasoconstriction during increased intraluminal pressures but are not responsible for myogenic behavior itself. We are the first to report that DPO-1 constricts intact resistance vessels from cerebral and skeletal muscle vascular beds and suggest that DPO-1 mediates vasoconstriction at rest by blocking open $\mathrm{K}_{\mathrm{v}} 1.5$ channels.

However, an important dichotomy should be addressed pertaining the pulmonary circulation and a role for $\mathrm{K}_{\mathrm{V}} 1.5 . \quad \mathrm{K}_{\mathrm{V}} 1.5$ is an important oxygen sensor in the pulmonary vasculature as evidenced by a loss of hypoxic pulmonary vasoconstriction (HPV) during formation of pulmonary arterial hypertension (PAH) whereby $\mathrm{K}_{v} 1.5$ expression is decreased. Reintroducing $\mathrm{K}_{\mathrm{v}} 1.5$ recovers HPV and ameliorates PAH (Moudgil, Michelakis, \& Archer, 2006; Pozeg et al., 2003). The reduction in pressure and recovery of resting tone might indicate that $\mathrm{K}_{\mathrm{v}} 1.5$ is setting resting $E_{m}$ in the pulmonary vasculature, and many groups support this notion (Firth et al., 2009; Gelband \& Gelband, 1997; Hong, Weir, Nelson, \& Olschewski, 2004). The simultaneous recovery of resting tone and HPV by only reintroducing $\mathrm{K}_{\mathrm{V}} 1.5$ seemingly meets the demands of ventilation-perfusion matching, however, is counterintuitive to control theory. In other words, a single species of ion channel would be responsible for both the open (vasodilation due to oxygen sensing) and closed (HPV) feedback in the pulmonary 
vasculature. It is also arguable from a physiological standpoint that $\mathrm{K}_{\mathrm{v}} 1.5$ cannot simultaneously set resting tone and be available for activation in an open loop fashion of oxygen-induced vasodilation in the absence of HPV, regardless of the oxygen control source (pulmonary arterial oxygen tension vs. mitochondria-derived reactive oxygen species) (Archer et al., 2000; Davies, Grant, Hughes, \& Jones, 1973; Hughes, Grant, Jones, \& Davies, 1974). In fact, recent evidence suggests HPV is driven by activating the release of intracellular $\mathrm{Ca}^{2+}$ stores via rho-kinase-dependent signaling (Aaronson et al., 2006; Robertson, Dipp, Ward, Aaronson, \& Evans, 2000). This might be thought of as indirect evidence for $K_{v} 1.5$ in a role for setting $E_{m}$ in the pulmonary vasculature. Furthermore, in the systemic vasculature oxygen acts as a vasoconstrictor and hypoxia does not seemingly affect $\mathrm{K}_{\vee} 1.5$ (Packer, Lee, Medina, \& Yushak, 1986; Platoshyn et al., 2006; Platoshyn et al., 2001). These dichotomies support the investigation of vessels from different vascular beds when seeking a role for ion channels in vascular reactivity and tone.

Accordingly, the second study (Chapter 3 ) is an extension to our conclusion regarding the mechanism of DPO-1 open state block of $\mathrm{K}_{\mathrm{v}} 1.5$. Our goal in this study was to investigate the mechanism by which DPO-1 directly inhibits native $\mathrm{K}_{\mathrm{DR}}$ channels of smooth muscle cells isolated from porcine right coronary artery. We then compared our results to previous work examining the open state block of cloned $\mathrm{K}_{\mathrm{v}} 1.5$ by DPO-1. Two studies were especially useful as references regarding DPO-1 block of human cloned $K_{v} 1.5$. Lagrutta et al. described the open state block of cloned $K_{v} 1.5$ by DPO-1 and showed selectivity for $\mathrm{IK}_{\mathrm{ur}}$ over other $\mathrm{K}^{+}$currents associated with the atrial action potential (Lagrutta et al., 2006). Du et al. also observed open state block of cloned 
$\mathrm{K}_{\mathrm{V}} 1.5$ by DPO-1 and showed that specific mutations in the $\mathrm{S} 4$ voltage-sensing segment reduced DPO-1-sensitive currents (Du et al., 2010). Both groups observed a time-, voltage-, and frequency-dependent inhibition of $\mathrm{K}_{\mathrm{V}} 1.5$ by DPO-1; hallmarks of open state block. Therefore, we determined the effects of DPO-1 on porcine coronary smooth muscle cell $K_{D R}$ in whole-cell patch clamp experiments similar to those performed on cloned $\mathrm{K}_{\mathrm{V}}$ 1.5. Importantly, we also observed a time-, voltage-, and frequency-dependent block by DPO-1 on native smooth muscle $\mathrm{K}_{\mathrm{DR}}$ consistent with those studies on cloned $\mathrm{K}_{v}$ 1.5. However, we observed two profound differences in our study versus those performed on cloned $\mathrm{K}_{\mathrm{V}} 1.5$. In an open state block experiment comparable to those performed by Lagrutta et al., DPO-1 does not exhibit a complete open state inhibition in coronary smooth muscle $\mathrm{K}_{\mathrm{DR}}$ as observed in cloned $\mathrm{K}_{\mathrm{V}} 1.5$. Instead, we show that approximately $30-50 \%$ of the current is reduced after application of DPO-1 suggestive of simultaneous closed state inhibition of native smooth muscle $K_{D R}$ channels. Furthermore, the voltage of half activation of cloned $\mathrm{K}_{\mathrm{v}} 1.5$ was unaffected by DPO-1 whereas we observed a left shift in the activation curve of smooth muscle $K_{D R}$ with application of DPO-1. We speculate that this difference may be due to the presence of other $\mathrm{K}_{\mathrm{V}} 1$ family subunits (e.g., $\mathrm{K}_{\mathrm{V}} 1.2$ ) in $\mathrm{K}_{\mathrm{V}} 1.5$-containing heterotetramers, which may alter effects of DPO-1 from those observed in previous studies of cloned $\mathrm{K}_{\mathrm{V}} 1.5$ homotetramers. This idea is supported by studies that show an association of $\mathrm{K}_{\mathrm{v}} 1.5$ with $\mathrm{K}_{V} 1.2$ in vascular smooth muscle (Albarwani et al., 2003; Kerr et al., 2001). Further evidence of the effects of DPO-1 on $\mathrm{K}_{\mathrm{V}} 1.5$-containing heterotetramer complexes is required to determine if our hypothesis is supported. 
In addition to comparisons of cloned $\mathrm{K}_{\mathrm{V}} 1.5$, we were interested in the overall mechanism of arterial smooth muscle $\mathrm{K}_{\mathrm{DR}}$ channel block by DPO-1. To determine the mechanism of block, we analyzed a variety of whole-cell patch clamp protocols to extrapolate $\mathrm{K}_{\mathrm{DR}}$ channel kinetics including activation, inactivation, and recovery time constants ( $\mathrm{T})$. DPO- 1 accelerated the activation time constant suggesting that peak current was reached faster in the presence of DPO-1. This is a common finding with drugs that block Kv1.5 (Jeong, Choi, \& Hahn, 2013; Jeong, Choi, Yoon, \& Hahn, 2012; Jeong, Yoon, \& Hahn, 2012), but has not been shown previously with DPO-1. We also observed two components of inactivation $\mathrm{T}$ (fast and slow) for $\mathrm{K}_{\mathrm{DR}}$. This is most likely due to a number of $K_{D R}$ channel influences in the native system or expression of $\beta$ auxiliary subunits such as $\mathrm{K}_{\mathrm{v}} \beta 1.3$ (Plane et al., 2005), which can alter $\mathrm{K}_{\mathrm{v}} 1.5$ channel kinetics (Tipparaju et al., 2012; Tipparaju, Liu, Barski, \& Bhatnagar, 2007). DPO-1 robustly and significantly accelerated both T components of inactivation. In contrast, DPO-1 significantly prolonged recovery from inactivation kinetics, indicating that DPO-1 may promote the inactivated state. Interestingly, mutation of a specific residue in the S4 voltage-sensing segment of $\mathrm{K}_{\mathrm{V}} 1.5$ mimics block by DPO- 1 and reduces the sensitivity of the channel to DPO-1 (Du et al., 2010). Therefore, we suggest a mechanism of arterial smooth muscle $K_{D R}$ channel block whereby DPO-1 first binds residues of a $K_{V}$ channel S4 segment, not necessarily $\mathrm{K}_{\mathrm{v}} 1.5$, in the closed state. This prediction has two observed effects: 1) a slight increase in voltage sensitivity of the $K_{D R}$ channel resulting in a left shift of the activation curve and 2) accelerated activation kinetics i.e. the channel opens faster. Upon channel opening, DPO-1 may bind specific S4 segment residues of $\mathrm{K}_{\mathrm{V}} 1.5$ and rapidly accelerate inactivation $\mathrm{T}$ components. The result is a 
shifting of the voltage window of activation to more hyperpolarized potentials and thusly prevention of $\mathrm{K}^{+}$conductance during depolarized potentials. While the voltagedependent block by DPO-1 in our study further supports this hypothesis, there are of course other possible explanations for the molecular mechanism of smooth muscle $\mathrm{K}_{\mathrm{DR}}$ inhibition. For instance, the effect of DPO-1 on auxiliary $\mathrm{K}_{\mathrm{v}} \beta$ subunits is unknown and these regulatory proteins may very well play a role in the effects on kinetics and voltage sensitivity observed in this study. Another possible mechanism of inhibition might involve the intracellular T1 domain that regulates $\mathrm{K}_{\mathrm{V}} 1.5$ inactivation. Disruption of the T1 domain results in $\mathrm{K}_{\mathrm{V}} 1.5$ inactivation type switching, specifically from P/C-type to U-type inactivation (Kurata, Doerksen, Eldstrom, Rezazadeh, \& Fedida, 2005). DPO-1 may have an affinity for residues in the T1 domain and promote and prolong inactivation during open and inactivated states, 'inhibiting' $\mathrm{K}_{\mathrm{V}} 1.5$-containing channels by changing the inactivation type. Further investigation of cloned molecular $\mathrm{K}_{V}$ machinery and the influence of DPO-1 on different combinations of $\mathrm{K}_{\mathrm{V}} 1.5$ containing heterotetramers with $K_{v} \beta$ subunits may reveal native smooth muscle $K_{D R}$ composition.

This study expands on our work done in MCA and GA resistance vessels by providing a biophysical association of DPO-1 with $\mathrm{K}_{\mathrm{DR}}$ channels in native smooth muscle cells. Collectively, our data indicate that DPO-1 is a sufficient pharmacological tool to investigate native $K_{D R}$ channels. In conjunction with other $K_{V} 1$ (correolide) and non-K 1 (e.g. $K_{v} 7$ agonists and antagonists) pharmacology, DPO-1 could provide a clear understanding of $\mathrm{K}_{\mathrm{V}} 1.5$-containing $\mathrm{K}_{\mathrm{DR}}$ channels in arterial smooth muscle tone and reactivity. Importantly, this work suggests a conserved role for $\mathrm{K}_{\mathrm{v}} 1.5$ in regulating 
arterial tone from resistance vessels in rat brain and skeletal muscle and conduit-like vessels of the porcine coronary circulation.

\section{$B K$ and BPA-MS}

BK channels are expressed in a variety of cell types, most notably neurons and vascular smooth muscle (Cox \& Rusch, 2002; Sah \& Faber, 2002). Tissue specific auxiliary BK $\beta$ isoforms alter the pharmacology and biophysics of the channel (Contreras, Neely, Alvarez, Gonzalez, \& Latorre, 2012). The $\beta 1$ isoform is associated with vascular smooth muscle BK channels and confers activation by estrogens and steroid hormones (Bukiya, Liu, Toro, \& Dopico, 2007; Knaus et al., 1994; Valverde et al., 1999). Accordingly, the estrogenic drug tamoxifen activates BK channels through interactions with $\beta 1$ (Dick, Rossow, Smirnov, Horowitz, \& Sanders, 2001). Our group previously showed that the xenoestrogen BPA activates BK channels in the presence and absence of $\beta 1$, however the presence of the auxiliary subunit increased the sensitivity to BPA by a log order (Asano, Tune, \& Dick, 2010). In Chapter 4 of this document we determined from which side of the membrane lipophilic BPA activates cloned BK channels with and without the $\beta 1$ subunit. To do this we synthesized membrane impermeable BPA-MS and used patch clamp electrophysiology to delineate extracellular vs. intracellular BK channel activation by BPA. We conclude that BPA activates BKa from an extracellular site as BPA-MS did not activate BK in inside-out patches where cytoplasmic portions of the channel are exposed. Interestingly, addition of the $\beta 1$ subunit reveals potential extracellular and intracellular activation sites. BPAMS did not match the efficacy of BPA on single channel open probability $\left(\mathrm{NP}_{\circ}\right)$ in insideout or outside-out patches indicating that the lipophilic BPA may have multiple $\beta 1$ 
activation sites. These data reflect the putative pharmacodynamics of BPA and we suggest activation of BK channels in vascular smooth muscle may occur during exposure to BPA. Whether or not this may have unwanted health deficits is uncertain.

The surprising findings that the $\beta 1$ subunit contains an intracellular activation site and that BPA-MS has less effect on $\mathrm{NP}_{\mathrm{o}}$ in single channel patches suggests that lipophilic BPA has two $\beta 1$ binding sites. Because BPA-MS is membrane impermeable it is possible only one activation site could be reached in patch clamp configurations. Our data indicate that both $\beta 1$ sites need to be bound by BPA to induce full activation of BK channels. Previous work conducted by my mentor shows tamoxifen, an anti-estrogen drug for treating breast cancer, activates BK channels via an extracellular binding site of the $\beta 1$ subunit, and we therefore hypothesized a similar mechanism of action for BPA (Dick, Hunter, \& Sanders, 2002). BPA-MS does activate BKa and BKa $+\beta 1$ channels from the extracellular side, however, we also observed intracellular activation of BK channels similar to that of lithocholate where specific intracellular $\beta 1$ residues confer BK activation (Bukiya et al., 2007). We predict dual activation sites on the $\beta 1$ subunit for two reasons: 1) addition of the $\beta 1$ subunit increased the sensitivity to BPA-MS by a log order in outside-out patches and 2) BPA-MS activated BK channels containing the $\beta 1$ subunit from inside-out patches and did not activate BKa alone. This may have implications to vascular dysfunction upon exposure to BPA, as overstimulation of ion channels can lead to tachyphylaxis, and could very well promote the progression of diseases states including hypertension.

While circulating steroids such as lithocholate activate BK channels via the $\beta 1$ subunit, xenoestrogens such as BPA do not have an endogenous physiological role. 
The effects of BPA must come through environmental exposure. The main route of BPA exposure is through the diet, although topical exposure is also possible (Porras, Heinala, \& Santonen, 2014). In the present study, we administered micromolar concentrations of BPA-MS in order to see an effect on BK channels. These concentrations of BPA may be well above a translational concentration to daily human exposure, as urine concentrations of BPA were at highest $8.5 \mu \mathrm{M}$ in factory workers (Wang et al., 2012). However, much lower concentrations of chronic BPA exposure alter the expression of ion channels (Derouiche et al., 2013; Kim, An, Yang, \& Jeung, 2013). Here we show high concentrations of BPA activate BK channels, which may contain health relevance to industrial workers exposed to chronic doses at higher levels than the general public.

This study supports previous findings indicating that BPA affects ion channels in the cardiovascular system (Gao, Liang, Chen, \& Wang, 2013; O'Reilly et al., 2012; Yan et al., 2011). More specifically, our group previously showed that BPA activates BK channels in human coronary smooth muscle cells and we expand on that knowledge here by showing extracellular and intracellular activation by BPA via the BK $\beta 1$ subunit (Asano et al., 2010). Therefore, BPA exposure may cause unwanted ion channel activation/inhibition in healthy persons and exacerbate preexisting disease states. While more information regarding the effects of BPA on BK channel function and expression are needed to delineate any specific pathological role, we provided a novel relationship for interactions with extracellular and intracellular BK $\beta 1$ residues. Furthermore, we support the notion that BPA affects ion channel function. 


\section{References}

Aaronson, P. I., Robertson, T. P., Knock, G. A., Becker, S., Lewis, T. H., Snetkov, V., \& Ward, J. P. (2006). Hypoxic pulmonary vasoconstriction: mechanisms and controversies. J Physiol, 570(Pt 1), 53-58. doi: 10.1113/jphysiol.2005.098855

Albarwani, S., Nemetz, L. T., Madden, J. A., Tobin, A. A., England, S. K., Pratt, P. F., \& Rusch, N. J. (2003). Voltage-gated $\mathrm{K}^{+}$channels in rat small cerebral arteries: molecular identity of the functional channels. J Physiol, 551(Pt 3), 751-763. doi: 10.1113/jphysiol.2003.040014

jphysiol.2003.040014 [pii]

Archer, S. L., Souil, E., Dinh-Xuan, A. T., Schremmer, B., Mercier, J. C., El Yaagoubi, A., ... Hampl, V. (1998). Molecular identification of the role of voltage-gated K+ channels, Kv1.5 and Kv2.1, in hypoxic pulmonary vasoconstriction and control of resting membrane potential in rat pulmonary artery myocytes. J Clin Invest, 101(11), 2319-2330. doi: 10.1172/JCI333

Archer, S. L., Weir, E. K., Reeve, H. L., \& Michelakis, E. (2000). Molecular identification of $\mathrm{O} 2$ sensors and $\mathrm{O} 2$-sensitive potassium channels in the pulmonary circulation. Adv Exp Med Biol, 475, 219-240.

Archer, S. L., Wu, X. C., Thebaud, B., Nsair, A., Bonnet, S., Tyrrell, B., . . Michelakis, E. D. (2004). Preferential expression and function of voltage-gated, O2-sensitive $\mathrm{K}+$ channels in resistance pulmonary arteries explains regional heterogeneity in 
hypoxic pulmonary vasoconstriction: ionic diversity in smooth muscle cells. Circ Res, 95(3), 308-318. doi: 10.1161/01.RES.0000137173.42723.fb

Asano, S., Tune, J. D., \& Dick, G. M. (2010). Bisphenol A activates Maxi-K (K(Ca)1.1) channels in coronary smooth muscle. Br J Pharmacol, 160(1), 160-170. doi: 10.1111/j.1476-5381.2010.00687.x

Bolotina, V. M., Najibi, S., Palacino, J. J., Pagano, P. J., \& Cohen, R. A. (1994). Nitric oxide directly activates calcium-dependent potassium channels in vascular smooth muscle. Nature, 368(6474), 850-853. doi: 10.1038/368850a0

Bukiya, A. N., Liu, J., Toro, L., \& Dopico, A. M. (2007). Beta1 (KCNMB1) subunits mediate lithocholate activation of large-conductance $\mathrm{Ca} 2+$-activated $\mathrm{K}+$ channels and dilation in small, resistance-size arteries. Mol Pharmacol, 72(2), 359-369. doi: $10.1124 / \mathrm{mol} .107 .034330$

Chen, T. T., Luykenaar, K. D., Walsh, E. J., Walsh, M. P., \& Cole, W. C. (2006). Key role of Kv1 channels in vasoregulation. Circ Res, 99(1), 53-60. doi: 01.RES.0000229654.45090.57 [pii]

10.1161/01.RES.0000229654.45090.57

Cheong, A., Dedman, A. M., \& Beech, D. J. (2001). Expression and function of native potassium channel $[\mathrm{K}(\mathrm{V})$ alpha1] subunits in terminal arterioles of rabbit. $J$ Physiol, 534(Pt 3), 691-700. 
Contreras, G. F., Neely, A., Alvarez, O., Gonzalez, C., \& Latorre, R. (2012). Modulation of BK channel voltage gating by different auxiliary beta subunits. Proc Natl Acad Sci U S A, 109(46), 18991-18996. doi: 10.1073/pnas.1216953109

Cox, R. H., \& Rusch, N. J. (2002). New expression profiles of voltage-gated ion channels in arteries exposed to high blood pressure. Microcirculation, 9(4), 243257. doi: $10.1038 /$ sj.mn.7800140

Davies, E. E., Grant, B. J., Hughes, J. M., \& Jones, H. A. (1973). Local control of blood flow in lungs of the coati mundi. J Physiol, 231(2), 106P-108P.

Derouiche, S., Warnier, M., Mariot, P., Gosset, P., Mauroy, B., Bonnal, J. L., . . . Roudbaraki, M. (2013). Bisphenol A stimulates human prostate cancer cell migration remodelling of calcium signalling. Springerplus, 2(1), 54. doi: $10.1186 / 2193-1801-2-54$

Dick, G. M., Hunter, A. C., \& Sanders, K. M. (2002). Ethylbromide tamoxifen, a membrane-impermeant antiestrogen, activates smooth muscle calcium-activated large-conductance potassium channels from the extracellular side. $\mathrm{Mol}$ Pharmacol, 61(5), 1105-1113.

Dick, G. M., Rossow, C. F., Smirnov, S., Horowitz, B., \& Sanders, K. M. (2001). Tamoxifen activates smooth muscle BK channels through the regulatory beta 1 subunit. J Biol Chem, 276(37), 34594-34599. doi: 10.1074/jbc.M104689200 
Du, Y. M., Zhang, X. X., Tu, D. N., Zhao, N., Liu, Y. J., Xiao, H., . . Liao, Y. H. (2010). Molecular determinants of Kv1.5 channel block by diphenyl phosphine oxide-1. $J$ Mol Cell Cardiol, 48(6), 1111-1120. doi: 10.1016/j.yjmcc.2010.02.010

Firth, A. L., Platoshyn, O., Brevnova, E. E., Burg, E. D., Powell, F., Haddad, G. H., \& Yuan, J. X. (2009). Hypoxia selectively inhibits KCNA5 channels in pulmonary artery smooth muscle cells. Ann N Y Acad Sci, 1177, 101-111. doi: 10.1111/j.1749-6632.2009.05040.x

Gao, X., Liang, Q., Chen, Y., \& Wang, H. S. (2013). Molecular mechanisms underlying the rapid arrhythmogenic action of bisphenol $A$ in female rat hearts. Endocrinology, 154(12), 4607-4617. doi: 10.1210/en.2013-1737

Gelband, C. H., \& Gelband, H. (1997). Ca2+ release from intracellular stores is an initial step in hypoxic pulmonary vasoconstriction of rat pulmonary artery resistance vessels. Circulation, 96(10), 3647-3654.

Hald, B. O., Jacobsen, J. C., Braunstein, T. H., Inoue, R., Ito, Y., Sorensen, P. G., . . Jensen, L. J. (2012). BKCa and KV channels limit conducted vasomotor responses in rat mesenteric terminal arterioles. Pflugers Arch, 463(2), 279-295. doi: 10.1007/s00424-011-1049-8

Hong, Z., Weir, E. K., Nelson, D. P., \& Olschewski, A. (2004). Subacute hypoxia decreases voltage-activated potassium channel expression and function in 
pulmonary artery myocytes. Am J Respir Cell Mol Biol, 31(3), 337-343. doi: 10.1165/rcmb.2003-0386OC

Hughes, J. M., Grant, B. J., Jones, H. A., \& Davies, E. E. (1974). Relationship between blood flow and alveolar gas tensions in lung lobules. Scand J Respir Dis Suppl, $85,17-21$.

Jeong, I., Choi, B. H., \& Hahn, S. J. (2013). Pergolide block of the cloned Kv1.5 potassium channels. Naunyn Schmiedebergs Arch Pharmacol, 386(2), 125-133. doi: $10.1007 / \mathrm{s} 00210-012-0776-5$

Jeong, I., Choi, B. H., Yoon, S. H., \& Hahn, S. J. (2012). Carvedilol blocks the cloned cardiac Kv1.5 channels in a beta-adrenergic receptor-independent manner. Biochem Pharmacol, 83(4), 497-505. doi: 10.1016/j.bcp.2011.11.019

Jeong, I., Yoon, S. H., \& Hahn, S. J. (2012). Effects of dapoxetine on cloned Kv1.5 channels expressed in $\mathrm{CHO}$ cells. Naunyn Schmiedebergs Arch Pharmacol, 385(7), 707-716. doi: 10.1007/s00210-012-0754-y

Kang, L. S., Kim, S., Dominguez, J. M., 2nd, Sindler, A. L., Dick, G. M., \& Muller-Delp, J. M. (2009). Aging and muscle fiber type alter $\mathrm{K}+$ channel contributions to the myogenic response in skeletal muscle arterioles. J Appl Physiol (1985), 107(2), 389-398. doi: 10.1152/japplphysiol.91245.2008 
Kerr, P. M., Clement-Chomienne, O., Thorneloe, K. S., Chen, T. T., Ishii, K., Sontag, D. P., . . Cole, W. C. (2001). Heteromultimeric Kv1.2-Kv1.5 channels underlie 4aminopyridine-sensitive delayed rectifier $\mathrm{K}(+)$ current of rabbit vascular myocytes. Circ Res, 89(11), 1038-1044.

Khan, S. A., Mathews, W. R., \& Meisheri, K. D. (1993). Role of calcium-activated K+ channels in vasodilation induced by nitroglycerine, acetylcholine and nitric oxide. J Pharmacol Exp Ther, 267(3), 1327-1335.

Kim, S., An, B. S., Yang, H., \& Jeung, E. B. (2013). Effects of octylphenol and bisphenol A on the expression of calcium transport genes in the mouse duodenum and kidney during pregnancy. Toxicology, 303, 99-106. doi: 10.1016/j.tox.2012.10.023

Knaus, H. G., Folander, K., Garcia-Calvo, M., Garcia, M. L., Kaczorowski, G. J., Smith, M., \& Swanson, R. (1994). Primary sequence and immunological characterization of beta-subunit of high conductance $\mathrm{Ca}(2+)$-activated $\mathrm{K}+$ channel from smooth muscle. J Biol Chem, 269(25), 17274-17278.

Kurata, H. T., Doerksen, K. W., Eldstrom, J. R., Rezazadeh, S., \& Fedida, D. (2005). Separation of $\mathrm{P} / \mathrm{C}$ - and U-type inactivation pathways in Kv1.5 potassium channels. J Physiol, 568(Pt 1), 31-46. doi: 10.1113/jphysiol.2005.087148 
Lagrutta, A., Wang, J., Fermini, B., \& Salata, J. J. (2006). Novel, potent inhibitors of

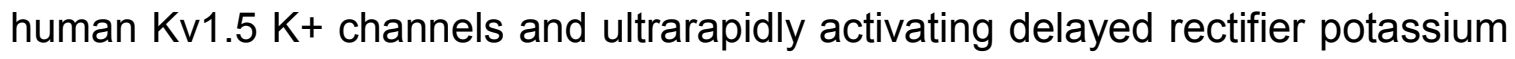
current. J Pharmacol Exp Ther, 317(3), 1054-1063. doi: 10.1124/jpet.106.101162

Moudgil, R., Michelakis, E. D., \& Archer, S. L. (2006). The role of k+ channels in determining pulmonary vascular tone, oxygen sensing, cell proliferation, and apoptosis: implications in hypoxic pulmonary vasoconstriction and pulmonary arterial hypertension. Microcirculation, 13(8), 615-632. doi: $10.1080 / 10739680600930222$

O'Reilly, A. O., Eberhardt, E., Weidner, C., Alzheimer, C., Wallace, B. A., \& Lampert, A. (2012). Bisphenol A binds to the local anesthetic receptor site to block the human cardiac sodium channel. PLoS One, 7(7), e41667. doi: 10.1371/journal.pone.0041667

Packer, M., Lee, W. H., Medina, N., \& Yushak, M. (1986). Systemic vasoconstrictor effects of oxygen administration in obliterative pulmonary vascular disorders. Am J Cardiol, 57(10), 853-858.

Plane, F., Johnson, R., Kerr, P., Wiehler, W., Thorneloe, K., Ishii, K., . . . Cole, W. (2005). Heteromultimeric Kv1 channels contribute to myogenic control of arterial diameter. Circ Res, 96(2), 216-224. doi: 01.RES.0000154070.06421.25 [pii]

10.1161/01.RES.0000154070.06421.25 
Platoshyn, O., Brevnova, E. E., Burg, E. D., Yu, Y., Remillard, C. V., \& Yuan, J. X. (2006). Acute hypoxia selectively inhibits KCNA5 channels in pulmonary artery smooth muscle cells. Am J Physiol Cell Physiol, 290(3), C907-916. doi: 10.1152/ajpcell.00028.2005

Platoshyn, O., Yu, Y., Golovina, V. A., McDaniel, S. S., Krick, S., Li, L., . . Yuan, J. X. (2001). Chronic hypoxia decreases $K(V)$ channel expression and function in pulmonary artery myocytes. Am J Physiol Lung Cell Mol Physiol, 280(4), L801812.

Porras, S. P., Heinala, M., \& Santonen, T. (2014). Bisphenol A exposure via thermal paper receipts. Toxicol Lett. doi: 10.1016/j.toxlet.2014.08.020

Pozeg, Z. I., Michelakis, E. D., McMurtry, M. S., Thebaud, B., Wu, X. C., Dyck, J. R., . . Archer, S. L. (2003). In vivo gene transfer of the O2-sensitive potassium channel Kv1.5 reduces pulmonary hypertension and restores hypoxic pulmonary vasoconstriction in chronically hypoxic rats. Circulation, 107(15), 2037-2044. doi: 10.1161/01.CIR.0000062688.76508.B3

Regan, C. P., Wallace, A. A., Cresswell, H. K., Atkins, C. L., \& Lynch, J. J., Jr. (2006). In vivo cardiac electrophysiologic effects of a novel diphenylphosphine oxide IKur blocker, (2-Isopropyl-5-methylcyclohexyl) diphenylphosphine oxide, in rat and nonhuman primate. J Pharmacol Exp Ther, 316(2), 727-732. doi: jpet.105.094839 [pii] 
10.1124/jpet.105.094839

Robertson, T. P., Dipp, M., Ward, J. P., Aaronson, P. I., \& Evans, A. M. (2000). Inhibition of sustained hypoxic vasoconstriction by $\mathrm{Y}-27632$ in isolated intrapulmonary arteries and perfused lung of the rat. $\mathrm{Br} J$ Pharmacol, 131(1), 5-9. doi: $10.1038 /$ sj.bjp.0703537

Sah, P., \& Faber, E. S. (2002). Channels underlying neuronal calcium-activated potassium currents. Prog Neurobiol, 66(5), 345-353.

Somlyo, A. P., Wu, X., Walker, L. A., \& Somlyo, A. V. (1999). Pharmacomechanical coupling: the role of calcium, G-proteins, kinases and phosphatases. Rev Physiol Biochem Pharmacol, 134, 201-234.

Stump, G. L., Wallace, A. A., Regan, C. P., \& Lynch, J. J., Jr. (2005). In vivo antiarrhythmic and cardiac electrophysiologic effects of a novel diphenylphosphine oxide IKur blocker (2-isopropyl-5-methylcyclohexyl) diphenylphosphine oxide. J Pharmacol Exp Ther, 315(3), 1362-1367. doi: 10.1124/jpet.105.092197

Swafford, A. N., Jr., Bratz, I. N., Knudson, J. D., Rogers, P. A., Timmerman, J. M., Tune, J. D., \& Dick, G. M. (2005). C-reactive protein does not relax vascular smooth muscle: effects mediated by sodium azide in commercially available 
preparations. Am J Physiol Heart Circ Physiol, 288(4), H1786-1795. doi: 10.1152/ajpheart.00996.2004

Tipparaju, S. M., Li, X. P., Kilfoil, P. J., Xue, B., Uversky, V. N., Bhatnagar, A., \& Barski, O. A. (2012). Interactions between the C-terminus of Kv1.5 and Kvbeta regulate pyridine nucleotide-dependent changes in channel gating. Pflugers Arch, 463(6), 799-818. doi: 10.1007/s00424-012-1093-z

Tipparaju, S. M., Liu, S. Q., Barski, O. A., \& Bhatnagar, A. (2007). NADPH binding to beta-subunit regulates inactivation of voltage-gated $\mathrm{K}(+)$ channels. Biochem Biophys Res Commun, 359(2), 269-276. doi: 10.1016/j.bbrc.2007.05.102

Valverde, M. A., Rojas, P., Amigo, J., Cosmelli, D., Orio, P., Bahamonde, M. I., . . . Latorre, R. (1999). Acute activation of Maxi-K channels (hSlo) by estradiol binding to the beta subunit. Science, 285(5435), 1929-1931.

Wang, F., Hua, J., Chen, M., Xia, Y., Zhang, Q., Zhao, R., . . Wang, B. (2012). High urinary bisphenol A concentrations in workers and possible laboratory abnormalities. Occup Environ Med, 69(9), 679-684. doi: 10.1136/oemed-2011100529

Yan, S., Chen, Y., Dong, M., Song, W., Belcher, S. M., \& Wang, H. S. (2011). Bisphenol A and 17beta-estradiol promote arrhythmia in the female heart via alteration of calcium handling. PLoS One, 6(9), e25455. doi: 10.1371/journal.pone.0025455 


\section{CURRICULUM VITAE}

Name:

Title:

Address:

Telephone:

Fax:

E-Mail:

Birthdate:

Birthplace:
Ibra S. Fancher, IV

Graduate student

Department of Exercise Physiology

West Virginia University School of Medicine

P.O. Box 9105, Morgantown, WV 26506
(304) 293-8047

(304) 293-5513

ifancher@hsc.wvu.edu

Oct. 13, 1986

Reading, PA

\section{Education:}

Undergraduate $\quad$ B.S.; Biology; St. Vincent College; Latrobe, PA (2005-2009)

Graduate Ph.D.; Exercise Physiology; West Virginia University School of Medicine (2009-2014)

\section{Awards and Honors:}

- Academic scholarship; St. Vincent College (2005-2009)

- Golden Key member since 2011

- Elected Treasurer of West Virginia University Graduate Student Organization, $(2012-2013)$ 
- NHLBI-T32 Pre-Doctoral Training Grant Recipient (2012-2014)

- Co-author on AHA accepted abstract: Acute Effects of Dietary Bisphenol A on Arterial Health

- $1^{\text {st }}$ place poster presentation award at $2^{\text {nd }}$ annual Appalachian Regional Cell Conference: Mechanism of delayed rectifier $\mathrm{K}^{+}$current by DPO-1 in smooth muscle and its functional relevance: depolarization and vasoconstriction.

- $2^{\text {nd }}$ place poster presentation award at 2014 WVU Van Liere Convocation

\section{Membership in Professional Organizations:}

- American Physiological Society (2012-present)

- American Heart Association (2013-present)

\section{Peer-reviewed publications:}

1. Asano S, Bratz IN, Berwick ZC, Fancher IS, Tune JD, Dick GM. Penitrem A as a tool to understand the role of BK channels in vascular function. J Pharmacol Exp Ther. 2012 Aug;342(2):453-60.

2. Fancher IS, Dick GM, Hollander JM. Diabetes reduces the function and expression of ATP-dependent $\mathrm{K}^{+}$channels in cardiac mitochondria. Life Sci. 2013 Mar 28;92(11):664-8.

3. Fancher IS*, Rottgen TS*, Asano S, Widlanski TS, Dick GM. Bisphenol A 
activates BK channels through effects on $\alpha$ and $\beta 1$ subunits. Channels. 2014 Jan 29;8(3), 1-9. *Contributed equally, co-first authors.

\section{In revision:}

1. Fancher IS, Butcher JT, Brooks SD, Rottgen TS, Skaff PR, Frisbee JC, Dick GM. DPO-1-sensitive $\mathrm{K}^{+}$channels contribute to the vascular tone and reactivity of arterioles from brain and skeletal muscle. Microcirculation (UMIC-2014-0083-R1).

\section{Submitted for review:}

1. Fancher IS and Dick GM. Diphenyl phosphine oxide-1 inhibits $K_{V}$ channels in porcine coronary smooth muscle by accelerating inactivation kinetics. (Channels).

\section{Published Abstracts:}

1. Janelle C Stricker, Cody E Nichols, Andrew Katz, Ibra Fancher, Tiffany C Cuppett, Kady Miletti, Corey Vasisko, Erinne R Dabkowski, Walter A Baseler, John M Hollander, and Michael R Morissette. Characterization of regression of exercise-induced cardiac hypertrophy. FASEB J April 6, 2010 24:Ib593

2. Ibra S. Fancher, IV, Walter A. Baseler, Tara L. Croston, Dharendra Thapa, Danielle Shepherd, Cody Nichols, Sarah Lewis, Rajaganapathi Jagannathan, Shinichi Asano, Gregory M. Dick, and John M. Hollander. Differential expression of mitoKATP subunits in cardiac mitochondrial subpopulations and the influence of Type I diabetes. FASEB J March 29, 2012 26:1057.6 
3. Shinichi Asano, Ibra Seaphus Fancher, and Gregory M Dick. Bisphenol A decreases BK channel expression in rat aorta via genomic mechanisms. FASEB J March 29, 2012 26:1140.2

4. Ibra S. Fancher, Tara L. Croston, Danielle Shepherd, Gregory M. Dick, John M. Hollander. Cardiac interfibrillar mitoK $\mathrm{ATP}_{\mathrm{TP}}$ channels are sensitive to diazoxide and have a regulatory subunit profile distinct form subsarcolemmal mitoK $\mathrm{K}_{\text {ATP. }}$ FASEB J April 9, 2013 27:1209.16.

5. Paul D. Chantler, Ibra S. Fancher, Corey Nida, Sara Fournier, Evan DeVallance, Trey S. Rottgen, Suzanne Bell, Gregory M. Dick. Acute Effects of Dietary Bisphenol A on Arterial Health. AHA, Dallas 2013.

6. Ibra Fancher and Gregory M. Dick. KCNA5 knockout mice demonstrate that $\mathrm{Kv} 1.5$ is a component of the native delayed rectifier $\mathrm{K}^{+}$current in vascular smooth muscle. FASEB J April 2014 28:1077.6.

7. Ibra Fancher, Jillian Noblet, Adam Goodwill, Johnathan Tune, and Gregory Dick. Mechanism of inhibition of delayed rectifier $\mathrm{K}^{+}$current by diphenyl phosphine oxide-1 in porcine coronary smooth muscle. FASEB J April 2014 28:1079.10. 
8. Trey Rottgen, Ibra Fancher, and Gregory Dick. Expression and function of BK and Kv1.5 channels in aortic smooth muscle from lean and obese Zucker rats. FASEB J April 2014 28:1077.5.

9. Paul Chantler, Erica Casto, Evan DeVallance, Sara Fournier, Ibra Fancher, and Gregory Dick. Acute effects of dietary bisphenol A on endothelial function in humans. FASEB J April 2014 28:677.14.

10. Joshua Butcher, Ibra Fancher, Jefferson Frisbee, and Gregory Dick. DPO-1 sensitive $\mathrm{K}^{+}$channels control the tone and reactivity of resistance-sized arterioles from bran and skeletal muscle. FASEB J April 2014 27: 1209.16.

\section{Presentations:}

Appalachian Regional Cell Conference

Ibra S. Fancher, Greg M. Dick, John M. Hollander. Diabetes mellitus reduces the function and expression of ATP-dependent $\mathrm{K}^{+}$channels in cardiac mitochondria. Poster, WVU Charleston Branch; October 12, 2012.

Ibra S. Fancher, Joshua T. Butcher, Jefferson C. Frisbee, Gregory M. Dick. Mechanism of delayed rectifier $\mathrm{K}^{+}$current by DPO-1 in smooth muscle and its functional relevance: depolarization and vasoconstriction. Poster, WVU Charleston Branch; October 26, 2013. 


\section{SoP AAPS Regional Research Forum}

Ibra S. Fancher, Tara L. Croston, Danielle Shepherd, Gregory M. Dick, John M.

Hollander. Cardiac interfibrillar mitoK $\mathrm{K}_{\mathrm{ATP}}$ channels are sensitive to diazoxide and have a

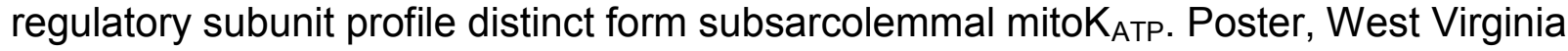
University; May 4, 2013.

Allegheny-Eerie Chapter Society of Toxicology Meeting

Ibra S. Fancher, Trey S. Rottgen, Shinichi Asano, Gregory M. Dick. Bisphenol A (BPA) activates BK channels from either side of the plasma membrane. Poster, West Virginia University; May 30-31, 2013.

Seminar at the University of Virginia.

Mechanism of inhibition of delayed rectifier $\mathrm{K}^{+}$current by DPO-1 in smooth muscle and its functional relevance: depolarization and vasoconstriction. April 11, 2014.

Seminar at the Ohio State University.

Mechanism of inhibition of delayed rectifier $\mathrm{K}^{+}$current by DPO- 1 in smooth muscle and its functional relevance: depolarization and vasoconstriction. June 27, 2014.

Seminar at the University of Wisconsin-Madison.

Mechanism of inhibition of delayed rectifier $\mathrm{K}^{+}$current by DPO-1 in smooth muscle and its functional relevance: depolarization and vasoconstriction. July 14, 2014. 
Seminar at the University of Illinois at Chicago.

Mechanism of inhibition of delayed rectifier $\mathrm{K}^{+}$current by DPO- 1 in smooth muscle and its functional relevance: depolarization and vasoconstriction. August 4, 2014. 